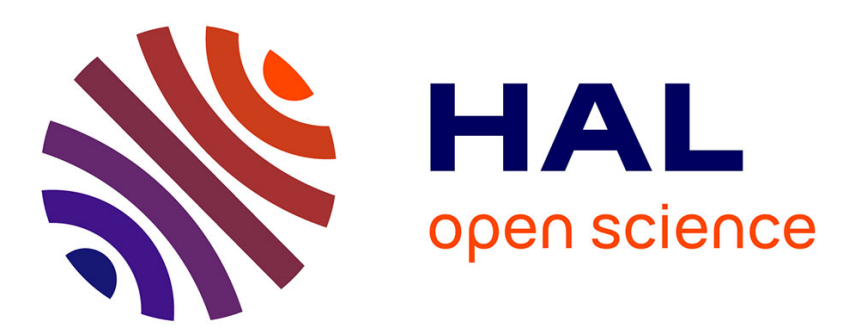

\title{
Recherches archéologiques en Gaule en 1954 (Période historique)
}

\author{
Raymond Lantier
}

\section{To cite this version:}

Raymond Lantier. Recherches archéologiques en Gaule en 1954 (Période historique). Gallia - Fouilles et monuments archéologiques en France métropolitaine, 1957, 15 (2), pp.279-347. 10.3406/galia.1957.1508. hal-01921111

\section{HAL Id: hal-01921111 \\ https://hal.science/hal-01921111}

Submitted on 4 Feb 2020

HAL is a multi-disciplinary open access archive for the deposit and dissemination of scientific research documents, whether they are published or not. The documents may come from teaching and research institutions in France or abroad, or from public or private research centers.
L'archive ouverte pluridisciplinaire HAL, est destinée au dépôt et à la diffusion de documents scientifiques de niveau recherche, publiés ou non, émanant des établissements d'enseignement et de recherche français ou étrangers, des laboratoires publics ou privés.

\section{(ㅇ)(1) $\$$}

Distributed under a Creative Commons Attribution - NonCommercial - NoDerivatives| 4.0 


\title{
CHRONIQUE DES PUBLICATIONS
}

\author{
RECHERCHES ARCHÉOLOGIQUES EN GAULE EN 1954 \\ Période hislorique*
}

IV

Les agils de: Fer

La fin de l'àge du Bronze moyen avait élé marquée par une extension de la civilisation atlantique sur le littoral ol. ses pénétrations vers le Nord-list al. le Rhône (haches à talon de type occidental). Pendant cette époque, deux zones d'influences avaient régné sur la Gaule : celle de l'Ouest, allantique; celle de l'bst en rapports avec l'Europe Centrale. Ces contrastes et ces liaisons s'exercent encore, lorsqu'au débul du premier àge du Fer entrent en scène le's port eurs de la civilisal ion des a champs d'urnes", qui ne peuvent représenter une seule nation mais, comme le fail est général pour toute invasion, une associalion provoquée par le hasard des ivénements, de peuples illyrien, celte, ligure ${ }^{1}$.

Les travaux de W. Kimmige ont mis a nolre disposition un ensemble de documents permettant de répartir, dans l'espace et le temps, un ensemble de trouvailles dispersées à lravers l'Europe.

* V. Gallia, XV (1957), fasc. 3, p. 139-178. (1) W. Kimnici, Feslchrifl für Peler Goessler. Tübinger Beilräge zur Vor-und Frühgeschichle, 1954, p. 41-98; - J.-J. Hatт, BSPF, LI, 1954 (Bull. cinquant.), p. 105-107.

(2) Rev. archeol. Est, 1, 1954, p. 7-28.
Dans l'état actuel de nos connaissances, l'expansion du peuple des champs d'urnes se traduit par plusieurs vagues successives, dont la premiere, environ 1200 avant, notre ère, a pour fossile directeur l'épée à languelte, dite de Rixheim, le couteau à manche et à rebord rabattu, les épingles a collerettes multiples et a lète de pavot. Les tombes de ces nouveau-venus ont été rencontrés en Champagne et dans l'Auxerrois, c'esti-dire sur des territoires occupés par des populations encore allardées à un stade néolithique. Bien plus important est le second mouvemenl, contemporain du IIallstatt $A$, qui s'étend au sud jusqu'au Massif Central et, a l'Ouest. i la Normandie. Bien loin de représenter un épisode dans l'histoire de la Celtique. continentale, ce déferlement des gens des "champs d'urnes" représente l'un des éléments fondamentaux des cultures de l'iage du Fer et la colonisation méthodique d'une large parlie des terres agricoles de la Gaule du Nord-Est par les Celles. Environ 950-800 (fin du IIallstatt I), le mouvement est achevé et au IIallstatt $B$ les groupes sont en place.

W. Kimmig a précisé les modalités de l'habitat de cette civilisalion : installations dans les groltes naturelles du Jura, et, de même que dans les Alpes, habitats à proximité des grands lacs; stations de hauteurs, d'accès 
dilficile ou inlentionnellement fortifiées (camp de Chaileau, à Salins (Jura); Mont-lassois; ramp de Chassey). La mise en marche des porteurs de celte cullure a éle provoquée par les modificalions du climal en Europe Occidentale. Sec et chaud pendant l'age du Bronze, une assez longue période humide commence avec le Ier millénaire avant notre ere. entrainant de vérilables. calastrophes dans les vallées fluviales el unc montée générale du niveau des lacs, amenant l'abandon des palafiltes. lons un essai sur les problemes el les perspeclives de la protohisloire frangaise, J.-J. Hatt ${ }^{3}$ a tris justement attiré l'altention de nos archéologrues sur les fails qui se produisent, environ 750 avant J.-C., et qui semblent avoir exercé une certaine influence sur l'évolution de sa civilisation : la pénélration d'un peuple cavalier, d'origine thrace-cimmerienne, amenant avec lui un lype particulier de mors de cheraux et qui aurail largement contribue a repandre en Ciaule l'usage du for. Il serail ulile qu'une étude soil entreprise des témoins laisisés par ces groupes pour préciser le ròle joué par cux dans l'évolution de notre Hallstallien.

Ine autre acquisition que nous devons a W. Kimmig est d'abaisser de pris de deux cents ans la date des uchamps d'urness dans la Gaule du Sud-Ouest, oi l'on relive dans les sípultures, associés a des formes réramiques dérivées des lypes des "champs d'urnes", des objels mélalliques du Ilallstatt. G de Reinecke. On peut se demander quel sera le résullat. de celte constalation sur les ronditions de la penétration des "ehamps d'urness" a travers la cianle du sud-ouest an $10 \mathrm{~s}$ direction de l'Espagne. En annexe au mémoire de $W$. Kimmig, II. Rex a tente de mellre en rapport avec la chronologie des mouvements celtiques les toponymes en briga, en dunum el en mag'ss.

La découverle du cimetiere des Jogasies (Marne) avait mis en lumiere la persislance du Iallstatlien à la peripherie du monde celtique où, depuis le Rhin moyen jusqu'i la Bohême, se lormait, environ 500 avant l'ere, la civilisation de La Téne. Ainsi le Jogasien, dont les allinités ne sont pas douleuses avec le groupe de Vix-MontLassois, est contemporain du début du second àge du Fer, de même que le Posthallstallien de l'Aquitaine et de l'Auvergne.

levant ces résultals nouveaux, une révision des cadres chronologiques, dans lesquels on avait, inscrit les diverses étapes de l'àge du Fer, devenait nécessaire et J.-J. IIatlo de proposer les dates suivantes: Hallstatt $I=700$ 5o) ; Hallstall II = 5)0-150; La Tene ancien $\mathrm{I}=5(00-400)$; La line ancien II = (100)-250; La Tine moyen $=200-120$ : La Tène récent $=120-30 ;$ I a Tène final, ou Gallo-lkomain précoce $=30$ av.15) apr. J.-C.

La découverte de $\mathrm{Vix}^{6}$ et celle de la Heuneburg, sur le haut I)anube? ${ }^{7}$ ont de nouveau posé les problemes des voies de pénétration des influences méditerranéennes en Gaule : vallée du Rhòne ou roule des Alpes. Occupé aux vie et,

(4) Feslchrifl I). Cinessler.

(5) BSPF, I.I, 1951, p. 379-384.

(6) R. Jofrrox, Mom. P'iol, 48, 195\%, p. 1 sq. Rerue des arts, 1951, p. 13-16; - E. CoCHE DE LA FerTi, (iaz. B.-A., 1954, p. 207-211; - Alnn. Bourgogne, XXVI, 1954, p. 119-120, 122.

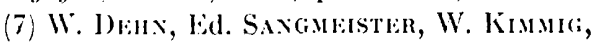
Germania, 32, 195.4, p. 29-4.4; -- W. Kimma, Rer. archeol. Est, V 1954, p. 216-252. 
$v^{e}$ siècles avant, l'ire, l'oppidum de Heuneburg est contemporain de celui de Vix. In premier élablissement, incendié al Ilallstatl B I (C. 1), élait pourvu d'une enceinle flanguée de bastions en saillies régulieress sur le modele méditerranéen. Iu Hallstatl tardif, une nouvelle enceinle entoure la colline dominant le cours du l)anube, faite d'un quadrillage de poutres de bois, dont les inlervalles elaienl remplis de Lerres et de pierrailles, comme le rempart d'Auaricum. Dans cel horizon 2, la céramique a fond bance est remplacé par unc polerie mince el lisse, à engobe rouge-noir, ornée de points curvilignes, innovalion locale. romme au Mont lassois, aceompagnée de lessons altiques a figures moires, d'amphores de la Cirande-diriere du lype de MareeyManloche, apparlenant i la phase lardive du Mallstal.l, récent.

bans relle controverse sur les voies du rommerce Médilerranée-(ianle, R. Bousquet n'a jamais resse de s'alever contre l'imporlance donnée it la voie des Mpes el du l)anuhe au délriment de celle de Marseille et de la vallée du Rhone. Il est dillicile d'admelle que Marseille ail civilise la (iaule el que la colonie ait apporlé dans les régions centrale et septentrionale des modes de pensée et de vie. La civilisation celtique est un phénomène direct el à retardement, dont les composantes sont multiples.

Dans une communication au Congres des sciences pré- et protohistoriques de Madrid (1954), J.-J. Hatt9 a tenté de concilier les deux hypothises proposées. Il fait observer que les anochoés à bec tréflé, jalonnant la route d'Étrurie en

(8) R. Botsocet, Rev. hisl, 1954, extrt.

(9) A paraître. Voir : BSPPF, J.1, 1954 (Bull. cinquant.), p. 109-110. direction des domaines celtiques du Rhin et du Ianube, par le Tessin, sont, contemporaines du re siecle avant l'ere el la plupart des objets grees de la fin du vie. Les deux voies auraient élé successivement empruntées, relle du Rhòne de 540 à environ 480, celle des Mpes de 480 à 400 . Faut-il voir dans celte relative abondance d'objels grees de la fin du $\mathrm{vi}^{\mathrm{e}}$ siecle "une lentalive des Grees d'organiser a leur profit les marchés de la Gelliquen, conséquence de la siluation mililaire el exonomique du monde hellénique it celle epocque? Exclus des marehés orientaux par les Medes, des marchés ocridentaux par les Etrusques ol les Carthaginois, ils auraient tente de relrouver chez les Celles une elientible nouvelle.

J'incerlitude n'est pas moindre quanl, aux centres de fabrication auxquets se rallacheraient, le cratire de la tombe prineiere de Vix. Sans lenir le moindre. comple des exarts entre les dales, Fr. Millepierere n'hésile pas a reconnaîlre dans ere mobilier funéraire le produil du pillage de Delphes par les Gaulois! (On ne s'arretera pas a la tentative d'explication du sujet représenté sur la lrise du cratere, les "Sept devant Thehes", proposée par J. Delepierre'1 d'où une origine argienne. Rumpf y reconnaîl un produit de l'industrie laconienne ${ }^{12}$, P. Amandry s'élève ${ }^{13}$ contre les conclusions de R. Bloch et R. Joffroy lirées de repères gravés au revers des reliefs du cratère, en faveur d'une origine étrusque. Ceux-ci auraient été gravés en vue du démonlage éventuel, pendant le transport de la frise et des anses el ne constituent pas un alphabet

(10) Nouv. rev. fr., 1954, nos 1-3, p. 554-557.

(11) Paris, de Boccard, 1955, $31 \mathrm{p}$.

(12) Mel. Bywanck, BOB.1, 29, 1954, p. 8-16.

(13) Rev. archéol., 1954, I, p. 125-140. 
homogène, mais un mélange de signes, de lethres el de chiflres. Dans la découlverte de Vix, la part qui revient au commerce elrusque se réduirail it l'onochoé de bronze, aux bassins et peut-être au colportage du cratere. Ch. Picard parlage cette opinion ${ }^{14}$ el met en garde contre des conclusions hâlives. Le procédé du repérage était bien connu i Corinthe, la ville des bronziers, et le vase a dû êlre terminé en (iaule. Un texle d'Hérodole ne fait-il pas allusion a certaines productions colossales des pays gréco-ioniens? ILes premiers résultats d'une élude métallurgique des mobiliers funéraires de Vix ont été publiés ${ }^{15}$, portant sur l'examen au microscope métallographique de la slructure du métal, bronze coulé ou en feuilles. En général, le métal en loble hatlue est plus pur que le métal coule al rontient moins d'élain. saul' celui des deux bassins a anses, renlermant 12 a $1.1 \%$ d'éain. Iess reliel's, le romverrete

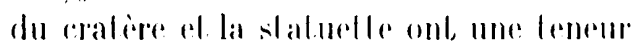
parliculierement blevere rn impureles.

La "Dame de Vix" a éte cllo allsisi l'objel d'un examentio : le crine a voule haule, la lace allongere aux orbiles moyennes, le ne\% élroil ol saillanl, le menton fort, offrent les caracleres d'une race nordique, éléments dominant en pays celtique depuis l'àge du Bronze et qui se conserverent inlacts dans les classes dirigeantes.

Un fail de rommerre expligue bien plus logiquement. yu'une prétendure invasion seylhigue, que n'appuie aurune confermation d'ordere hisloriguer, la disper-

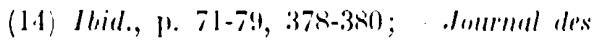
amaleurs d'arl, :5 :

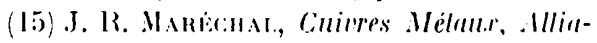
ges, 19\%4, $1^{\circ}: 0$, р. 40-43; no:?, p. 40-46.

(16) P. IE CHARtis, BSPl', I.I, I!51, p. 55(1-5:3.3. sion en Europe Occidentale des pointes de fleches I riangulaires en bronze, depuis les sources du Rhòne el la haule vallée de la Sacone jusqu'í la Loire. L'origine. de l'arme doil elre recherchee dans l'orbite de la cirece ou des colonies grecques de la Mer Noire, au ve siecle avant notre ère, plutòt que dans les centres mélallurgiques de la scythie'7. Elles sont arrivées en Belgique el en France à la suite d'échanges commerciaux par l'intermédiaire de l'Italie et des rols alpins, peut-êlre aussi par les vallées du Rhône et de la siaône.

Jans ces recherches sur les objets et les chemins du commerce de l'élranger avec la Gaule, on est en droit d'altendre d'uliles précisions des foulles sousmarines entreprises au long des coles provencales. I es réramiques, enlermées dans l'épave fouillée par la "Calypsos" and Cirand-Congloue, relivenl des ollierines greegules de Rhodes al de Conide, italo-

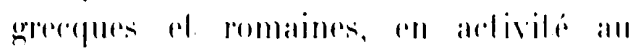
fer sivele avand .J.-C: ${ }^{18}$.

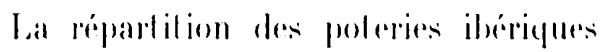
a lavers la Gaule n'esl pas moins riche en enseignements. Son aire de dispersion depasser les limiles du liltoral pyrénén, entre Impurias, Béziers, Ensérune, débordanl a l'onest en direction de loulouse (cimelière saint-Roch), s'élendant a l'list au-dela du Khòne sur la Provence. I.es foulles d'Albintimiliumis onl apporlé les preuves de l'importance. de rese exportalions all $\mathrm{I}^{\mathrm{e}}$ sierele avanl. nolere ire, marquanl te developpement. des exhanges enlere les deux preninsules.

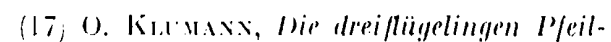
spilaten in Frankireich. Silndien zur Verhreilung und hislurischen Anssage der bronzen I'frilspilzen (Ah)andl. d. Ciepster und socialwiss. Akanlemie. llayence, $1^{\circ} 1,195.1$, p. $8 !-141$ !

(18) li. Bisorte, Cithllia, XII, 1954, p. 35-54.

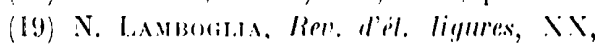
1951. P. 83-125. 
italique et ibérique, apres la conquête romaine. Mais est-ce la une raison suffisante pour tenter de rajeunir ces productions souvent bien anléricures it ce $\mathrm{II}^{\mathrm{e}}$ siecle avant J.-C.?

Al'Occident, les courants commerciaux allantiques n'élaient pas moins importants ${ }^{20}$. Depuis l'age du Bronze, les navigateurs médilerranéens suivaient un ilinéraire les conduisant des còtes ibériques vers la Grande-Bretagne et l'Irlande. Mais la dillicullé de la navigation, icueils, brumes, courants marins d'une exceptionnelle violence, interdisaient l'accés de la Manche par l'Ouest aux marins venant du Sud. Aussi, ¿ l'exception du litloral du Devon, oi se nouent les relalions avec l'Ibérie, les coiles anglaises n'ont pas été touchées par le trafic méridional, et les (iermains, riverains de la Mer du Nord, ont moins recu par mer que par la voie continentale, celle-ci leur apportant le sel de la seille at. le vin par la roule du Rhin. Ine ire nouvelle s'ourrira lorsegu'il ful posibible d'átablir un ilinéraire allant is la Mer du Xord en contournant. l'Armorique et en longeant, le littoral français de la Manche. Ce sera la roule des invasions saxonnes a parlir du ${ }^{\mathrm{e}} \mathrm{e}$ siècle de notre ire.

Si l'on peut aver vraisemblance reconslituer res itinéraires maritimes, il est osé, pour ne pas dire plus, de vouloir préciser le lype de navire ulilisé par Pylhéas, lo "premier grand navigateur provençal $)^{21}$, pour son expédition vers les rivages de l'Europe septentrionale.

L'intime contact de la ville el de la rivière, la route qui marche, a été évoqué

(20) R. 1)1ox, Bull. assoe. genglfaphes fr., $\mathrm{n}^{\text {ns }} 2.43-244,1954$, p. 128-135.

(21) E. Davix, Bull. assoc. Guill. Bude, 19:4, p. $65-71$. par I. Armand-Calliat ${ }^{22}$, à l'occasion de l'exposition "La Saòne et l'histoire", tenue en 1953 i Chalon-sur-Saône. Les berges, déja recherchées des Néolithiques évilant les plateaux calcaires, domaine des Campigniens, se peuplent pendant l'àge du Bronze. Verdun, l'île Saint-Jean à Màcon et Chalon, centre métallurgique important, font déja figure de ports. Au premier àge du Fer, l'aggravalion des conditions climatiques entraine, comme en Alsace, l'abandon des rives fluviales et les circonstances étant peu favorables a des échanges par la vallée du Rhòne, la Bourgogne entre en contact avec la Méditerranée par la vallée du Danube. Les mouvements du peuple des "champs d'urnes" emprunlent le val de Saone (Sassenay, Chalon, Lacrost, Mâcon). l'époque de La Téne marque l'apogée industrielle et commerciale de Chalon qui, de même que la tiene sur le lace de Teuchatel el Torl sur la Thile, est. un point d'embarguement ol un centre de batellerie tries imporlanl, mème si l'un considire comme des oflrandes aux divinités fluviales les armes el chaudrons ramasses en si grand nombre dans le lit. de la saòne, cependant que Matisco, dans l'île Saint-Jean, suit, la décadence de Màcon, remplacé par l'oppidum de Ia Rochette, où César installera ses magasins d'approvisionnement. Au er $^{\text {er }}$ siècle avant l'ère, le cours de la Saine est jalonné, a Chalon, à Seurre, a Verdun, a Allercol, a Lax, à Auroux, it Tournus, a Saint-MarlinBelle-Roche, de toute une suite de ports fluviaux, où débarquent le vin de Campanie, l'huile de Bétique, et Pontailler commande déjà le chemin vers Genève al Besançon. Ce rôle de

(2:) I. Ammaxd-Caldat, Ann. Bollgogne, X.XVI, 1954, p. 107-118. 
transporteur de matériaux lourds se poursuit dés le débul de la période gallo-romaine, lingols de plomb de Bretagne, calcaires de Flacé et de Tournus, passent par la batellerie de Chalon, point d'aboulissement at de contact entre la route el la rivière.

Ces condilions naturelles ont exercé aussi leur influence sur les modalités du peuplement de la Bourgogne pendant, l'age du Fer ${ }^{23}$. La densilé de l'oceupation reltique du Chatillonnais est liée a l'abondance du minerai de fer dans le limon des plateaux, résidu de l'érosion des roches balhoniennes.

Jans une notice, qui est mieux qu'un guide, H. Rolland24 précise les élapes de l'histoire de Cilanum : ville hellénislique jusqu'i l'arrivere de Marius en 102 avanl J.-C. ; ville romaine primilive de 102 a la prise de Marseille en 19 ; ville romaine jusqu'i sil destruction, environ 270 de notre irre. Lal cile doil son nom an dieu lopique Gilaness, yni apparaîl surr lés dédicaress conjointement a celui des Cilaniques, diviniles proleretrices, et sal naissance a un proint d'eau fixe, centre de l'aggloméral ion primitive. Le's dernieres ampagnes de fouilles, en direction de la zone occupée par les sanctuaires, ont donné d'importanles découvertes : autels aux (ilaniques el à Hercule, dieu guérisseur et protecteur des sources, nymphée monumental, temple de Valeludo, et l'arhèvement du déblaiement du très ancien nymphée ${ }^{25}$, centre du sanchuaire de Glanum, précise certaines conditions du développement. urbain de la ville, celle-ci ayant

(23) Abbe J. Jor.y, Mem. acad. sc. arls et b.-lellr. Itijon, 1947-1953, p. 221-2:26.

(2.1) Gilumm. Nolice archeologiqne, sinintRemy-de-Provence, 195.

(25) 11. Rol.tane, Ciallia, XII, 1954, p. 148452. progressivement déhordé ses limites pour s'élendre, hors de son cadre primitif, le défilé rocheux, el gagner la plaine. Iu fond du bassin, gisaient, des monnaies de Marseille des $\mathrm{II}^{\mathrm{e}}$ el,

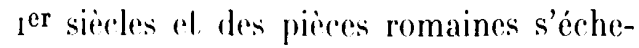
lonnant jusqu'au rìgne de Maximin (235-238), des aulels avec dédicares a Apollon, el au-dessus, on a relrouvé des blocs archilectoniques ayant apparlenu aux parties hautes d'un édifice dominant le nymphée, dont relevail aussi un acroliere a palmetle, avec un buste de femme portant le torque, image de l'aleludo, idenlifiée avec la source sacrée. Une inscription au nom de M. Agrippa, donne la date, 20-19 avant l'ire pour' la construction du temple de Valetudo (r) la restauration du nymphée. Au quarlier d'Aurignan, de nouvelles sépullures onl ile relrouveres sur la voies d'Eimaginum-Cilamum-Ciabellior. l'une est, du ger sierle avant l'ere.

la découverte, a Marseille, an Sud-list. dr la Bulle saint-Laurend ${ }^{26}$, en bordure du quai du porl anliefue, d'un chapileaus ionicue apporte des indicalions sur la siluation occupée sur la colline par le lemple d'Apollon, à l'entrée du port, sur l'emplacement où s'élèvera l'église Saint-Laurent. Déjà vétuste lors du siege de 4:3 avant. J.-C., le temple, s'il fut, alors épargné, disparut lors des grands travaux d'urbanisme marquant la reconstruction de la ville a l'époque de Néron et qui entrainerent la disparition des vestiges de la ville greeque. Sur la voie d':iix, de nouvelles sépultures du cimetière gree ont été mises au jour, rue Tapis-Vert : couches de rendres avec charbons de bois et foyers rituels reposant sur l'argile, contenant deux coupes à glacure noire; deux sarcophages

(26) R. Br:xort, Rev. archeol., 195)1, 1, p. 16-43; Gallia, .11, 1954, p. 4:6-4:8. 
en mollasse sableuse ; sarcophage d'enfant. avec mobilier funéraire comprenant un aryballe de verre bleu foncé à incrustalions de dents jaunes et bleues pales d'origine égyptienne, et un fragment de plaquette de terre-cuite représentant un sphinx; sarcophage abrilant deux squelettes, une coupe de style libre du troisieme quart du ve siecle, porlant les traces de la réparation a une anse, décorée d'un personnage laisanl une libalion sur un aulel el, sur les flanes, joueur de flûte assis devanl un personnage drapé ; coupe plate en argile rose ; paire de strigiles en bronze; alabastre en albatre également de provenance égyptienne.

in rapporl général ${ }^{27}$ expose les résultals des fouilles de l'établissement gree d'Olbia, a Hyeres (Alpes-Marilimes). la rhronologie du site, d'après la céramique et les monnaies, s'inscrit entre la fin du $\mathrm{s}^{\mathrm{e}}$ siecle avant notre ère el le $\mathrm{II}^{\mathrm{e}}$ après J.-C. La présence de lessons, dits "wisigothiques" et d'un complexe architeclural chrétien avec une petite église précise une réoccupation au début du Haut Moyen àge. I deux kilomètres au find de la fortcresse, dominant le rivage el la rade d'Hyères, le plateau de Costebelle aurait élé le siege d'un habitat hellénique, antérieur à l'établissement fortifié de la plaine, sur le rivage de l'Mlmanarre, mais qui ne peut être antérieur au we siecle avant l'ère et aurail été évacué en 123-122 avant J.-C. Costebelle serait un oppidum indigène, fortifié par un mur de gros blocs à l'Est, sur le bord externe du plateau au Nord vers le sommet de la déclivité, faisant couple avec le comptoir massaliete.

(27) J. Cocpry, Gallia, XII, 1954, p. 3-33 ; Cit. Gallia, VIll, 1950, p. 126.
Les fouilles de 1953-1954 à Entremont (Bouches-du-Rhòne) ont révélé l'existence de deux niveaux d'occupation dans l'insula bordant au Sud et au Nord la rue XVII a ${ }^{28}$; le premier horizon est daté par des tessons campaniens, des drachmes et des oboles de Marseille des années 200 avant l'ère. Au cours d'une deuxième période, le sol fut exhaussé, vraisemblablement au milieu du II $^{\mathrm{e}}$ siècle el les constructions élevées au sud disparurent, leurs pierres élant, utilisées pour la voirie. Sur le côté méridional de la rue de larges substructions marquent l'emplacement de deux constructions à des niveaux différents, dressées hàtivement, implantées de force dans le quadrillage urbain et ouvrant sur une sorle de cour, accompagnées des alignements d'un portique, dont deux piliers sont sculptés de têtes coupées et serpent à tète écaillée. Le caractère religieux des monuments est confirmé par la découverte, au niveau de la salle hypostyle el sur la rue, au pied des piliers remployés, d'une quinzaine de crìnes-trophées, dont trois sont encloués.

Les découvertes faites à Ensérune (Hérault) ont précisé la stratigraphie du site en divers points de l'agglomération $^{29}$.

A la pointe orientale de l'oppidum du Cayla de Mailhac (Aude) ${ }^{30}$ avait été aménagé l'accès d'un habital sous la forme d'un passage, large de $3 \mathrm{~m} .90$ pratiqué dans l'épaisseur du rempart et traversant une tour rectangulaire. Un chemin, longeant l'enceinte sur une trentaine de mètres y conduisait. Ce dispositif, contemporain du Cayla IV (III ${ }^{\mathrm{e}}-\mathrm{II}^{\mathrm{e}}$ siècle), remplaçait une cntrée plus ancienne. Il semble avoir été arasé

(28) F. 13Exort, idib., p. 285-29.1.

(29) J. Jaxioray, ibid., p. 417-122.

(30) DU MEิME, ibid., p. 412-413. 
et comblé a la phase finale de l'occupation du sile (er siecle avant. J.-C.). Tout en gardant son caractere de palsage courerl, l'acress antuat cile alors reporlé plus it l'ouest et reeconstruit suivanl III axe différent. Dans la plaine, de noureaux rnsevelissements ont éte reconnus apparlenant all groupe du Cirand-Bassin II (milieu du vie el début du se sierles).

Mais il n'y a pas que ces grands chantiers qui aient relenu l'allention des fouilleurs. De nombreux oppida provençaux ol languedociens ont été l'objet de recherches attentives : camp a triple enceinte au Mont Lauze (AlpesMaritimes), avec (abanes hallstalliennes et épées à antennes; lessons des àges du Fer et gallo-romains, traces de foyers dans un abri en conlre-bas ${ }^{31}$; ... habitats el fonds de cabane's du Violithigue an Carolingien is Saint-listive (ollioules, Var $)^{32}$; oppidum du Casteled, i Fontvieille (Bouches-du-khòne), défendant le passage des marais, aver courehe grecque du vie siecle, directement sousjacenle i un horizon médiéval; i l'intérieur du rempart, traces l'habilations, coupes altiques a figures noires, roupe éolienne, poterie indigine peignee des sites de La T'ène, imitations des coupes ioniennes, amphores ${ }^{33}$; - oppidum de la Teste-Nègre, aux Pennes-Mirabeau (Bouches-du-Rhône), céramiques indigènes à décors de dents de loup, campaniennes, amphores gréco-italiques a engobe blanc rappelant celles de l'épave du Grand-Congloué, puniques, fibules de La Tène $\mathrm{Il}^{34} ;-$ - oppidum du plateau de Pierredon, a Eyguilles (Bouches-

(3I) J. Alв1x, BSPP, I.I, 195.1, p. 409 ; Bull. al mem. inst. fouilles de prehist. del d'archéol. Alpes-.Marilimes, 11, 1929-1953), p. 77-82.

(32) S. Gagilinl:, Gallia, XII, 1954, p. 124.

(3i3) If. Brasotr, ibid., p. 430.

(34) Dу мюме, ibid., p. 431.
du-Rhòne), resles d'un pressoir à huile ${ }^{35}$; au sommet, de l'éperon de La Plaine, a Peipin (Basses-Alpes), oppidum aree: enceinle comportant deux murs l ranserersaux, polerme a chicane daus l'angle:

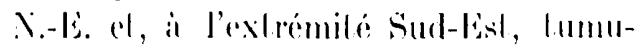
lus a rnceinle circulaire it la base, rouches de cendress el leswons de grands vases a cordons el impressions digilales ${ }^{36}$; - station néolithique du VieuxCarniol, à Carniol (Basses-Alpes), réeccupée au premier àge du $\mathrm{Fer}^{37} ;-$ fonds de cabanes au Roc de Conilhac, sur une éminence au sud de Ciruissan (Aude), contemporains de la période de transition entre les àges du Bronze el, du Fer et du Hallstallien ${ }^{38}$; an Perch Maho de Sigean (Aurle), en avant du mur d'enceinte. un denxieme ajpareil, large de $0 \mathrm{~m}$. so, séparé des remparts par un fossé sere formanl cont re-estarpe, proerede de forliticalion identique a relui qui, at stainl-Bblaise (Bourdere-duRhòne), proliggeait la colonie massaliote, exemple partait d'un empront lail par les indigines aux construrteurs marseillais au Ive sirele avant l'eres39; nouveaux sondages dans l'oppidum de La Monedière à Bessan (Iérault) dans les fonds de cabanes ayant des tessons ioniens et attiques a figures noires allant jusqu'au $v{ }^{\mathrm{e}}$ siecle avant J.-C. et montrant que le site a été occupé un quart de siècle avant celui d'Linsérune; - sondages dans l'oppidum de La Roque, entre Montpellier ot Mèze (Hérault), au confluent de la Mosson et du Coulazon, entouré à l'Ouest el au Sud par une enceinte cyclopéenne ${ }^{40}$, maisons reclangu-

(35) Du mîms, ibid., p. 431-432.

(36) H. Rorraxis, ibid., p. 416-147.

(37) S. Ga(ixil:Rl, ibid., p. 211.

(38) I. I.otis, ibid., p. 111-113.

(39) J. Javioray, ibid., p. 415.

(40) Du mìms, ibid., p. 416. 
laires en pierres seches et, dans l'une l'elles, un grand aulel-foyer en argile cuile, enlouré de murelles al decoré sur deux de ces colles par an lriple registre dormements incises, sorles de greceques preses du bord, ebevroms losangess, sur les deux aulres colés deux registres de grecoues at de losanges al, lans rhaque angle inlérieur, qualre rhevrons; i la surface rouches de cendres contenant des os d'ovides et, au centre, quatre chenets de terre-cuite sans lêtes avec cercles incisés sur les flancs, une lète de bélier isolée et huil disques supports de rasest ; ... fouilles sur le versant Xord-Ouest de l'oppidum de Murviel-les-Monlpellier (Héraull), maisons merlangulaires, longeres an sud far une ranalisalion, mosaïquées on "puse testacemm el rndujts peints, sur une terrasse soutenue a l'aval par III important analemma en moellons, disposes en assises isodomes: aménagements du per siecle de nolpe ire, sucredanl is des installations de Ial Tene III, dont. des éléments architecturaux d'un monument dressé sur une terrasse surplombant less maisons ${ }^{42}$; ... mêmes dispositions dans l'oppidum de Vié Ciontal, à Mons el Monteil (Gard), dominant la vallée de la loroude, entouré d'une enceinte cyclopéenne et réoccupé aux temps gallo-romains ${ }^{\mathbf{3}}$; - vestiges de l'occupation hallstaltienne dans la région de Montpellier ${ }^{44}$.

Ces diverses découvertes n'apportent seulement pas des précisions nouvelles sur les modalités de l'occupalion de la Provence et du Languedoc dans l'espace et dans le temps, elles renseignent aussi

(41) Dt мìn, ibid., p. 422-423.

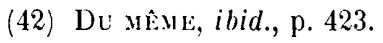

(43) Du м̇ेмr, ibid., p. 424-425.

(14) J. Ardmint, Cahiers ligures de préhisl. ol d'archeol., III, 1951, p. 101-113. sur les croyances des populations de la Ciaule Méridionale : cultes du foyer el des divinilés domestiques; popularile dans lo pays d'Aix ol le Gomlat-Venaisin flecouverle des malais de Cialissamme, Bouches-du-Rhònej 45 du culle de Belenus, apporlé par les Vénélo-lllyriens el, ¿ Sainl-Remy-de-Provence, on saisit un moment du passage des divinités indigènes au panthéon gréco-romain.

La multiplicité des découvertes de lessons grees dans ces oppida est le témoin des eflorts faits par les commergants marseillais pour ouvrir a leur trafic les marchés gaulois, et cela des le siècle mème de leur installation en Ocridenl. Ivec leurs parotilles, pénélreront aussi dans le Languedoc de nouveaux modes de ronstruction adoplés par les habitanls des opprida. I'antres documenls, tromvailles d'amphores ilaliques sur la plage du Cirand-Radeau, aux saintes-Maries-de-la-Mler (Bouches-duRhòne $)^{16}$, el au laree de la cole rocheuse des Mberes (Pyrénées-orienlales) ${ }^{47}$, se rallachent au commerce ilalique des vins au dernier siecle avant l'ere.

Pour le centre de la France des inventaires ont élé publiés sur les camps, enceinles et stations gauloises reconnus dans la IIaute-Loire ${ }^{48}$ et la haule et moyenne Corrèze ${ }^{49}$. Dans ce dernier département, la grotle du PuyGérald ou des Contrebandiers, à Lissac ${ }^{50}$, a élé occupée au Hallstattien et entre 50 avant el 50) après J.-C. ; au Puy du Tour, à Monceaux ${ }^{51}$, des sondages au

(45) J. Govrvest, Ogam, V1, 1954, p. 257-262. (46) V. Bworr, Gallia, NII, 1954, p. 432.

(47) J. Jaxioray, ibid., p. 140.

(18) P. Bat.LET, Bull. soc. sc. nal. el d'archéol. Haule-Loire, XVII, 1954, p. 69-88.

(49) M. Vazront.tes, Bull. soc. lill. sc, et arts

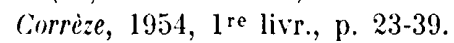

(50) P. F. Focrine, Gallia, XII, 1954, p. 198.

(51) Du mise, ibid., p. 197-198. 
sommet de l'éperon rocheux, entouré par la boucle de la Dordogne el, de ses aflluents, la Malefarge et la Souvigne, ont amené la découverte d'une slratigraphie depuis le Néolithique jusqu'au $\mathrm{I}^{\text {er }}$ siecle avant notre ère. Dans le Cantal, les plateaux de Charmensac ${ }^{52}$ et de Saint-Victor-sur-Massiac ont élé habités depuis le Iallstallien. Des forlifications ont été relevées à La Calcidouze et aux Grands Causses de Saint-Georges-deLevéjac ${ }^{53}$, sur la partie Nord-Ouest de l'oppidlum de La Garenède (Aveyron), au-dessus de La Graufesenque, entouré d'une enceinle avec amorce de chemin pavé, les tessons recueillis se rapportent ¿ la transilion entre les deux àges du Fer et aux ${ }_{1 \mathrm{e}} \mathrm{e}^{\mathrm{et}} \mathrm{e}^{\mathrm{er}}$ siècle avant J.-G.54; -... en Dordogne, le camp de Pouyoulet ${ }^{55}$, fermé au sud par un gros rempart et IIn large fossé, abritait, all vie et re siècles, un pelit élablissement industriel (scories de fer). Sur le niveau neolithique, les IIallstaltiens avaient installé un oppidum au Camp de César, a Saint-Amand (Cher) $)^{56}$. Des londs de cabanes de la fin du deuxième du Fer a Villeneuve-la-Guyard (Yonne) ${ }^{57}$ ont, donné des poteries du type de celles recueillies a l'oppidum de Vix (Còted'Or), dont la coupe stratigraphique a été dressée $e^{58}$. La poursuite des fouilles de cette station a fait connaittre un nouveau site hallstaltien sur le Mont Lassois, localisé sur le flanc de la montagne, face à la vallée de la seine, et

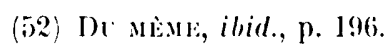

(53) I. Bassax, ibidl., p. 103.

(5.4) J): мйм, Melanges..., II, p. 35-38.

(5)) C. Barnileri, Bull. sor. hist. el archenl. Perigurd, CXXXI, p. 49-52.

(56) Le Berry républicain, 2.4 aoùt 1954.

(57) R. Lours, Ciallia, XII, 1954, p. 52:3.

(58) 13. Jorrov, Germania, 32, 1954, p. 59-65; Bull. sor. archèol. el hist. Châtillonnais, 1954, p. 130-131. comparable par sa richesse au gisement fouillé par J. Lagorgette : milliers de tessons à décors peints, fibules de lypes variés, bracelets, torques fragmentés, boutons d'appliques, anneaux de jambes, boucles d'oreilles, épingle à tète ornée en bronze, clous de fer, balle de fronde en argile. Ce gisement V, qui correspond ¿ une occupation très dense, est daté par la présence d'un pied de coupe ionienne et un rebord de couvercle d'amphore allique. Lne importante précision pour le débul de l'histoire du site est apportée par la découverte d'un nouveau lumulus au pied de la montagne, à proximité du tumulus princier arasé lui aussi. Le caractère de la céramique et la présence de deux épingles de bronze, dans le tertre funéraire de 32 mitres de diametre a la base, primitivement en lerre avec seulement une reinture de pierres enfermant, en son milieu un loculus de pierre, permet de faire remonter, d'une façon certaine, l'occupation au déhul du Hallstatlien, soil le vin ${ }^{\mathrm{e}}$ siècle avant notre ère, date que laissaient déji entrevoir quelques objets archaïques du gisement I, malheureusement trouvés dans des conditions stratigraphiques défeclueuses.

Dans cette mème Bourgogne, cerlains lieux-dits médiévaux évoquent le souvenir de forlifications $s^{59}$, peul-être de slations gauloises de pasteurs, auprès des pacages et des points d'eau, le bétail étant alors la principale monnaie d'échange. Des sondages récents à l'oppidum de Mesmonl. (Cóte-d'Or) ont précisé l'existence de cing horizons, du Néolithique, de l'àge de Bronze, de

(59) I. L.liBe, Rel. archeol. Lisl, V, 1954, p. $87-90$. 
Irallstalt et de La Tène60. Le puits funéraire de Boucharai, à Lux (Còted'()r), relive des aggloméralions installées au Bronze el au Fer, autour du gouffre d'. Iurélie ${ }^{61}$. Pendant ces mèmes périodes, les sablières de la vallée de la seine, a l'Est de Troyes (Aube), ont élé le siège d'une importante occupation dans les ilots el les marérages aux bords des rivieres el des voles d'accesés. La fréfuence des inondalions en aval et en amonl de Troyes explique les déplacements successifs des élablissements.

Dans l'Lis. la reprise des fouilles sur la colline du Châleau, à Prélin (Jura), a permis de préciser la dale de construclion du relranchemenl occidental, conlemporain de la période II des "champs d'urnes". Plus tard, au Hallstattien, sur l'emplacement du cimelière, des Iravaux furent entrepris, mais toute celte partie du sile reste toujours occupée par des tombes à inhumation et it incinération ${ }^{63}$. Une fortificalion assez complite, vallum barrant l'éperon, murs en chiranc. parapets et, vers l'extrémité de la poinle, un réduit, assurait la délense de l'oppidum du Chàtelel, a Vitry-les-.Xogent (Haule-Marne) ${ }^{64}$. En Alsace, on a reconnu l'existence d'habilats hallstattiens a Bilwisheim, à Gingsheim el a Hohfrankenheim (Bas-Rhin ${ }^{65}$. En Brelagne, dans la presqu'île de La Torche, ¿a Plomeur (Finislere), un important habilat avait été installé,

(60) Em. (irrot, l.e Bien Publie, 6-7 mar's 1954.

(61) Abbé .J. Jowx, sous le plancher. Spéleo(club Dijon, $1^{\circ} 2,1954$, p. 7-14.

(62) Driotox, Almanarh de l'Indépendenl de l'sube, 195.4, p. 58-64.

(63) L. Li:Rat, Gitlia, NII, 1954, p. 473-174.

(6+1) P. Batleter, Bull. sc. nal. el archéol. HauleMarne, Xlil, 195.1, p. 39-5i).

(65) P. Wernert, Gallia, XII, 1954, p. 396. au débul de l'ìge du Fer, sur l'emplacement d'un lumulus. Les mobiliers montrent une persistance des industries du Bronze à celle date ${ }^{66}$.

Les découvertes ne sont pas moins importantes dans le domaine funéraire des àges du Fer. L'abri sépulcral des Points-Rouges, à Quinson (BassesAlpess ${ }^{67}$, abrilait une curieuse sépulture hallstallienne, pratiquée à l'kist, le long de la paroi rocheuse, dans laquelle gisait, un squeldle, la libe an sud-()uest, les membres allongés, arrompagné d'un mobilier : sur le ventre une ereinture en loble de bronze, ornée au repoussé de poncluations el de bossettes ; a droite du bassin, un pic laillé dans un galet calcaire; sur les tibias el sur le thorax, des lames de silex. L'intérèt de cette trouvaille est dans les rites de la sépulture près de laquelle, au centre de l'abri, se dresse une sorte de bétyle et, peints sur la voûte, juste a l'aplomb de celui-ci, deux grosses ponctuations rouges. Deux aulres poncluations, semblables, mais plus pelites, ont été relevées, l'une à la verlicale du cràne de l'inhumé, l'autre à relle d'une demi-mandibule gauche de sanglier. Au début du Iallstattien appartiennent les mobiliers des deux lombes de la grolte du Creux de Miège, a Mireval (Hérault), deux épingles de bronze à tète globuleuse, une a lète enroulée et des tessons incisés el peignés ${ }^{68}$, ainsi que le nouveau tumulus de $\mathrm{Vix}^{69}$.

$A$ la civilisation des champs d'urnes se rattachent : une incinération, au lieu dit "Le Haut de la Noue du Polpier",

(66) P. R. Gior, ibid., p. 407-40\%.

(67) B. et B. Bотrte, BSPF, I.I, 1931,

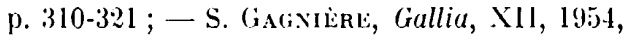
p. 12:2.

(68) R. P. Charrles, B.SPF, LI, 1951, p. 200. (69) Rev. archéol. Est, V, 1954, p. 228. 
a Eicury-le-Repos (Marne), dont l'urne cincraire det ail recouverte par une assielle ornce a linlerieur de rombinatisons

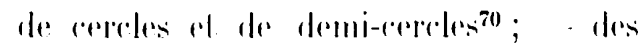

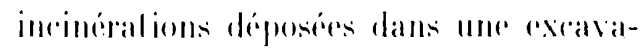

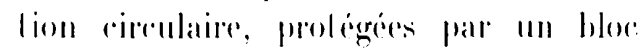
dre grese, pratiqués dans une enceinle rectangulaire réulilisée au second age du Per, au lieu-dit "Le Charmont", a Vert-la-(iravelle (Marne) ${ }^{21}$; - pres d'Auxerre. aux abords de la ferme de Champagne, un "champ d'urnes" est conligu à une enceinle rirculaire, et dans la sablière Brojon, une tombe a donné une épingle à colleretle de la phase préliminaire des "champs d'urness. Il serail inléressanl de pouvoir daler exartement les anceintess derouvertes danse les siables alluviommaires des

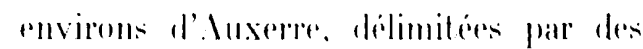

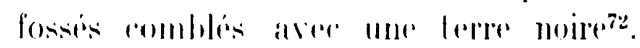

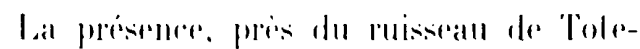

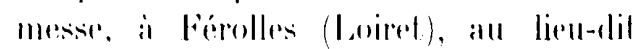
"la Martrove", de séfullures de cente rivilisalion marque un nouveraul jalon de son expansion en direction de la Ciatule Cenlraler3. Faul-il rapporler is ces groupes lis fibule a agrale circulaire et ardillon libre, recueillie an $\mathrm{Monn}$ Ilérapel ${ }^{74}$, el un cénolaphe du lumulus $\mathrm{V}$ de Montaubert, a Salles-la-source (Aveyron), mal délimité, dont la table manque, à cella orientée N.-().-S.-L. et qui n'a pas été utiliséne? I Bréviandes (Aube ${ }^{76}$, l'exploilation d'une sablière mil au jour une sépullure hallstaltienne a inhumation, dont le mobilier, détruit par

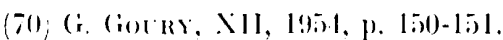

(71) De misus, ibid., p. 151-152.

(7i) R. Kapps, Rer. archeol. List, V, 1451, ग. $20: 3-20.4$.

(73) R. Louss, (iallia, NII, 1954, p. 505-506.

(7.) Li, BErciTnor, Cahl lorrains, VI, 1954, p. 7.

(75) L. Bassax, Giallia, N1I, 195.1, p. 103.

(76) J. Barlen, Almanach de l'Indépendanl de l'Aube, 1954, p. :87-5x. les ouvriers, comprenail un vase, un bracelel de bronze orne de dents de buup

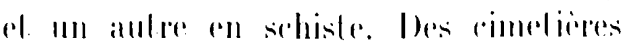

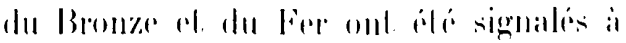

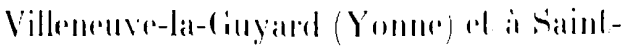
lonis-less-inens?

Ine allention partieuliere sera prithe a la publicalion d'une élude d'H. Lorimy sur le tumulus de Cérilly (Cóle-d'Or'), fouillé en 186:3, comnu seulement par un court résumé. L'existence, à Cérilly non loin du Mont Lassois, d'un énorme tumulus, laisse entrevoir son appartenance au groupe des lombes princieres de Vix et des Mousselots, a SainteColombe. Mais aux lemps où Il. Lorimy rédigeail son article. on ne soupeonnail pas encore l'importance de l'oppidum hallstallien du Mont Lassolis. lin maison du cararlere lros incompled, de la fouille, a l'exceptions d'un annean d'or, on ne sait prescaue rion du mohilier funcraire. Toutefois, les lringles de fer. Jes unes

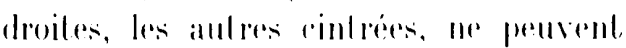
repressenter les grilles d'un loyere lilles appartiennent vaisemblablement an reste d'un trépied. analogue a colui du lumulus de La darenne, a sainleColombe. Malgré les incertiludes, nonséquences de recherches mal conduites, il $y$ a de grandes probabilités pour que cet énorme lumulus appartienne au groupe des sépultures princieres de Vix. Ine autre découverle, à peu près contemporaine, colle d'un cimelière à tombes plates sur l'emplacement de la gare de Chatlillon-sur-Seine (Cóled'(Or), s'étalant sur les périodes de La Tène I et II, pose un cerlain nombre de problimes? ${ }^{79}$. En effet, la plupart des tombes de La Téne I de la région se

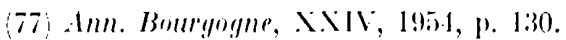

(78) Il. Lonsmy, Bhill. sor. archeol. et hisl. Chilillunnais, 1954, p. 131-13.1.

(79) 12. Joltnor; ibill., p. 135-138. 
présenlent sous la forme de sépullures adventices dans un lumulus, donl la lombe centrale remonle an Ilallskallien. Toulefois des lombes plales sonl connues a Corl-sur-seine, a Benlan-sur-()urere,

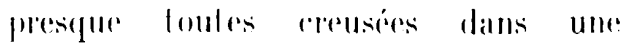
graviere. Tomber plates of fombes sous lumulus sont comlemporaines, puisque leurs mobiliers funéraires sont, ident iques, mais on ne peul. les assimiler inlégralement aux sipullures marniennes. (On ronstate en effel dans les lombes du Chatillonnais l'absence de lerre noire, étrangere au sile, el de céramiques. On peut alors supposer gue les porteurs de la rivilisation de Ia Téne I, établis en Choilillommais, n'étaienl pas des Marniens.

Ine ringuantaine de lumulus des igers du fere s'etendent sur le territoire de Baceon (Indre $)^{80}$. Jans la HauteMarme, a l'inlérieur de l'enceinte du Chatelel, a Vilry-les- Vogent ${ }^{81}$, se dressembl trois l.mmulus du débul du Iallshatlien al de la line?

lin Mlsace, les sepullures a inhumalion hallstalliennes de la sabliere de Bischollscheim (Bas-Rhin), pratiquées dans le loess el le loehm, onl donné deux bracelets lommelets en lignite, deux anneaux en fil de bronze enroulées en sphères et un cercle Lubulaire ${ }^{82}$. I)ans le même département, a sichweighouse ${ }^{83}$, un cimetière ¿ Lombes plates de la fin du Hallstattien et du début de Ia Tène a élé découvert an lieudit, Schelmenwasen. I)ans le HautKhin, les mobiliers funéraires des tombes plates à inhumalion, trouvées au cours de lerrassement à la sortie Sud de Colmar,

(80) Abhé. J. Nouks, Rel, archèol. Esl, V, 1954, p. 205.

(81) P. BaLlit, Bull. soc. sc, nat. el archéol. Haule-Marne, XVII, 1954, p. 39-55.

(82) Abbé A. Glony, Cahiers d'archéol. el d'hisl. Alsace, 134, 1954, p. 20-24.

(83) J.-.. Hктт, Gallia, XII, 1954, p. 487-188. entre la roule ol la voie ferrée84, apparlennent au Ilallsall, B et, dans la forebt de Kastenwald, un lertre luneraire conlenail huil sépullures : une incinéralion du Ilallstalt $b$ (environ 8()() aranl .J.-(i.), une inhumation du II. a aree epere de bronze ol. six du H. d. L'inlérè de la découverte ast de faire connailre la présence, dans un seul tumulus, de lombes appartenant a trois périodes successives du IIallstaltien, supposant alors l'ulilisation du mème tertre pendant plus de trois cents ans, de 800 a 500 avant notre ire.

Dans le Midi de la (iaule, une lombe ouverte au lieudil "La Médecine", a Villeneuve-de-Volx (Basses-Nlpes), s'apparente par son ronlenu all sépultures du cimeliere d'l yium (Śant-13laise) ${ }^{85}$. la trouvalle d'une rouelle gravée of de bosselles en bronze dans la grotte de Couillow (Ariege), laisse entrevoir un dépot fumeraire de la fin de l'age du Bronze on du déhut du premier àge du

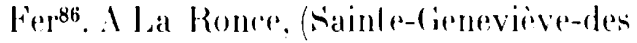
Bois, loiret ${ }^{87}$, la sépullure a incineration centrale, sous une voûte circulaire, conlenait une urne de bronze hallstallienne; les tombes adventices, dont l'une a donné une fibule a timbale et un stamnos de, bronze enveloppé d'étolle, appartiennent a la période de transilion entre le Bronze et le Fer.

Ja reprise des fouilles dans le cimetiere de Charmont à Vert-la-Gravelle (Marne) a prouvé que les sépultures étaient entourées par des enceintes déterminées par un fossé aussi profond que large, creusé en

(84) М. JЕнц et Ch. BONхะт, Cahiers d'archéol. et d'hisl. Alsace, 134, 1954, p. 25-31. ; - J.-J. Ilatr, ibid., p. 31-32; - Gallia, XII, 1954, p. $485-497$.

(85) II. Roldaxi, Gallia, XII, 1954, p. 447 448.

(86) A. Glory, ibid., p. 359-360.

(87) H. Zlraith, Rel. archéol. Esl, V, 1954, p. 206. 
forme de $\mathrm{V}$, rile qui avait échappé aux premiers fouilleurs, avant, tout préoccupés de récoller des objets8 ${ }^{88}$ La photographie aćrienne a révélé la présence de semblables rnclos funéraires quadrangulaires a SaintDenis-les-Sens (Yonne), non loin d'un cimetiere i enceintes circulaires du second àge du Fer, à Champagne-sur-Yonne, à Foissy-sous-Vanne. Les nombreuses sépullures de la vallée de l'Yonne, au Yord de Sens, it sens, is sainte-Colombe, a Jouancy. a Noslon, a Champigny, a Villeneure-laCiuyard. lémoignent de l'importance du Sénonais an premier àge du Fer ${ }^{89}$. La surveillance archéologique de l'exploitation des sablières des (irosejllers et des Mardelles, i Cheny (Yonne), sur la rive droite de l'Yonne entre le confluent du serein et celui de l'Armançon, a fait. r'onnail re' un site ou habilats el cimelieres se superposent depuis le Véolithique jusqu'aux temps mérovingiens, à l'exreption de l'igge du Bronze. Lit lia eneore, on retrouve des enceinles rirculaires entouranl des incinérations conlemporaines de la civilisalion des champs d'urne's, ou qualdrangulaires aver inhumations do la Trene I el II; deux auleres lombes de La l'ime II delaient inseriles dans une enceinle délimilese par des lrous de poleanis.

l'exploralion des lumulus de Dommarien (IIaule-Marne) of des tertres funéraires du Montsaugeonnais ${ }^{91}$, isolés ou rassemblés par petils groupes, contemporains les uns des "champs d'urnes" (Montseaugon I), les autres du Hallstatlien, laissent percevoir les diflérencess entre les mobiliers funéraires du Mont-

(88) C. Gotar, Gillia, . X11, 1954, p. 151-152.

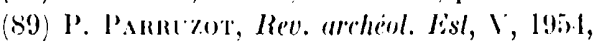
p. $71-73$.

(90) R. I.ots, ciallia, XII, 1951, p. 515-517;

Ann. Bourgogne, XXI1, 1954, p. 130.

(91) Abbé 1'. Moctox, Rev. archéol. Lisl, V, 1954 , p. $7-2.1$. saugeonnais et, reux du plateau. Il reste difficile de raceorder le peuplement de cess régions a celui de la Marne, de la llauleSaòne el du Chat illonnais. C'est ainsi que la frontière semble s'ètre un peu déplarée par rapport i sa siluation au premier aige du Fer, et que les lumulus de la bordure du plateau, alors rallachés au groupe du Chàtillonnais, recoivent à la fin de La Téne des objets caractérisliques du Monlsaugeonnais. I La Tène, les lertres funéraires sonl presque tous abandonnés et un hialus chronologique sépare le Inallstattien de la fin de La T'ene I, représentée par de nombreuses sépultures secondaires. Des tombes de La Téne, dont les mobiliers furent en bonne partie dispersés, ont été lrouvées a Damery (Marne) $)^{92}$. lans une sablière a Rivièreles-Fosies (IIaule-Marne) ${ }^{93}$. et a Villeen-Woère (Meuse), dans une arriere press Le Tombois (Teine I) Th $^{94}$.

Parmi les découvertes d'objets, on retiendra : l'epee de leer à poignee à sphère de la rue Thénarl a sens (Yonne), se ratlachant au groupe hallstaltien final du Chatillonnais ${ }^{95}$; l'annealu de jambe hallstallien d'Augisey (Jura), en bronze plein, cannelé exlérieurement, du Musée de Beaurais: ${ }^{96}$ l'éperon de bronze de La Tíne III du Musée de Blois ${ }^{97}$, de provenance inconnue, présentant, un dispositif nouveau : perpendiculairement au plan déterminé par l'are de cercle et la pointe, s'élire une tige allongée, devant, s'engager dans une gaine solidaire de la chaussure, pour emprècher l'éperon de tourner; - le chenet en argile à têle de

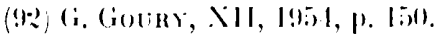

(93) P. Blidat, Bull. sre. Mal. ... Maule-.Marne, X111, 1954, p. 59-60.

(9-4) E. Disont, Gallia, XII, 195.1, p. 16.

(95) R. L.otis, ibid., p. 517-518.

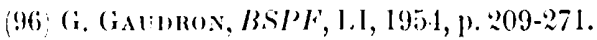

(97) Du misur, ibid., p. 271. 
bélier de Lillebonne (Seine-.Iaritime) ${ }^{98}$, el te torse cuirassé a ocelles. avere peedoral orne d'une routelle a six rayons, ol ceinluron a boucle ovale, lrouvé dans un labour au sud-bist du chait eatu de Cormeil, a Fox-Amphoux (Var)

Dans le classement des agrales de ceinlure hallstalliemneston, te lype de Chàtillon-sur-seine, déroupé dans une plaque de tole de bronze, a lalon reed angrulaire aver trois palles de fixalion, prolongées par un appendice lriangulaire lermine par un crochel el ornés au trémolo d'un décor de rigzalgs, es le modide le plus ancien, dalanl de la fin du Mallstall. II ou do débul du Mallstall II b. L'aire de dispersion en est. relalivement restreinle. Champagne, Franche-Combin a Bourgogne.

1 prepos de deux réramigues de la vallée du Ciardon, conserveres an Muséum dre Ximes, des précisions chronologigues sont données pour la polerise dile de Polada : lasseses surbaissóes a boulon cylindrique, Bronzer II ; langurelle on boulon, Bronze III-IV; ansers ad ascill, on lunulées, sige du Ferrol.

les rapports de la religion et de lia representalion de la figure humaine dans l'art cellique, oin le masque joue un ròle capital, expression de la partie pour le tout, rendent vaisemblable l'accession des Celles is une conception personnelle du divin el cela contrairement aux Iradilions généralement admises. Mais celle notion du divin se serait maintenue dans les limites d'un arl, jugulé par des imagres

(98) M. Yvaht, Bull. soc. normande ét. préhisl., XXXV, 1954, p. 137-1.43.

(99) l' BexoIt, Gallia, . XII, 1954, p. 436-437. (100) R. Jorrnos, Rer. archeol. Est, V, 1954, p. $305-311$.

(101, J. Akха1., BSPF, L, 1974, p. 389-391. symboliques de forres naturelles éparses ol obscuresioz.

1)u Lresor de Mauron (Morbihan), seules ont subsisté 16 pieces lrouveres a mème la lerre du champ, dit "La Bande du Pé", a la ferme du Cirand-Valled 103. I monnaies, slateres coriosoliles, correspondent a des coins déji connus el représentent la découverte la plus méridionale. laile dans les limiles de la rilé de Corseul. le staliope, en or blane, portant, a l'avers un profil humain, au revers, la moitie inférieure d'un corps de cheval, un cercle perlé a rayons, lromé a sainl-Alban (Lomere), se ratlarhe a la derniere periode du monnayage arvermetes. Ia piece d'argent, recueillie a la liruyere ('Tarn), pres de l'ancienne lerme du Reresos, ollere une imilation encore peal déformé deune. drachme de Rhoda. Le stalere d'or, lrouve dans un jardin, all Mans (sarthe), rue Mangeard, vers le faubourg de Pont-

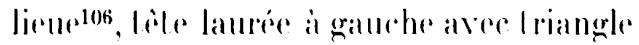
pommelé sur la joure, aurige lemant le rexillum ele le cheval androcephale autdessus d'un guerrier au revers, a probablement éle frappé dans la ville meme. In sujel d'une monnaie gauloise ${ }^{107}$, rheval et bucrine sur une lace, cerl deboul la queue repliée en s, sur l'aul re, on rappelle. le symbolisme du cerf, Cernnunnos et le dieu au rert du Donon, dont la masio domine la vallée de la Bruch, lien de la découverle. Le lrésor de monnaies gauloises et romaines d'Hussigny-Godbrange (Meurlhe-el-Moselle), oì dominent les

(10); P. LambRschts, Oeer Kunst en Werelbeschouving der Kellen, Varia historica, 1954, p. $55-69$.

(103) P. Mertat, Gallia, NII, 1954, p. 168. (10.1) A. Sortor, I'.-1. ... Lozere, 1954, p. $403-404$.

(105) P. J.anrolsse, Gallia, XII, 1954, p. 227. (106) P. Connoxxnk-DÉthI\%, ibid., p. 172.

(107) E. Laxcketrneno, Cahiers d'ancheol. el dhisl. Alsace, 134, 1954, p. 
frappes Trévires, a vraisemblablement été enfoui sous le règne d'Auguste ${ }^{108}$.

lne élude récente ${ }^{109}$ sur le statère de Vercingétorix a la tite casquée conclut a l'aulhenlicité de la monnaie, réfute les arguments lires du silence des auteurs, et dresse le: calalogue caracléroscopique de ces pièces, procédé permellant de distinguer les frappes authentiques de leurs copies ${ }^{110}$. l)ans l'examen des constiluantes d'un trésor de monnaies gauloises, le pourcenlage des catérogies représentées détermine le caractere spécifique d'une encaisse. Ainsi le trésor des Coriosolites du Petit-Celland (Manche) et de Jersey renferme trois séries également réparties. Ces dépoits ont done une commune provenance. dont la cartographie peut indiquer les centres de dispersion ${ }^{111}$.

(ue faut-il ronclure des cont remargues relevés sur les monnaies gauloises, par l'apposilion d'un poincen de petit diamilre postérieurement a leur mise an rirculation112:? La contremareque avail, pour objel de domer provisoirement. rours a des esperenes ómises hors da pays.

l'aire de dispersion des monnaies deor, allribueses aux Aulergues Cénomansitis forrespond is une unile numismalique, bien yue ne relevant pas de ce groupe, mais dépendant, d'un centre silué en pays venite. Ils lémoignent de relalions commerciales aver les Redons et les Namnetes, ¿ la fois par lerre el par le cours de la Vilaine, puis vers les rades osismiennes.

La prósener dans les enfouissements de

(10k, I". 1.. Visx, tham, VI, 195.1, ). 19519R.

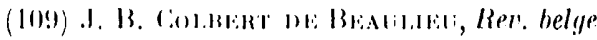
de mumism, 19:4, p. $57-7.4$

(110) lou мlist, ogam, VI, 1954, p. 289-295.

(111) Io wìnk, Bull. soc. fr. numism., 1954, 1.. :212-:13.

(112) 191 MEMlli, Gallia, XIJ, 195.4, p. 55-7:2.

(113) Dor wisul, Mém. sor. dhisl. of d'archéol Brolatme, .34, 1951, р. $5-38$. monnaies de potin peut s'expliquer par des pertes de guerre ayant raréfié le numéraire et la nécessité de nouvelles frappes que les Romains n'assuraient pas. Elles correspondent a des especes de petite valeur, émises par les Gaulois apres la conquête et probablement jusque sous le règne d'Auguste, allestant peul-être un souci du vainqueur de laisser au vaincu une illusion de libertét14. De mème dans le Nord-Ouest de la Gaule, entre l'Armorique, la Loire et l'Escaut, on releve l'existence d'un numéraire de petit module. frappé sur des flancs d'argent à litre plus ou moins bas, succédant à des émissions préromaines disparues au cours des guerres de la conqquête ${ }^{115}$.

I.es modalités de la technique pour la fabrication des monnaies at la roix languedociennes et du hassin garonnais. imilées des piecess de Rhoda, ont éte l'objel de rechererhes nouvedles"lla. Signialons, plus pour la yualilé de ses reproduclions que pour sese interpretalions philosophicon-esthéligues, londlés sull IIII classement rehronologique sujel is raul ion, III onvrage sur les momnairs ganuloises 117 .

V

Épogle Garmo-Romane:

I. La compuềle. Truncaux mililaires. Ce ne serait plus au confluent du Rhome et de la Inurance qu'on deit resherreher le sile de la balaille livere, en 102 avanl . J-C., par Marius allx Ambrons et, aux

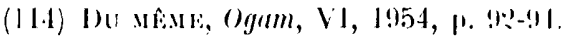

(L15) Du vîne, ihid., p. 119-126.

(116) D); мsuse, ibid., p. 126-130.

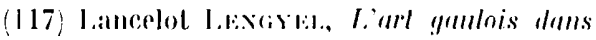
les midailles, Piris, 1954. 
Teutons, mais alu confluenl du Rhone et de l'Isire, oì elail placé son camp d'observalion, alors que son camp de bataille aurail éle dressé sur la colline des Baumeltes'. Descendant au sud-Ouest sur les rives de la Torse, par deux fois a vingtqualre et quaranle-huit, heures d'intervalle, Marius écrase successivement ses ennemis. (On se demande quels rapports pourraient itre élablis entre la statuaire d'Entremont of un triomphe de Marius en souvenir de rette vicloire.

list-il Irop téméraire d'espérer qu'après les résultals négatifs des fouilles de Chailillon et de Myon (Doubs), la harehe de guere soil définitivement enterrés entre partisans d'Alaise el d'Alise? ?

L'examen des itinéraires suivis, lors de la rampagne des Ciaules, ne cesse de relenir l'allention. La géologie, la géographie el re qu'on peut reconnaîle du lracé des anciennes pistes gauloises a travers le Cihalonnais, laisserail suppomser que les

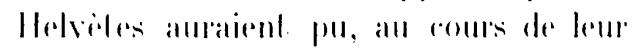

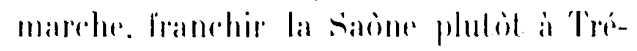

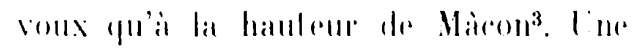
aggoloméralion gauloise antail existe a Beurey, prese de siainl-Gervalis-sur-Coulrhes, de meme que la forèt de Voluse aurail jour un roile dans ceet épisode. Dans la recherche de ces ilinéraires, on doit tenir romple des facilites apportées aux problimes du lransport du matériol mililaire el des moyens offerts sur place au ravitaillement. Lin essayant. de préciser le lracé du chemin suivi par César, passant du lerritoire des Helvites a celui des levernes all cours de l'hiver 52 (B. Ci, VII, 8, 2-3), on est amene is priter une cerlatue importances

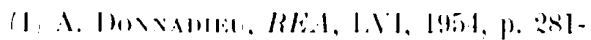
$\because 996$.

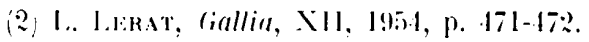

(3) M. Boxval . Mem. sne. dhisl et d'arrheol. chalon-sur-Sigume. NXXIII, 195.1, p. 86. à un sile archéologique situé près de Roux (Ardiche), au voisinage de Montpezal, dans la vallée de la Fontauliere, non loin du col du Pal, franchi par César: lit, alı Marugier, près d'un chemin dallé, s'élend un habil at ent ouré d'une double enceint $\mathrm{e}^{4}$.

In délail de la topographie d'Alisesainle-Reine permel l'explication des termes, declinia el denexa, qui apparaissent dans le lexte des Commentaires relatifs a la derniere bataille de 525 . Il s'agil des pentes descendues par César au cours de son ultime manoruve, pour rejoindre dans la plaine le rorps de Latbienus. César quitle alors son poste de commandement de Flavigny, mais ce mouvement n'a pu se deveropper qu'en deux temps, la monlagne de lalavigny olfranl deux pentes sucersives, ditail lopographique relevé par César.

L'un des passages les plus obscrurs des Commenlaires as colui qui lataile de la

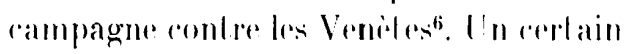
nombere des problemes qu'il prese resianl. coll suspens par suite du manyue de domnéps précises, il eal vain de recherrerer l'emplatcoment exarel d'une balaille navale, donl on ignore trop de circonstances. Ville ne se serail toulefois pas déroulée all large: du Croisic: ou de la Cornouaille. D'autre part, on ignore si César a longé la crote. morhihannaise au Nord ou an siud, il n'a pas cependant longé lit Briere. On ne posside enfin aucune preceision autorisanl un choix entre saint-Gildas of . Irzon pour le sile do ramp résarien, mais il est. peu vraisemblahle quil ail orcupé les. hauteurs de Giuérande. Ces imprérisions lrouvent, leur explication dans ter calatrlepe mème de l'ouvrages simple schéma,

(4) J. Saltes, Gallia, XIt, 195.4, p. 453.

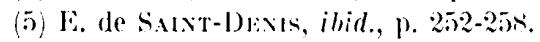

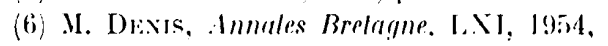
p. $126-153$. 
reuvre de circonstance et de propagande? La campagne contre les Venetes a comporté la seule grande balaille navale des Ciaules, mais ces populations furent loin d'avoir élé exlerminées, puisque dans la suile elles prennent part a trois soulevemenls généraux. Il n'est donc pas surprenant qu'on soil amené à apporter des restrictions is la réalité de la répression c'́sarienne. Des vaisseaux avaient échappé au désastre el quelques princes el. leurs clientèles avaient pu fuir vers la cole anglaise du sud-()uest, suivant la vieille roule des trafiquants vers le minerai. On retrouvera dans le Wessex res colons armoricains, installés dans les Hill-Forts B, centres de leur domination sur une paysannerie passive. On peut antssi interpréler les lextes relatifs a la rampagne de $5 x$ a la lumiere des découvertes archéologicyurs. César, arant la halaille navale, livere a proximité de la cole morbihannatise, an large de la presqu'ile de Rhuis, n'a pas pénétré dans les terres all-delis d'une ligne courant. de Vannes a l'embouchure de la riviere d'Auray. I l'ouest de relte ligne, des rhambres soulerraines, abris ou rachelles, se rallachent a la lulte antérieure ou postérieure a l'exode des Venètes. Ceux-ci en fuyant onl pu emporter une partie de leurs biens et de leur encaisse métallique. L'existence d'un monnayage venete, au temps de l'indépendance, est prouvée par la multiplicité des dépòts, mais il est a remarquer que, rares sur leur propre territoire, ceux-ci sont nombreux à l'Eist el, a l'Ouest de leurs frontières, comme si la fuite du numéraire vers l'extérieur de la cilé élail la conséquence de leur lutte contre les Romains et de leur défaite. Bt, celte constatation vient a l'appui de la

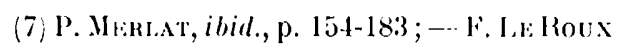
et Ch. Givonvanc' H, Ogam, VI, 1954, p. 51-70, 300-304. réalité de la part active prise par ces groupes it la lutte contre l'envahisseur aux côtés de la confédération armoriraine el apportent de sérieuses prósomplions en faveur de la survivanee du gros de la populalion et des relations avec la Cirande-Brelagne ${ }^{8}$. Le trésor de guerre de: l'Étal, venite n'est pas au fond de la mer. Il serail resté sur une hase voisine d'un port où se concentrait la flotte bloquée, aux mains des reliquii, c'est-it-dire encore. rnfoui aujourd'hui, ou pris par César.

On n'hésitera pas a classer dans les opinions téméraires, les divagations d'u un curiste et ami des sources", qui alleribue. aux Romains l'élablissemenl du camp de Chassey9, dans le bul. d'y réunir les baigneurs des thermes de sant enay-les-Bains où Jules César serail venu lui-mème faire.

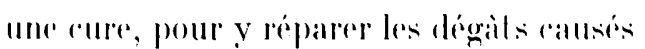
i soll organisme par les légendaires orgeries romaines, al il a drouve encore un jomrnal pour acrueillir de lelles ineplies.

signalons un "Varle-mecum historicgur", redigé par E. J. Tripsi" an sujet du loe bello grallico, al une élude de Mlle Berlaul. surll le brigandage dans l'ocedidenl. romain sous le Haul-kimpire.

2. Les villes gallo-romaines. - La civilisation romaine fut essentiellement, urbaine. Avant la conquète il n'y avail, pas de véritables villes en Ciaule : la ville gallo-romaine est un apport de Rome, "symbole omniprésent d'un systeme religieux, social et politifue ", comme lo. remarque P. (irimal' dans un pelit live

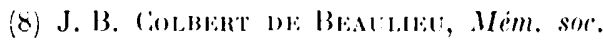
hisl. el archeol. Brelagne, X.XXII1, 1953, p. 5-5:;

Annales Brelayne, L. XI, 1951, p. IX.1-200.

(9) Rev. archeol. Esl, V, 195) 1, 1. 3013; - I.e Bien Public, 28-V1-1954.

(10) Gand, De Vlan, 195.1.

(11) Annales Midi, 66, 195.1, p. 91.

(1) I.es villes romaines. (ioll. "(Gue sais-je?" $n^{\circ} 657$. Paris, 1954. 
où il a trìs heureusement, condensé ae qu'on sail de l'urbanisme romain, qui diffusa il lravers le mondre anlique des conceptions monumenlales, forum, hasilique, curie, théatre, amphithealre, thermes, aqueduc, enceinte a portes et arc de triomphe. Celle forte armalure urbaine qui a joué un ròle des plus importanls dans l'ocure de la romanisation, n'étail rependant pas uniforme cl. l'auleur a su montrer romment elle s'élait adaptée aux tendances particulières et créer des lypes monumenlaux, tels en ciaule les amphithéil res a scrine, répondant aux habiludes of aux goûts d'un peuple.

Des précisions ont été apportées a la lopographie du site de Marseille: sur la voie d'lis, des resliges de la nécropole grecque du ve-r ve siecle, bouleversée par les sépultures romaines en tuiles il profil quadrangulaire du I $^{\text {er }}$ siecle de notre ire, ct. au Bas-For-Sainl-Nicolas, dans la cour de la raserne des légiomnaires d'autres lombes sous luiles el en amphores remployees pour l'inhumation d'enfants, lémoins du cimeliere du Bas-Limpire s'élendant jusculài saint-Victor".

Deux nouveaux segments do l'enceinte d'Arles (Bouches-du-Rhòne)s ont été relevés : l'un à l'exlrémilé occidentale de la rue du Refuge, vers le rond-point des Arènes, appartient it la partie Nord du rempart du caslrum et repose sur un sorle entaillé dans le rocher; l'autre, sous le Palais de l'Archevèque, relève de la muraille du Bas-Lmpire, avec remploi de blocs moulurés de grand appareil. Dirigée S.-E.-N.-O., elle se silue dans le prolongement de la partie encore visible dans la cour du Muséon Arlaten. Ce serait au $1^{\text {er }}$ mars 327 que la cité aurait pris le nom de Constantina et le 10 octobre 353 , celui

(2) F. Benolt, Gallia, XII, 1954, p. 426-429. (3) De MÈ̀r, ibid., p. 429 . de Conslantira: la ville doil done s'appeler Comslantia al pas serulement col(onia) Arelal(ensium $)^{4}$.

L'histoire urbaine d'Aix-en-Provence (Bouches-du-Rhòne). enregistre de nouveaux progrès, trois découverles permettant, de préciser le périmètre de la colonie et l'orientation du cardo. A l'époque augustéenne, le périmitre de l'enceinle d'environ 4.000 metres se rapproche de celui des grandes cilés des vallées du lihòne el de la seine. Après les lroubles du ve siecle qui entrainerent, l'arasement. du rempart el la destruction de grands édifices, dont l'amphilhéaitre, les parties orientales et méridionales de la colonie sont occupées par un quartier rural chrétien, dont les habitalions sont grossierrement élablies sur les ruines du Baslimpire. $A$ une éporgue plus lardive, un cimelière y inslalle ses tombes sous luiles, dont l'une peut itre datée de 52l. Ce quartier inférieur, la "Ville des Tours", apparlenait à l'évêque du Moyen igge el clail indépendant du costrum, dressé it l'Est de la colonie sur l'emplacemet du castellum de C. Sexlius Calvinus. Au Nordbist du beffroi de l'Ilotel de Ville, un tronçon du carde, bordé de trottoirs et pavé de grandes dalles a élé mis au jour. La direction de la rue, qui semble s'infléchir vers l'Est, apres sa rencontre avec le decumanus, a donné son orientation aux réseaux d'anciens chemins el aux limites des propriétés du quartier . Nord de la ville. lin cimelière, adossé à l'kist à la colline rocheuse, bordait la voie des Alpes, ì la sortie de la porte Nord de la colonie, située à la hauteur de la Traverse de l'Ilôpital.

Des travaux de voiric à Fréjus (Var) ${ }^{6}$,

(4) H. Roltaxd, Lalomus, XII, 1954, p. 201206.

(5) F. Bkxort, Gallia, XII, 1954, p. 294-300.

(6) De мÈME, ibid., p. 437. 
entre les emplacements du théil re el du rempart septentrional, n'ont rencontré aucne conslruction antique. A l'()uest de la porte de l'Agachon, en dehors de l'enceinte, s'étendail un dépoloir, ulilisé anx fer el I $^{\mathrm{e}}$ siecles.

La continualion des reeherehes dans le quartier de la Villasse, à Vaison-laRomaine (Vaucluse), a ell pour premier résultat l'achivement du dégagement de la maison au Dauphin, donl on posiside une descriplion. Au-deli de ces batiments, un péristyle se développe sur loule la largeur de la demeure ot un hassin a exidre a élé dégagé. (On peul se demander. si ce dernier ensemble apparlient it lit maison. La présence d'une entrée particuliere sur la rue pourrait indiguer son indépendanere. I louses de cel ensemble, rourt une rue a colomnatde. bordere du rotes de lat maisen pare none rangée de bouliegues, ratheledanl la dilléremere d'orientalion de la rue ele de la dementere.

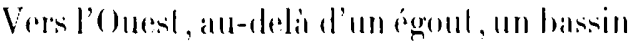

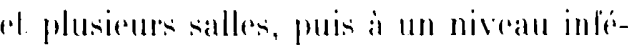
rieur, les vestiges d'une nouvelle consIruelion. Ainsi s'esquisse une rhronologie de la rilé, une premiere prériode élanl marque par les vases du ler sierle; une deuxieme, aver poleries de la Graufesenque correspond a la construction dese monuments publics et du quartier de Puymin; apres les invasions de 263 s'ouvre une période de reconstruction et une qualrieme est contemporaine des grandes invasions. Lors de réparalions au pont romain, une partie du lablier ancien a été mise au jour, avec ses rainures praliquées dans le dallage ì un écartement. de $1 \mathrm{~m}$. (65).

Les somblages entrepris au pied de lare de triomphe d'()range (Vaucluse ${ }^{8}$ onl lait connaitre l'existence de fondations, rele-

(7) J. SAtTEL, ibid., p. 151-161.

(8) De viskl, ibid., p. 156-157. vanl. d'une construction anlérieure is son édification el pourant représenter les fondations d'une porte placée en arriere d'un remparl.

Dans l'ant iquilé, le quartier d'A vignon (Vaucluse). séplendant audour de l'église Saint-l)idier juscuto la place, avail elé occupe par des maisons an 110 , puis aux

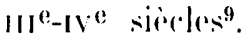

L'histoire urbatine de Narbonne ast encore imprécise of on accueillera lavorabemenl la collaboration apportée par le regrette abhe sigal a la lopographie des

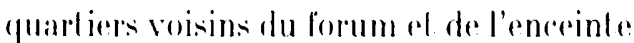
du Nord-()uest. sous less laves des rues du Lieulenant-Colonel-Deymes et Rougelde-l'lsle, l'abbé sigal avail dégagé un

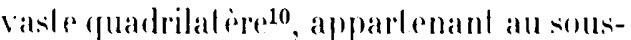
sol d'un monument du début du fer sierde

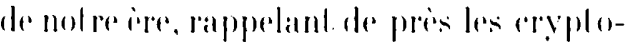

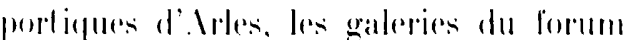

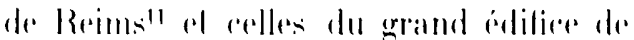

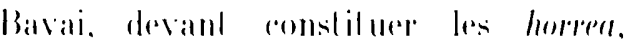
resereves des provisions de la ville all voisinage du forum. La vie narbonnaise

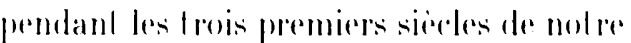

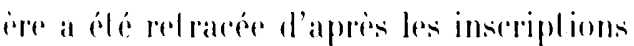
dans un mémoire de diplome d'aludes supréreures d'histoire presenté par Yolande Ciaillard ${ }^{12}$ devanl la Farulte des Letleses de Montpellier.

Les travaux de reconstruclion dans less quartiers sinistrés de Valence (I)ròme) ont amené quelques découverles isolées ${ }^{13}$ : dépoloirs des $1^{\mathrm{e}}-\mathrm{I}^{\mathrm{e}}$ siencles dans les jardins de l'ancien couvent de la Visitation; lroncens du decumanus et deux grands egouls dans l'ancien couvent des Trinilaires; sépullures au quarlier saint-

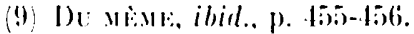

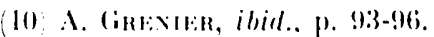

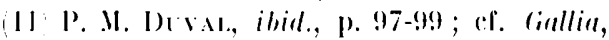
Xlll, 195\%, p

(1:) Rere hisl., c(:X111, 195.1, p. 381.

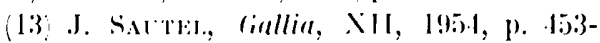
15.1. 
Jacques sur l'emplacemenl du cimetiere anlique deja connu.

Deux straligraphies urloaines ont pu etre élablies i saint-Bertrand-de-Comminges (Ilaule-(iaronne) sur l'emplacement de la basilique rivile fétablisiement. Bordiere $)^{4}$, ol a Bordeamx (Ciromde), le long du mur oceridental du Palais (iallien ${ }^{15}$. l'ne mosal̈que i déror géomélrique des we-re siocles, des fragments arehilecluraux el un morecau de relief (buste de Terpsichore) onl éle lrourés impasse

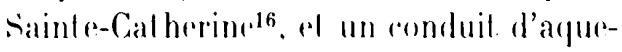
dur a Begles. an lieu-dil "Ponl des Ars" ou "Moulin des Ars". I a mur en pelit. appareil al les colommes en marbre de Campan, fromves plare Pey-Berland, appartiennenl peut-ibe i l'ancienne église sainle-lléline. Des substructions gallo-romaines ont elé reeonnues devanl. l’immeuble de la Caaisse d'Épargnel7.

les moyens mécaniques employés dans les lerrassements enl repris a Cahors (I tol) sur l'emplacement de l'ancien enrelos des Carrisses's ont amene la destrundion d'un reseatl de mults définisisant un ensemble arehilerelural, donl "l'arre de l)iane" aul Cord de la ville n'élail qu'un écément, comvant appoximativement une surface de $3000 \mathrm{~m}^{2}$. limilée a l'ouest. le long d'une rue anlique, par un mur de clóture, au Cord par une aul re muraille longlemps considérée comme le vestige d'un rempart barrant d'list en Ouest la presqu'île. A l'intérieur, on entrevoit un complexe de haliments, grandes salles a plan rectangulaire, parfois lerminées en abside, aux

(14) I. I.abnol'ssl:, ibill, p. :216-217.

(15) Sainl-Berlrand-ale-lamminges. I.ugdunum Convenarum, centre lourislique durl el dhishoire, Toulouse, 195.1.

(16) J. Col Pr), Gallia, XII, 1954: p. 202-207.

(17) Binalo-Sinktal, Bull. el mem. sor. archeol. Bordeaur, INII, 1945-1950, p. 11-19.

(18) M. Labrocssti, Giallia, Xl1, 195.4, 1. $2227-230$. sols revelus de mosaïques au Sud de l'are, bélonnées au Nord. Toutes ces construclions ne sont pas contemporaines et la st rat igraphie donne I rois élats suecessil's : de l'étal initial, donl peu de traces sont. apparentes, on comnaîl de gros bloces en gress de Frontenace en rapport aver le soubassement d'un porlique; puis, sans lien aver ceel édifices, une reconsibucfion décisive en moellons de pelit appareil, fixanl le plan définilif du monument qui subira un remaniement final amenant la construction ou la reconstruclion de l'are ; l'apparition desc chainages de hriquess el, un luxe pardiculier dans le ehoix des reveltements rararelerise col emsemble. (On a rherehe a identitier l'édiliese avere des thermes, rependanl malgré la présence de plusicurs ranalisalions, sa destination reste enrore imprécise.

loint d'aboul issement de la voie marquée par la nalure pour conduire, par le lauragatis ol la vallée de la Garonne, de Carbonne a l'oréan, saintes (CharenleMarilime) lul, aux lemps gallo-romains, un rentre urbain tris imporlant. (On doil aux recherehese de .l. Cloued ${ }^{19}$ de grands progris dans l'histoire du developpement de la rile, qui avail un périmetre sensiblement plus élendu qu'on ne lesupposait, englobant les hauteurs de sainl-Vivien, des sables. de l'Inopilal et de la Providence. Sur la colline sainl-Vivien l'établissement de multiples terrasses de soutenement avait permis l'utilisation presque complete d'un lerrain lres accidenté. De grands monuments au sommel. du coteau et, sur son penchant, des habilations en bordure de la Charente

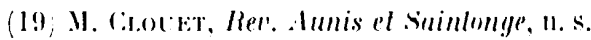

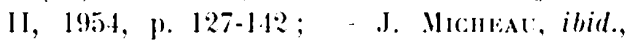
p. 103-111 ; Dt wăk, Recherches lopographiques, historiques el archeologiques sur Mediolamum Santonum el le développemenl de Suinles an Moyen âge, diplome ét. sup. d'Hist. Toulouse (Annales Midi), 66, 1954, p. 91-92. 
étaient desservis par de grandes arlires. Situés hors de l'enceinte, an we sirele, les coteaux de Saint-Vivien al de SaintViclor forment. less laubourgs, et un cimelière est installé sur les ruines des édifices romains. In point imporlant de l'histoire urbaine au Bas-limpire a pu être fixé : celui du castrum²0, dont aucun vestige n'est apparent sur le sol. L'enceinle, en forme de lraperze irrégulier, faile de blors rmpruntés aux édifieres délruils, entoure le quarlier sainl-Pierre avee la lal hédrale. corur de la rili an Moyen age, sur la rive gauche de la Charenle. Ia muraille, épaisse de 1 mètres al flanguée d'une vinglaine de tours carrées, longe l'extrémilé occidentale du jardin de l'llopital el. de la se dirige au Yord jusqu'il la Charente, passant pres de la porte diguiore disparue el sur l'emplarement de la rue du Rerm-

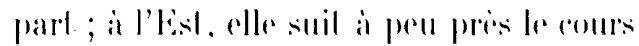
de la riviere, s'acerorhe an sud sur les rorhers de la rue Berlonniere, pour ensuile rejoindre la Charente pres de la rue Maturenseril. la developpement de la ville avait nécessité de nouveaux travaux d'adduction d'raux. Des rexherehes, fait es sur le penchant du roleanu de la Grevere ont revele l'existence de deux analisitlions, dont l'éloignement est plus grand sur le còté méridional où jusqu'ì ce jour une seule conduite était connue. La nouvelle branche, moins importanle que la principale, présente une pente asse\% forle, d'où un débit assie' devé, et se dirige vers le quarlier de saint-Pallis, sur la rive droite de la Charente. Des précisions onl élé aussi apportérs sur l'alimentalion en eau de la rive gauche. Le canal, traversant la vallée de la Charente, aboulissail a une plateforme horizont ale, base

(20) M. (isotle, "1p. cil, p. 83-102; Alnn. Midi, 66, 1954, p. 94.

(21) A. Тнао, Rev. Suintonge el Amnis, 195.t, p. $112-11 \overline{1}$. probable d'un ourrage de distribution plaré à l'extrémilé du grand aquedue, face i l'aggrlomeration. Des siphons de plomb, ulilisés pour la traversée de la Charente, pouvaient rejoindre directrment l'mplacement de la Prison, où d'imporlanls vestiges ont été Irouvés. Deux départs des eaux sont ainsi a envisager ol il est it remarquer que lout point plus has que l'emplarement de la plateforme ne pouvail plus itre alimenté el que la remontere des raux an sommet du coterall du Calpitole idail, hydrauliquement, impossible.

Ouelques déeouverles onl élé failes a limoges (Hanle-Vienne) : aqueduc ou igoul creusé dans le rocher ou danns le luf au quai saint-Martial. ou des murs on grand appareil onl éle reconnus; niveau gallo-romain place des dacobins, soms lo jardin de l'ancien courent des Carméliles; base moulurée de granil pres de l'emplatrement d'un édifiere délruil rue de

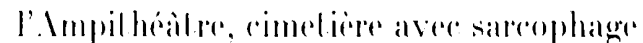
roll grosises briques on on dalles do granil. dépendant probablement de l'église primilive de la sainte-Trinite, sétendant depuis la rue du Pont-saint-llarlial an rhemin de la Font-Pinot.22.

A Poiliers (Vienne) ${ }^{23}$, des restes de maisons anlérieures à l'enceinte du $\mathrm{JV}^{\mathrm{e}}$ siècle qui les recouvre, ont été retrouvés dans un jardin vers le milieu de la rue des Pouples el, at Tours (Indre-el-Loire) ${ }^{24}$ des Iraces d'une chaussée large de 10 met res, dirigée. Lord-Sud, semblent avoir conduit. au Nord du temple gallo-romain préédemment découverl el dynamilé par les services de la keconstruclion, rue Nalionale, construil sur plan circulaire

(2) J. Plinniler, Bull. soc. archeol. ol hisl. Limousin, XXXIV, 195.1, p. 570-571; - Ciallia, XII, 1951, p. 18:3-185.

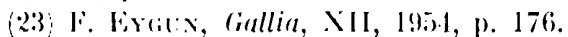

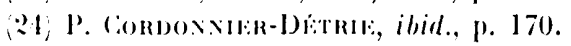


comme le samcluaire du Moulin du lí. lal présence de celle vole expliquerail celle de fragments de porliques, mis au jour rue de la scellerie. Un tronçon de l'aqueduc souterrain, alimentant la ville galloromaine a été retrouvé à Larchay (Indreel-Loire) dans la propriété Fradin ${ }^{25}$.

Le netloyage de la Tour du Tunnel et du mur occidental de l'enceinte du Mans (Sarthe) a amené la découverte d'une polerne basse ${ }^{26}$, n'ayant pas de rapports aver les aulres polernes déja connues, faisant connaîlre l'existence d'un embarradire (poutrages) immédiatement en amont du plus ancien passage connu de la Sarthe, le pont Issoire acluel. En amont des inslallations portuaires antiques avaient déjà élé reconnues lors de la créalion des quais. Ce sont aussi des indicalions sur le port lluvial de Vichy (Mllier) que révèle l'examen des varialions du lit de l'Allier ${ }^{27}$, construclions sur pilotis depuis le square Mbert Ier jusqu'au bassin des Cygnes, témoignant de l'imporlance de la navigation fluviale par laquelle arrivaient, au $11^{\mathrm{C}}$ siècle de notre ère, les amphores d'huile de la Bélique.

La destruction du vieux pont de la Guillotiere is Lyon ${ }^{28}$ a permis de récupérer un certain nombre de lextes épigraphiques : dédicaces à un prêtre de l'autel de Rome el d'Auguste, a un procuraleur de la province de Lugdunaise el d'Aquitaine, i ESlagabale par les cives romani in Tribus Provinciis consistenles, datée de 220 de notre ère. Ces inscriptions ne proviennent pas du site de l'antique colonie fondée en t3 après J.-C. Elles ont élé prises sur

(iv) La Nourelle Répubique, T'ours, 12-X-1!5-1. (:6) 1'. Conpoxime-1) 1954, p. 172-175.

(27) Dr A. Morter, Tourisme jt. I'ichy-Cannes, $n^{\circ} 51$, fécr.-mars 1954

(28) A. Aldix, J. GLey, P. Wintaumar, 1KEA, IVI, 1954, p. 229-3.66 ; - CRAI, 1954, p. 6.t-69; - J. Cancopsto, ibid., p. 69. l'aulre colline de la Croix-Rousse, oì se rélébrait le culle des Trois Provinces de la (iaule, dans le sancluaire lédéral, dont la vaste terrasse élait taillée dans le plateau au-dessus des Terraux, a petile dislance du confluent. Celle trouvaille renseigne aussi sur la destruction des monuments romains de Lyon par l'exploitation de la pierre de taille au Moyen ige. De ces opérations on a une preuve lopographique : si le lènement situé immédialement, au-dessous de la terrasse du sanctuaire s'appelait alors "Le Perrier" c'est qu'il arait longlemps servi de carriere.

l)ans la zone du Vieil Hòpital, à Vienne (Isire) ${ }^{29}$, ce qu'on avait pu considérer jusqu'ici comme de grands escaliers au long du mur du Palais des Canaux, ne peul èlre que les gradins courbes d'un édifice destiné à des spectacles, apparlenant sans doule aux vestiges d'un théatre de myslires de Cybele et d'Allis. Celle hypolhèse de Ch. Picard a élé vérifiée par la découverte des restes d'une scène el l'inscription d'un locus de la confrérie des I)endrophores. Le bas-relief du sacrifice à Cybèle appartient à la scène de ce théalles, ainsi que deux fragments relrouves au théitre de Vienne.

En plein centre du vicus de Boulae, en bordure Sord-Oust de la rue du Forum, aux Fins-d'Innecy (IIaute-Savoie) ${ }^{30}$, des travaux de construction ont facilité l'établissement d'un commencement de stratigraphie.

I la hauleur de Chalon-sur-Sacine, le coude décril par la Saòne correspond au site le plus proche du plateau bourguignon et de la ligne de partage des eaux entre la Médilerranée et la Manche. Il marque aussi un relais entre le Midi et le Bassin Parisien. Cette posilion explique le carac-

(29) A. Britul, Gallia, XII, 1954, p. 463-465. (30) DC MÈE, ibid., p. 462. 
tire des agglomérations qui se suceident. sur ces emplacements, nées de la route ou plus exactement du transbordement de la voie de terre a la voie d'eau ${ }^{31}$. lin itinéraire connu, dés le Ille millénaire avant l'ère, suit une ligne à peu pres droite depuis Chalon jusqu'a la haute vallée de la saòne par Demigny, Beaune, Fleury-sur-()uche, Chàtillon, Troyes.

En Bourgogne, le chanlier d'AliseSainte-Reine (Gole-d'Or)32 a élé ouvert dans la partie Nord de la parcelle 399. De part el d'autre d'une voie venant de l'est el longeant au Sud le sancluaire dit " dolménique ", deux maisons ont élé dégagées avec cheminées demi-rondes et caves. Deux blocs "mégalithiques " élaient encastrés dans les maçonneries romaines. I I)ijon ${ }^{33}$, des démolilions rue Longepierre ont lail réapparaître la muraille du II $^{\circ}$ siecle, revilue exlérieurement d'un parement de grands bloces lailles en pieress d'Asnieres, dissimulant un blorage de moellons disposes obliquement. la base de la lour pourrail ide anligue. Rue de Gray el rue de Colmar ${ }^{34}$, dans le pare des Ponls el Chausseres, des fosiess a inhumation relevent du cimeliere ouvert pres de la Voie d'Igrippa. A sens (Yonne), rue du Général l)ubois, sur l'emplacemenl ou ful découverte la mosaïque du Soleil maîlrisant ses chevaux, de nouvelles Irouvailles permeltent de dater des denx premiers siócles l'occupalion de celle partie de la ville gallo-romaine qui se prolonge encore sur le me siecle et au-deliala. L'élude slratigraphique, faile aux arenes de sens, semble devoir dément ir la théorie admise de la ruine de la ville a l'extrème

(31) P. Gus, Mem. sore, Whisl. de dareheol. Chalın-sur-siome, XXX111, 195\%, p. 106. (32) 1. I.HRAT, Ciallia, XII, 1954, p. 17. (33) De MEMt, ibid., p. 177.

(3.1) G. Grimall, Reu. archeol. Est, V, 1951, p. 194 .

(35) R. Lotis, ciallia, XII, 195.4, p. 5:0). fin de la période gallo-romaine ${ }^{36}$. Des fouilles a duxerre (Yonne) a a lentrée de la rue Cauchois pour dégager la hase de l'enceinle de la fin du $\mathrm{II}^{\mathrm{c}}$ sirele sur face interne, au Nord-Ouest de l'ancien palais épiscopal, ont montré que le sol élait plus élevé dans la cilé el que le rempart soutenait celte terrasse. I a présence d'une monnaie de Constantin II, datée de 321 ou 326, recueillic dans le mortier, est-elle un document sullisant pour reculer au premier quart du $\mathrm{Jv}^{\mathrm{e}}$ siecle la construction du rempart? Deux niveaux, gallo-romain el mérovingien, ont été isolés et le second a donné les vesliges d'un atelier de tabletier, installé, au ve siecle, pres de la domus episcopulis.

Bien que ne subsistant qu'au niveau des fondalions, on a pu suivere le trace exarel du remparl gallo-romain de Beauvais

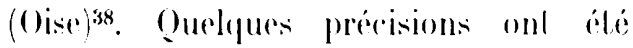
apporlées sur les condilions de l'allondrement de la porte de lironze, derout verle a senlis, qui avail bascule stre le sol anlique de lerre hallue. Les laress d'incendie des panneaux de boss blaient encore visibles sur le lerrain, ou less penlures de fer demeuraienl engageesi39.

En Alsace, les diverses phases de l'oceupation du sile de Seltz (Bas-Rhin) ont pu ètre déterminées ${ }^{40}$ : le camp militaire installé sur cel emplacement. a l'époque rlaudienne avail été anéanli par un incendie en 70 apres J.-C. Le camp flavien qui lai succéda, plus réduil, dans son étendue, ful désaffecté apress la ronstruction du limes; des aleliers arlisanaux s'inslallenl sur la palissarle, elle-meme ayant pris l'emplacement de

(36) . InII. Mirli 66, 195.1. 1). 1331.

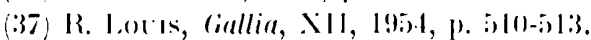

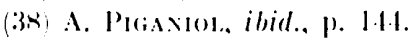

(39) De neste, ibid., p. 1.16.

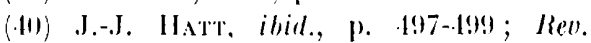
d'Hsace, 95, 1951, 1. 1115-111. 
baracquements militaires en bois brùlés en 70. Ce petit établissemenl ful. lui aussi. délruil à plusieurs reprisés en 97 (?). à la fin du me $^{\mathrm{e}}$ ou all débul du $11^{\mathrm{e}}$ siecle. Sur le parvis de l'église, le Iracé de l'enceinte du Bas-Limpire a pu ètre suivi, et il est probable que le sanctuaire primilif stappuyait en partie a l'ancien rempart romain, sous lequel des restes de murs relevent de ronstructions incendiées a la fin du In ou au débul du nine siècle.

I strasbourgoti, la principale découverte est celle d'un vaste entrepoit militaire a proximilé de l'Ill at de la voie romaine, sur l'emplarement de la rue de l'. Lillat. en dehors de l'enceinte du camp mililaire, el d'al eliers d'arlisans travaillant on marge du camp dans les quarliers civils des camabae, sans doule sous te controle de l'autorité mililaire, en l'espere des potiers. Au débul $\mathrm{du} \mathrm{I}^{\mathrm{er}}$ siècle, un bras de l'ill éait utilisé comme décharge par les habitants du voisinage. Puis environ (if) apres J.-C., une crue du Rhin creusant le lit de la rivière. dresse sa berge au-dessous de la rue de l'Ail. Les potiers, installés sur ces emplacements, postérieurement à l'arrivée a strasbourg de la VIIIe légion, transiorment la berge en dépotoir d'atelier. Environ 90, sur la berge remblayée et stabilisée, sont construits un quai et une darse pour l'embarquement des marchandises, recouverts après 97 par les murs d'un asse\% grand édifice, situé prés de la Voie romaine et de l'Ill, probablement. utilisé pour le stockage et la distribution des approvisionnements de l'armée du Rhin et des garnisons du limes, montrant l'importance prise par la ville, sous les Flaviens et Trajan, a la suite de

(41) DU мล̀. Ge, Gallia, p. $323-339$; - - Rev. archéol. Est, V, 1951, p. 98-100. l'annexion des Champs lécumales et l'élablissement d'une roule directe Rhinl)anube. La conslruction, sous Trajan, de la manutention entraine te déplacement des potiers qui s'installent a Kixnigshoften, pris de la Chartreuse, là où avaient été les fours à tuiles de la légion. Argentorate fut aussi une grande manufaclure rhénane de poteries militaires comprenant trois catégories principales: cruches, assieltes, marmites, grandes jalles, pelves, braseros en terre commune ordinaire, orangée ou rougeàtre; nombreuses formes en lerra nigra el un ensemble considérable de poteries en lerre jaune pàle, orangée ou rositre recouvertes d'un engobe peu résistant rouge, lie de vin, marron ou ocre clair, trìs courantes dans les ramps mililaires de la vallée du Rhin et du limes (Rothbemalle, ou Welleranware), vraisemblablement d'origine balkanique el apportée en (iaule orientale par les légions VIII Augusta et XI Cilaudia. Deux documents, grallites en caracteres grees sur deux lessons, apportent des arguments en faveur de cette hypothèse et tendraient a montrer que, sous les Flaviens, la langue grecque était concurremment ulilisée avec le latin ${ }^{42}$. I l'angle Nord-()uest de la place Kléber ${ }^{43}$, enlre la banque schwartz et le Café de lirance, à l'occasion de travaux de reconstruction, on découvrit dans une rigole siluée entre deux cailloutis de voie se prolongeant vers le Nord par une rampe menant it un sol bélonné, correspondant à une sorte de terre-plein dominant quelque peu la voie, des céramiques permettant une straligraphie : au niveau inférieur, 3.13 .

(4) J. ScawarT\%, ciallia, X11, 1954, p. 339(43) J.-J. HATt, ibid., p. 488-496; - Cah. d'archeol. et ahisl. Alsace, 134, 1954, p. 57-70. 
cendres de l'incendie de 70 ; sol flavien; couche de l'incendie de 90 ; remblais de Trajan surmontés des traces de l'incendie de 235. Dans ce niveau on mit au jour les fragments d'une sliele aux quatre divinités, Junon, Minerve, Hercule, Mercure, d'un chapiteau orné de feuilles d'acanthes d'une torsade et de fleurons i l'abaque, au-dessous desquels deux têtes viriles bouclées, puis deux têles de femmes voilées; des tronçons de colonnes reposant sur un socle en grès gris, brisé par les ouvriers. L'ensemble appartenail sans doute à une colonne de Jupiter au Géant anguipède, dressée certainement à proximité du lieu de sa découverte, rappelant les groupes jalonnant le tracé de la voie venant du Pont Saint-Nicolas a la place Kléber, crée pour relier la ville au limes, chacun de ces vestiges indiquant peul-être l'emplacement d'un carrefour. Ces monuments auraient été aballus sur place après la catastrophe de 235), comme ayant un earactere dynastique. Au point de vue arlistique, il s'agil d'une ceuvre d'une très bonne lechnique du débul, du $\mathrm{II}^{\mathrm{e}}$ siècle, époque à laquelle travaillait a Argentorale une importante école de sculplure, de laquelle on connaissail déjà deux œuvres : la lite de Caracalla jeune et la Parque filant du sarcophage de Florenlina trouvé au cimetière de Koenigshoffen. On peut mettre l'activité de ces ateliers de sculpteurs en rapport avec les travaux entrepris par Septime-Sévère, lors du second consulat de Caracalla, dans le prétoire légionnaire. I'autres découvertes complitent la connaissance de la Lopographic antique de la cilé : tour el porte de l'enceinte flavienne en bois, rue des Vaux; rue de la Croix et des Socurs, complexe de bâtiments militaires en bois, flaviens, avec soubassements de pierres en hérisson de l'époque Trajane; parements de petit appareil sous IIadrien; - quartier extérieur à l'enceinle rue de la Division Leclere, occupé des le I $^{\text {er }}$ siecle et dont, les maisons sur pilotis furent abandonnées à la suite d'inondations sous les règnes de Claude ou de Néron, reconstruiles puis incendiées en 70 . Sur le terrain exhaussé à l'époque des Flaviens s'élèvent de nouveaux battiments en bois anéantis en 97. Un petit édifice en pierre est contemporain du $\mathrm{II}^{\mathrm{e}}$ siècle. Rapprochés des observations failes rue de l'Ail, rue des Vaux el ruelle SaintMédard, il est prouvé que le Rhin, quelque temps avant l'incendie de 70, avait connu une période de fortes crues, de li les travaux de remblai de la période flavienne. l)ans un quarlier enerere mal romnu, rue du Jeu-des-linfants, un sondage a donné une stratigraphie.

Jans le Nord de la lirance, les fonilles se conlinuent a Amiens (Somme), a Arras (Pas-de-Calais) et a Bavai (Nord).

1 Amiens ${ }^{44}$ l'amphithéalre $(100) \times$ 107 metres) presque circulaire, est limite a l'bist par deux murs rectilignes et parallites qu'un troisieme suit parallelemenl a 6 mètres de distance. Plus au Sud, sur une chaussée, deux murs appartiennent, soit à la façade, soit à un escalier. Les limites des thermes de la rue de Beauvais n'ont pas encore élé atteinles. De nouvelles disposilions ont été reconnues. C'est ainsi que l'épaisseur des murs décroil à mesure qu'on avance vers le sud, precisant peut-être une moindre élévalion de l'édifice. L'emplacement des thermes était occupé, antérieurement au $11^{\mathrm{e}}$ siecte, par deux colonnes au Géant anguipede,

(14) J. Hetroos, (iallia, XII, 1954, p. :219134 
auxquelles se rallathent, les fragments d'une frise en lris haul-relief. scemes d'une Gigantomachie avec des Éros affronlés comballant par paires. Dans la partie Vord de la ville, rue Émile Lesot, au voisinage de la voie romaine d'Amiens a Boulogne, un sarcophage renfermait un important mobilier de verreries: deux bouleilles i panse ròtelée, deux halsamaires, un carchesium orné de fils serpentiformes des fabriques de Cologne de la seconde moitié du II ${ }^{\mathrm{e}}$ siecle. L'importance d'Amiens i l'époque romaine s'explique par som caractère essentiellement, militaire au rroisement de roules imporlantes et de la Somme ${ }^{45}$ : ville de garnison et gìte d'étape sur la route de Brelagne.

De nouvelles maisons ont élé trouvées i) Baudimont (Pas-de-Calais) ${ }^{46}$, incendiées dans la seconde moilié du II $^{\mathrm{e}}$ siècle lors de l'invasion des Chauques. Ie site ful réocrupé aux ${ }_{1 I}{ }^{\mathrm{e}}$ et $\mathrm{IV}^{\mathrm{e}}$ siecles. La présence d'un atelier d'osellerie semble indiquer le caractere artisanal de ce quarlier de Nemelacum (Arras).

I Bavai ${ }^{47}$ se poursuil mélhodiquement le déblaiemenl du double portique du grrand édifice, dont la partie ()uest est. culierement dégagée. Des reconnaissances ont été faites à la base de l'enceinte, laite de malériaux de remploi. Ellle se poursuit à l'Est de la zone archéologique en dehors de laquelle les travaux de reconstruction ont facilité la connaissance de la topographie anlique. Au Nord et à l'Est du grand édifice, rue de Valenciennes, (irande Rue el sous l'église paroissiale, de nombreuses consIructions it hypocausles élaient orientées

(15) k. Win., Rev. du Nord, XXXV1, 1954, p. 141 sip.

(46) J. Hetrosos, Gallia, XII, 195.1, p. 134136.

(47) Du мЀмE, ibid., p. 136-142. selon les mèmes axes que la basilique cl. les deux porliques; rue de Valenciennes, au milieu d'un complexe d'habitations, étail pratiqué un bassin rectangulaire dallé et entouré de pierres bleues. Sous le chœur de l'église, des restes de constructions et de décors architecluraux indiquent la présence d'un édifice important ayant la même orientation que le grand ensemble de monuments publies silués plus a l'Ouest. mais on ne peut allirmer qu'il s'y rallachait. Le mur et l'aduedue Nord-Sud de la rue des fommeries correspond a un cardo limilant le quartier à l'Est.

3. Les monumenls. . L'union du forum et du sanctuaire est une des ('aractéristiques de l'urbanisme gralloromain. Cette partie de la cilé, si clle. représente le point de rassemblement, de la population ciladine el rurale, est arant tout le centre religicux et politique de l'agglomération'.

Quelle pouvait ètre la signification de la salle souterraine, dégagée à Thiverny (Oise), au lieu-dil "Les Carrieres ", en bordure de la roule de Creil a Saint-Leu-d'Lsserent ${ }^{2}$ ? On propose d'y reconnaître l'emplacement primitil' d'un bassin où naissait une source, agrandi au $\mathrm{IV}^{\mathrm{e}}$ siecle. Le hasard de Iravaux d'éventrement de la colline, a 700 mètres au Sud des ruines, a révélé l'existence d'un habital antique, peul-ètre conlemporain de La Tène III : alelier de tailleurs de pierre ayant Iravaillé pour le sanctuaire; fonds de rabanes et un puits.

La découverte, fare it Champannesainl-Hilaire ${ }^{3}$ a une centaine de mètres

(1) A. Grisurn, Ilommage à Iucien Febere, 1954 , p. $63-66$

(2) A. Pigaviol, Gallia, XII, 1954, p. 145.

(3) l. Ergix, ibid., p. 181-182. 
en amonl du hameau de Ia Baudonniire, au flanc d'un coleau descendant en pente douce vers le Clain, de la moitié supérieure d'une pierre aux qualre diviniles, Jupiler, Minerve, Esculape ou Vuleain, of peul-ître Vénus, doit Alre rallachee i un temple, dont on connaîl de gros blocs, des lambours de colonnes al des fragments de corniche sur la place ol dans le village voisin.

La lrouvaille la plus imporlante, faite an sancluaire des sources de la Seine a éte celle du dispositil de raptage de la sourersarrés: a l'Est la canalisation précédemment mise au jour sous la grande cour, on a rencontré une petite salle où l'on descendait par Irois marches, aver bassin monolithe en ralcaire pralique dans lo dallage el pourve diune banquelle inlérieure a rhatpue extremile, dessemi far une ranalisalion prenanl l'eau a la sonree meme. I'n lepp-plein el une bonde assuratent la vidange de relle haignoire ellipsoüdale dans un deversoir el, de lia, dans le ranivean rejoignanl la piscine. Ces installations sont anterieures a l'ediliealion du grand péristyle el. sans doule renlemporaines de la cella Nord. sur l'aulre versant du vallon, on reconnut l'existence de conslructions, habilations ou alcliers. Il n'est pas sans interels de relereró que le sanctuaire des soureess de la seine est placé à la limile de deux communes, Poncey-surl'Ignon ol saint-(iermain-sources-Seine. On peut alors se demander si la soure sarerer n'élail pas siluee a la frombiere d'anciemmes reireonscriplions préceltipues, gauloises, pagi du Moyen àge, comme le sameluaire de Morilasgus ol Ilygie a Mlésia. l'n aulre sancluaire de

(4) I., L.1:RAT, ilidl., p. 175)-176.

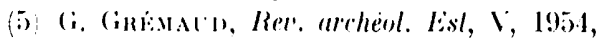

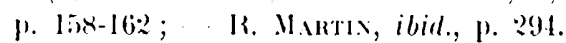

frontieres aux limites du pagus Cabilonensis el du pagus .Malesconensis, sur l'actuelle ligne de bornage des communes de Mont-saint-Vincent et de Saint(iingoux-le-Nalional (Saòne-el-Loire) dressé dans les bois pres de Porlus, sur un bas-plateau granilique ${ }^{6}$. repose sur une plateforme bétonnée, formant trottoir at pourve de murs avant pu supporter une colonnade, ou les piliers d'une galerie couverle, a layuelle on accede a l'bst par des degrés; une salle carrée de 8 mitres de colé, dont les murs en pelit appareil parementés avaient regu une décoralion inlérieure de slues peints de feuillages stylisés et de motils géomélriques. représente la cella du famum. Au rentre, on recueillil les restes d'une lable de pierre en ralcaire hane: el, sur le sol, une teite d'enfianl joufllu aux rheveux houcles. l'avant-bras cerele d'un loracelet filiforme, apparlemant a une statue plus grande que nalure, el des fragmenls de figurines en lerre-cuile. les series monelaires, rachés solds le pavement dans un vase de lerreruile, s'olendent d'Alexandre-sievire à Constance, et l'enfouissement dans les sancluaire abandonné dans la seconde moitie du ro sirele peut alre mise en rapport avec l'invasion les dlamans. du sud de l'édifice s'élendent des sols en lere ballue.

dux Fonlaines-salés (Yomne), se poursuil le dégagement de l'aile meridionale du temple. dallé en pierres de Pouillenay (Coble-d'or) Le plan élant. celui d'un héròn, le sanctuaire devail. etre consareré à la fois a $10 n$ culle des heros el a relui des soureres. Le puits decourert étail vaisemblablement desline a l'usage des pelerins.

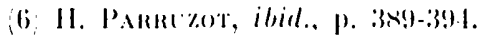

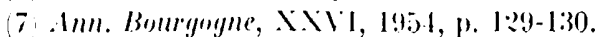


Ie Combalou, a l'Ouest du Larzar, aux falaises ef aux pentes abruptes, est une forteresse naturelle, un cap-barré avec murs en pierres sieches. Sur les pentes Cord-Ouest, une construction carrée à double enceinte peut représenter un fanum, fréquenté depuis les lemps augustéens jusqu'a reux de Salonine. La présence d'un sanctuaire au Combalou est a rapprocher de celles de la grolle-temple du sargel, une autre bulle du Larzare el des vestiges galloromains relevés plus au Nord, sur la pointe saint-Georges, sanctuaires de sommels.

L'existence d'un sacellum païen à ciel ouvert, accompagné d'un pelit cimetiere sur l'emplacement de la chapelle saintJulien, i sarremezau (Ilaule-(iaronne), est conlirmée par les recherches laites dans les murs ou furent remployés des aulels consarerés a Mars ou a Hercule el une stile lunéraire à Irois personnages.

lin plan a été donné de la piscine rirculaire, entourée d'une enceinte oclogonale, el de l'amorce d'un portique ¿ colonnes, du temple de sources de Ciraon, à Montloourg (Loirel), où l'on avait retrouvé au siecle dernier des ex-volo de bois en forme de silhouettes humaines el, récemment, une slatuette de Vénus en terre grise de l'Allier:0. I)ans ces régions de la Loire et de ses aflluents ${ }^{11}$, les monuments culluels sont assez nombreux : deux temples de vici a Irevant el a Neuvy-sur-Barangeon (Cher), sur plan carré, entourés d'une galerie a colonnes; sancluaire à double cella octogonale, distante de 40 metres et réunis par une galerie, l'ensemble

(r) L. BAssix, Velunges..., II, p. 56-61.

(9) I. Lannol:ssi: Gallia, X11, 1954, p. 219.

(10) I3. Locis, Gallia, p. 506.

(11) A. Convarat, Rev. archéul. Esl, V, 1954, p. $: 202-203$. enclos dans une encerinle à porlique sur la face orienlale, a Champillet (Indre); sancluaire de source a plan reclangulaire a Fonts (Indre) ; vaste ensemble relevant peut-ètre d'une villa, comportant certaines salles a destination religieuse, dont l'une carrée en forme d'exédre avec autel cylindrique el lite de Mercure at trois salles entoures de galeries a colonness, al La Tourelle (Cher). Dans l'Auxerrois of dans l'Avallonnais ${ }^{2}$, a Auxerre, un temple orlogonal dédié ¿ Ipollon est silue en bordure du vallon dans te faubourg de saintAmalre; Entrains, aver ses sanctuaires de Jupiter, d'Apollon, de Mercure, de Mars, d'Epona, ses mithrea, apparait comme le centre religieux de la ciritas Aulessiodunensis; d'autres lieux de culte sont connus a sougires-en-Puisaye, avec ex-volo sous forme de chevaux de pierre, a Crain (temple de Minerve), ¿ Gy-l'Évèque, temple de Vénus, lieu de culte a sainl-dignan pris sainlePallaye; dans l'Avalonnais, un centre religieux s'ordonne aulour de SaintPere-sous-Vézelay, avec ses sancluaires dans le village, à La Corvée-sainl-Jean, aux Fontaines-Salées; d'autres encore élaient consacrés à Mercure au Montmartre, aux cultes dionysiaques à Vézelay.

Le relevé par R. Amy des trous laissés par les crampons fixant les lettres de l'inscription sur l'archilrave ont apporté des indicalions sur l'histoire de l'arc de triomphe d'Orange'3. Le nom de Tibere et les litres qu'il revelail en 27-26 occupent le début du lexte, mais a la fin on releve le mol restiluit, d'où il ressort que la colonie d'Orange a "restitué " le monument à l'empereur. Il apparaîl ainsi que l'arc élait d'abord

(12) R. Lotis, ibid., p.:204.

(13) A. PIgaxiol, CR.1I, 1954, p. :20-21. 
municipal, dresse a la limile du pomoerium, plulis qu'un are de lriomphe el dalerail du rigne d'Auguste. II faudrait inlerpreter reslituil comme signifiant la conversion d'un arc municipal en un monument triomphal ayant pour objel d'honorer l'empereur.

Ies criliques ont éé adressées aux essais de restilution de l'arc de triomphe dil des. Amours et du Tricéphale de Lulerest, proposanl de grouper, sur une meme lace. Imours el imbriealions; sur une aulre lace, peul-ître celle de l'entrée. les pilastres auraient, prononé une plus lorte saillie pour encadrer quelque has-relief. On peul. aussi imaginer des pilastres ornés d'acant hes el d'imbricalions. Mais n'est-il pas un peu osé, si l'on envisage les rapports entre l'art reltique el l'art. gallo-romain. d'écrire que l'art galloromain n'a jamais engendré de "monstress", mais il est juste de souligner la grande marge d'incerlilude à prévoir pour loute lentative de reconstilution.

Le degagement de l'orchestre au théalre de Mandeure (I)oubs) ${ }^{15}$ a été mené a lerme. Con loin du théatre, un puils a clé exploré pres d'un petil. réduil comporlant des canalisalions de chaullage. Apros l'achat de l'emplacement du théatre d'ilba Ilelviorum, a Nlba (l)ròme), les fouilles ont amené le dégagement de l'encerinle méridionale avec sa galerie rirculaire et ses vomiloires ${ }^{16}$.

On doil a Ch. Picardiz une lres inleressanle conlribulion anx recherehes

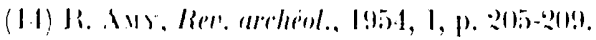
Voir : lallia, Xll1, 1955, p.

(15) I.. I.1:нат, rallia, NII. 1954, I1. 161 ;

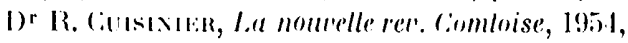
p. 113-1.1!.

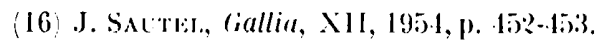
(17) Axrmunox, sludi in onore di Carlo Anli, 1954, extrt. concernanl l'emploi arehilectonique des figures monumenlales de Caryalides au théilre de Vienne (Iscre) el dans les théalres ocridentaux. Iux deux fragments viennois, l'auteur ajoute un troisiène documenl, une "femme drapée " (Esp. (777)), trouvée dans les ruines des hyposkenia du théatre de Vaison. Outre ces Caryatides gallo-romaines, datées en parlie de l'époque augustéenne, on rencontre dans le mème lemps en Espagne, au théalre de Mérida, une série de bas-reliefs. vraisemblablement décors de scrines thé:ilrales, reproduisant, plus ou moins grossièrement des Caryalides. I Vienne el a Vaison, les sculptures provenant des déblais de la scene, il élail logique de rechercher leur emplacement. De mème que les slatues de Pan ranephore aux théalres de Pompee a Rome el de Siegeste, ornaient les paraslienia llanquant de corps rentral de la serene, la Caryalide viennoise devail décorer l'un des paraslienia de la froms scaenae, peul-illes vers l'emplacement de la Porte Royale. Ces fragments montrent limportance exceptionnelle de l'influence de la sculplure d'inspiration hellénislique dans la décoration des grands édifices publics au début de l'kmpire. Le suceres remporté par les Caryalides du Panthéon d'Igripla, auve de I)iogénis l'Al hénien, copies inspirées des Caryalides de l'Erechteion, antérieurement a 26 avant J.-C., précisent, la filiation de ces décors. du point de vue de la chromologie, on prêlera allention aux lapporls a etablir entre les lhéalres de la Ciaule. méridionale ol ceux de l'bspanne"s. l'inseriplion de la thyméle, au theidre. de Merida (Lspagne), donne l'année lli avant l'ire pour l'édifice dont le plan 80.

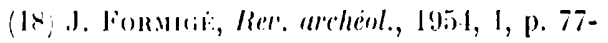
s). 
esl presifue idenligue a redui d'oranger.

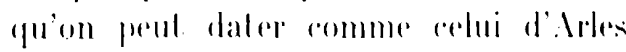

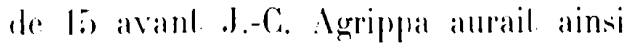
fail larailler dans le mème lempes en Espagne ef dans le Midi de la Ciaule.

Iu "Palais des Thermes" de Caluny, a Paris"19. les fouilles ont surtoul porté dans langle Sud-()uest, en bordure de la rue du Sommerard al mime sous celte lure. On sait mainlemanl que less salles

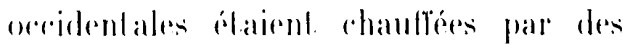
hyporallstes ablolis sur la lerre ballue. alors que les pieress an . Vord, all cenlle

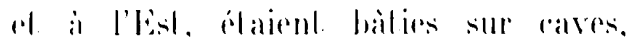
non rhanllés, el on pent lenir pour arequis que presque loules les salles du monument étaienl an meme niveau all rez-de-chaussée ol que la rour du Musee de Cluny élail dejà un espare libre a l'angle sud de l'ádifice galloromain. An sud, on a recommu $11 \mathrm{n}$

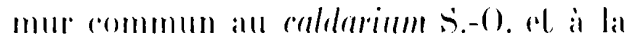
gramde salle, égalemenl rhamliore, conslil.uaml som prolongemenl. I la suile de res lavalux, il se rontimme que les lhermes de Clumy onl éte comstruils d'un seul jel el n'ont subi alucune réparalion imporlanle.

Des lerrassements sur l'empladement. des thermes gallo-romains d'Aix-en-()the (Yomne), au lieu-dit "Les fontaines", ont donné un abondant matériel archéologique ${ }^{20}$, apportant d'utiles indiralions ¿ l'hisloire de l'édifice, oceupé depuis le $1^{\text {er }}$ siecle de notre ire jusqu'au cours du I I $^{\mathrm{e}} \mathrm{s}$. Il ne semble pas avoir trop soultert de l'invasion de la seconde moilié du $\mathrm{In}^{\mathrm{e}}$ siècle, mais paraîl avoir élé abandonné pour un demi-siècle après les troubles apporlés par les brigandages de Malernus. Faut-il reconnaitre, à Sens (Yonne), dans les ruines

(19) A. PIgaxiol., Gallia, XIJ, 1954, p. 142. (20) 13. IAcrorx, Rev. archeol. Esl., V, 1954, p. $24-38$. dre Ia Molle du Ciar.21. Ies restes de thermes, dont lenerente exterientere ot

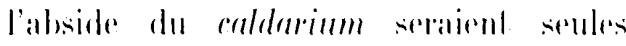
ronnues?

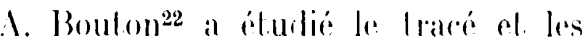
aménagements des deux aquedues soulerrains amenant au Mans (Sarlhe) les eaux des sources de la vallee d'saac et celles du plateau de siarcé, sourees de la fonlaine sainl-Martio, de Vonnel el ruisseau de (iironde. I des Romains avaient ronstruil, pour colleceler les raux de la vallée d'lsalar, an lien-dil "les Fonlaines", un alpuedur d'emvirem 1.500 milles. Les galeries sonl. en pelit appareil, voûtés en moellons, pourvestes de regards de $10 \mathrm{~m}$. lis, el de $4 \mathrm{~m}$. 9) de hauleur, munis de corbeaux de pierere pour la descenle. Láaguedure suil la vallée recueillant d'auleres sourees, se dirigeanl vers le versinn Nord de la rue de la Riviere, les jardins de la rue des Chatels. l'ancien rlos Maregol ol laverse le boulevard Végrier, mais on ignore son lracé dans la ville. Láaquedure des Fontenelles, long de:3 km. 300), suivail depuis sa souree le nivellement du lerrain el se Irouvail, en maint endroil, presqu'i fleur de lerre. I louchy (Loirel), au cours d'une exploilation de silex, sur le versant Cord de l'ouanne, pres du Moulin de la Forge ${ }^{23}$, on mil au jour un tronçon d'acpueduc, lait d'un canal aux parois lalérales légèrement renflées en leur milieu, encardré dans un blocage rectangulaire de rognons de silex noyés dans un morlier de chaux el couvert de dalles jointives mobiles. Il semble que cette canalisation captait les eaux de la fontaine sainle- Inne el les conduisail à Triguières, où l'on connaît

(21) R. I.ouls, Gallia, XII, 1954, p. 518-519.

(2) Bull. soc. d'agrir., sc., el arls surlhe, 1953-1954, p. 27-15.

(2:3) R. Loc1s, (inllia, XII, 1954, ए. 5066-508. 
l'existence d'un temple el de thermes. Au lieu-dit "La Bouilletle", a Bize (Aude) ${ }^{24}$, on a peul-ittre retrouvé un fragmenl d'aruedue, el au "Paradou " (Bou(rhes-du-Rhone), des lravaux d'approfondissement du bassin de raptation de la sourere de l'. Irecoule ${ }^{25}$ ont lail disparaîlere les restes de ladueduce de la meunerie anlicue de Barbegal. Ine galerie avee. poleries du ger sircle a élé lrouvée dans une lonlaine a la perte de Rieulord, rommume d'Agen-de-l'Aveyron ${ }^{26}$. On a pus suivere le laré de l'aduedue de la Bonillide amenant it Intibes les eaux de lat souree de Valbonnewe le ranal d'adduclion en soutermin aboutit is un aquedure tantòt rreusé dans le roc, tantot. construil sur areades au passage des dépressions. L'arasement du versant de la bulle. lourhant la roule de six-

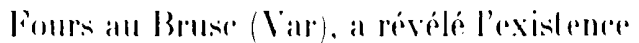

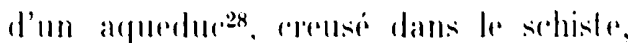
donl le camal, hanl de I m. 80 , a section rurviligne. se rélrécit. aux partiess

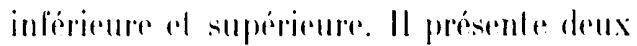
modes de donstrullion : deux segments an lunnel a voulte arrondie, séparés par une lranchée, longue de 8 milres, rouverte parr un dallage de grandes playues de lul. I l'extrémilé sud-list de la partie degagée, la faille du rocher est soutenue par des piliers de tuf. L'aquedur drainait les eaux d'infiltration vers un réservoir pour le ravilaillement du port. L'importance de la canalisation semble permeltre de proposer pour sa construction une dale anlérieure à la concquite romaine el d'idenlifier Le Brusc avece T'auroenlum. Des bassins el uu aque-

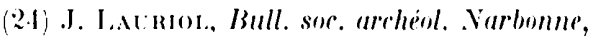
1951-2, p. I.XXIV-Ixxi.

(25) 1. Br:xort, Gallia, XII, 195.1, p. 129-430.

(:6) 1. Bassax, Velanges.., II, p. 1j-1X.

(27) li. BisolT, Gallia, XII, 1954, p. 440.

(28) Ituid., p. 435-436. duc venant du plateau de Boudonneau ont été reconnus à Montélimar (I)ròme). entre la colline de Monlreau ed ir laubourg d'Ayga $a^{29}$.

Ine description est donnés de da figuration d'une maison sur unl slur: peint de Vichy (Allier). De forme ronde. elle se dresse sur un soubassement de morlier uni, surmonlé d'un gros appareil losangigue el d'une double rangée dre briques; all-dessus apparaissent. de hautes poulcelles de bois, pruis un auldere rhainage de briques al ensule de nouvelles rangées de poultrelles. la maison, perrese d'une haule porte en plein cintre, élait couverta en rhaume. Ine construction annexe montre des poul.res de hois directement posíns sur le soubassement ot supportant une maconmerice losangigue.

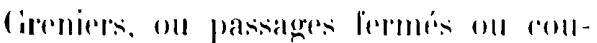
verts pour la promenade a la diseression

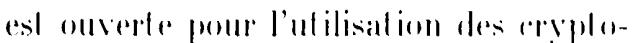

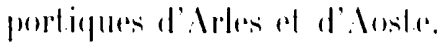

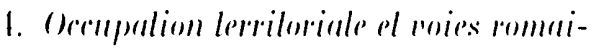
mes. In lail importanl est bien mis en lumiere par le réperloire arehéologigue du département de l'Aube du regrelle Maurice Toussaint' : le contraste entre la densité du peuplement de ces lerritoires pendant la période gallo-romaine ol. l'abandon de vastes régions de venues: incultes, l'habitat moderne se concentrant. le long des vallées de l'Aube, de la sieine et de leurs aftluents. On propose de voir dans ces transformations la matérialisa-

(29) J. SAlTter., ibidl. p. 154.

(30) I) A. Morala, Tomrisme 51, n" il, avril 195.1.

(31) IR. Augusto Sraciond, Rendiconli alel. Acad. Lincei. (\%) se. Morali, IX, 19\%4, p. (ili)657.

(1) Reperbire archeologique du deparlement de l'Aube (Periode yallo-romaine el éponque franque). Paris, 1954. 
lions stll la rarle de la position oceupee par les Trieasies, entre les deux gyandes tribus gandoises des lingons ol des

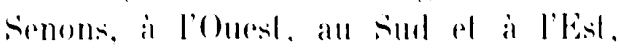

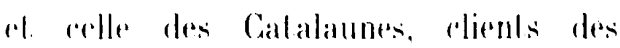
Remes. all Vord. la cilé. donl Augusto-

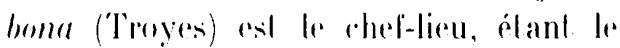
lieul de passige entere la Bourgogne el le Remois d'une parle entre le pays de langress el le Bassin Parisien de l'aulre. l'explialion vaul deiler relemue, d'autanl plus qu'elle semble recevoir une confirmalion du lail que le nomvean mode de réparlilion de l'habilal anx temps mérovingiens lend a sarliculer le lone des vallexes lluviales. Je voudrais rencore signalor (p. $4: 2-110$ ) l'importanle: momographie consareré i l'histoire urbaime d'Alugustolome ol l'inventaire

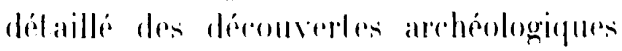

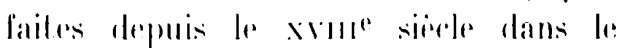
solls-sol de Troyes.

lare serier de bommes illuslrations comduil le lecelene a lravers la Provence romainr roller llanger. Varson. Arless

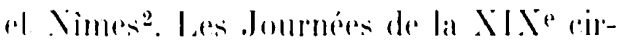
ronseription arreheologigure ont été l'oreasion de l'elablisisement d'une carte de l'orleanais gallo-romain³. L'altenlion est alliree sur l'absene de frontieress lluviales entre les riles, sauf pour la Rinialde el le saulde, el sur l'imporlance des limiles forestieres, forèts d'Orléans, de Bruadan, de Marchenoir, avec parfois des enceintes forlifiées et des lumulus. L'habilat semble asse\% liahe of peu variable. Des régions marécageuses, comme la sologne, ou forestires comme

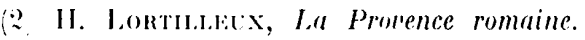
coll. "Plaisir du voyage ". Paris 1954.

(3) Abbe Norke, Bull. liaisom protis. soc. hisl. al archéul. Orléanais, $\mathrm{n}^{n} 30$, nov-dec. 1954, p. 56. I.abhe Nouel a publie une carte archeologique de la regrion de la I.oire moyenne a lepoque gallo-romaine. IR. Iotos, Gillia, XII, 195\%, p. 504.

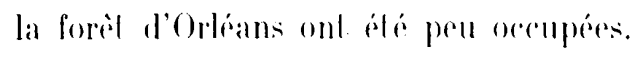
Il en est aul rement de la llaule-Beance el. du Giatinais en bordure du longe. less villes gauloises onl sulssisté mais de noureatux centres apparaisirent alors: Monlbouy, Honlargis, Heung-sul-I obire. les ressourees maturelles sonl exploilées: blé de la Beauce, fer (serories de Toury). Orleans, le grand marche des Ciarnules, est altsis un rentre lluvial oi débarquent. les poleries amenées par eau de l'Slliere, la pierese de Bulays pour la labrialion dessareophateres.

lent-on valablement limere des romelusions sur limportaner de lenerupalion humaine d'un lerriloire en laisanl élal. avanl loul, de la malure du sol? La question a ale pasere a propos du loress d'Mlsace el des Gallo-Romains. Mevanl le pelit nomber des villats. on serail amené a supposere la persistance l'une pepulation pen romatnisere, al restre

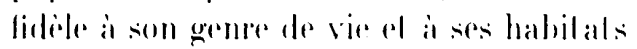
primitifs. הi relle imlerprélaliom est acereplable, il en apparail antrement du lableaul propose des modalibes de l'exploilation dissoredere de la conlrée. kien n'aulorise a recommailere dams les fonds de cabanes du loess de replle épeque, plulot que des habilats permanents, les traces du passiage de sememes, de messiers, de mosisonneurs, de pilles menant leurs bèles sur les champs dépouillés el les jacheres, mais ayant leurs bases normales dans les grandes fermes romaines de la région ${ }^{4}$.

Les documenls provenant du labularium d'Orange el les pieces annexes renseignent sur l'organisalion de la propriété et montrent le raractere minutieux de la comptabilité des villes. Les fragments cadastraux font connailre un territoire divisé en rectangles

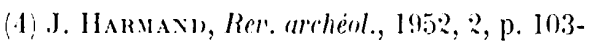
105. 
représenlant des renluries, simples ou doubles, constituant non pas un ensemble unique, mais plusieurs ensembles. Les lextes, copies des registres du labularium, comprennent, des fragments du cadastre rural, des lots, dits merides, qui ne peuvent qu'être urbains, des mots ave area, terrains publics dans l'enceinte urbaine. L'objet de ces pièces élail de déterminer quelles portions du domaine avaient été occupées sans aulorisation par des particuliers. Ceeux-ei ne sont pas invilés a les évaruer, mais une laxe est fixée par pied carré, ainsi qu'un inlérèt de retard $(6 \%)$. Ces documents révilent, l'état, de la complabilité publique ol prouvent, avec quelles alternatives de négligence elle etail I enues.

Sur la cole provencale des sondages onl. permis de délimiter un petil port. anlicque à sémeme, dans l'anse des lauroms, a peu de distance de Ponteau

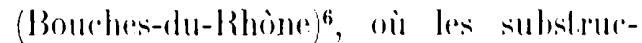
lions de derox quais, less sols bélonnés de magasins en bordure de la mer en le seuil d'un entrepòt. ouvrant sur une rue perpendiculaire au ford ont été dégagés. Dans la mer, on distingue les amoreses de deux ouvrages protégeant l'entrée du port, peut-ètre la Dilis Posilio de l'Ilinéraire Antonin, fréquentée d'après les céramiques, du $\mathrm{I}^{\text {er }}$ au IVe siècle, alimenlée en eau par un aqueduc, en parlie laillé au flanc du rocher au Nord de Séneme, qui fut. reconnu et déblayé. On conlinue ì recueillir sur te littoral de los (Bouchesdu-Rhòne), dans les alluvions du Rhòne, d'abondants lémoins céramiques de l'occupation anliquer?

La présence de tessons éoliens el,

(5) A. Pigaxiot, $(: R .1 I, 1954$, p. 302-310.

(6) F. 13:xoIt, Gallia, XiI, 1954, p. 133-434.

(7) De mine, ibid., p. 432. d'une grande patère d'Arezzo, porlant. la marque L. Titi figu(li), dans l'habilal. du Caslellan, a Istres (Bourhes-duRhòne $)^{8}$, ou a élé dégagée une case it abside avee trou de poteau central, prouve la conlinuilé de l'habilat diss le vi ${ }^{\mathrm{e}}$ siècle avant, l'ère, postérieurement, aussi à la conquête romaine. La mime succession reparait dans l'oppidum dess Encourdoules, a Valauris (Mpes-Marilimes), ou le romain se superpose it un habital préromain. Cette adaptation de l'hahit at indigène à la civilisalion romaine: est particulierement inarque an NontBastide, a Eze (Alpes-Marilimes) Vié-Cioulal de Mas ol Monleil (Gard) ${ }^{11}$. A Murviel-IesMonlpellier (Iléraulti), des aménagements du I $^{\text {er }}$ siècle de notre ire sucerdent, a des installations plus anciennes's.

1 Auriol (Bouches-du-Rhome 13, des: restes de gros murs onl ale reconmus a "la Vorimatuden, dans un quartier lres riche an vestiges romains ol. sul la rempe des Tourascfues, les resles d'un grand hassin bélonné semi-circulaire al un lragment de conl repoids de presovir a huile. leux pressoirs a vin élagés ont été dégagés a Anlibes (Alpes-Marilimes), au domaine de l'oliveraie ${ }^{14}$, ayanl appartenu a une installation agricole comportant le fouloir el au-dessous une cuvetle bétonnée pour le nelloyage. Le domaine possédait aussi une huilerie. l)ans le Var, plusieurs nouvelles villas sont is signaler : a Pugel-Ville ${ }^{15}$, dans la vallée de l'Aille, ocruprée depuis le:

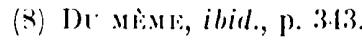

(9) De: misul, ibid., p. 110-141.

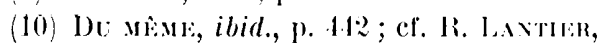
ilidt., . XIII, 1955, p.

(11) J. JaNToraY, ibid., p. 244-125.

(12) Di; MÈE, ibid., p. 423.

(13) F. Brovort, ibid., p. 314-3.5.

(14) De misus, ibid., p. 439-440.

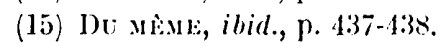


I $^{\text {er }}$ jusqu'au débul du we siécle; - a La Roquebrussanne, au domaine du Grand Loou, imporlanl élablissement, agricole auquel succéda au Moyen ìge le domaine de Filsiacum, déja existant a la fin du $\mathrm{II}^{\mathrm{e}}$ siecle de notre ère ${ }^{16}$ -. luiles el tessons de Ia Graufesenque, au Luc, lieu-dil " le Terme "17.

Jes constructions ont été relevées a Ipt (Vaucluse), au quartier des Toureltes el des Rosalieresi8 ; ... dans la Drome. a Chaleauneul-de-Cialore ${ }^{19}$, ¿ Luc-en-I)ioisere a lix-en-I)iois, à Sainle-Croix, à Saillans, d Jubenasson, a Egluy, à Louste ef au Pégue ${ }^{21}$; - dans l'Ardiche, à Saint-Peuray ${ }^{22}$.

Les fouilles qui se poursuivent a CastelRoussillon (Pyrénées-Orientales), dans les ruines de Ruscino ${ }^{23}$, onl fourni des renseignements sur l'occupation de la région en contact des le $\mathrm{VI}^{\mathrm{e}}$ siecle avant l'ere avec les trafiquants helléniques, apparentée ethniquement avec les groupes de la cote catalane, envahie par les porleurs de la civilisation des "champs d'urnes" à la fin du Hallstattien, puis par les Celles dans la seconde moilié du III $^{\mathrm{e}}$ siècle. Les ruines romaines recouvrent celle partie de l'habilat.

La région de Bize (Aude) parait avoir

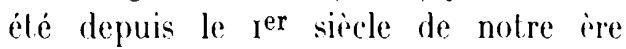
un centre de colonisation agricole ${ }^{2 \cdot}$. On connait des emplacemenls de villas aux Isoz, à La Buade, à Landelongue, au domaine de Bouquillan. I.es sites furent réoccupés au ive siecle. Au ier sircle

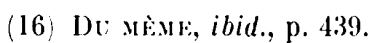

(17) De vìns, ibid., p. 439.

(18) J. SAlTti, ibid., p. 456.

(19) De мisme, ibid., p. 154.

(20) De: мk̂ne, ibid., p. 454-455.

(21) De мEेмr, ibill, p. 452.

(22) De MÈne, ibid., p. 452.

(23) J. JANTORAY, ibid., p. 411-112.

(24) J. I.ACrol, Bull. comm. anliq. Narbonne, 1951-1952, p. 64-102. avanl J.-C. appartiennent aussi les substructions dressees sur une esplanade ménagée au flane d'une colline el limitée vers l'Ouest par un important soutenement a Colombières-sur-Orb (Hérault) ${ }^{25}$.

L'achevement des fouilles de l'immense villa de Montmaurin (IIaute-Garonne) ${ }^{26}$ permet de situer dans le temps l'oceupalion du site qui correspond a celle des élablissements languedociens. A une premiere installation des $\mathrm{I}^{\mathrm{er}} \mathrm{rI}^{\mathrm{e}}$ siècles succède la grande villa élevée au milieu du III $^{\mathrm{e}}$ siécle, dont la prospérité ne semble avoir duré guère plus d'une rentaine d'années. Les découvertes nouvelles intéressent les constructions siluées au Nord el à l'Est dans le prolongement de la partie centrale de la villa : au Nord-list, une grande construction circulaire termine la villa de ce còté, qui comprend aussi de vastes pièces dont trois à absides; au Cord, des communs s'ordonnent autour de deux grandes cours, que prolongent au Nord-(Ouest 180 réduits ou cours. La partie centrale dispose d'un péristyle et d'une cour où se dresse un laraire, petile colonnade circulaire entourée d'une galerie et, en avant, un autel avec l'inscription J. O. M. De nouveaux fragments de sculptures ont été recueillis. A celte mème période de construction on peut ratlacher la grande salle et les deux hypocaustes a conduits rayonnants, semblables a ceux de Montmaurin et de saint-Loup-de-Comminges, élevés sur les ruines d'un édifice plus ancien, avec hypocaustes a pilelles et pièces de dimensions moyennes, découverts a Puységur (Gers), au pied du village en bordure de la Garonne ${ }^{27}$. L'importance de la décoration, chapiteaux et bases

(25) J. Jaxioray, Gallia, XII, 1954, p. 417.

(26) II. I.aвnolsse, ibid., p. 217-21R.

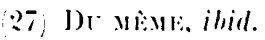


de colonnes, éléments de plinthes et de corniches en marbre, plaques de revêtement et les restes d'un grand autel de marbre blane, laissent supposer l'existence d'un sacellum ì l'intérieur de la villa, détruite par un incendie et sur les ruines de laquelle furent établis un cimetiere et une chapelle chrétienne dont on relrouva deux chapileaux se rallachant a la production des ateliers aquilains de la période mérovingienne. Dans le mème département des vestiges d'habitats galloromains, le plus souvent agricoles, ont élé relevés à Grépac, sur la rive droite de l'Ariege, au Nord du village ${ }^{28}$; a Boussens, au voisinage de la voie romaine remontant la vallée de la (iaronne ${ }^{29}$; à Auzas, au quartier du Quillet ${ }^{30}$; a Plaisance-du-Touch, lieu-dit. "La Tuque "31 ; a l'lsle-en-I)odon, sur la rive de la save, mais ces ruines pourraient itre celles d'une station de la roule desendant la vallée de la riviere ${ }^{32}$. Les restes d'un grand édifice ont été dégagés à Auch (Gers) ${ }^{33}$, sur l'emplacement. de l'Ilopil al psychial ricque. ainsi que des vestiges d'habilals it Montforl-du-liers, au-dessus de la ferme de "La Médecine "34. et a Monlréal

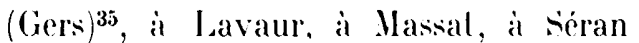
el Roquevidal (Tarn) ${ }^{36}$. Est-ce un sanctuaire, associé à une forge éolienne. dont les creusels de fonte avaient écé aménagés à mème la roche schisteuse al garmis de terre réfraclaire. qui a été

(2) 1)1 Mlistis, ilial., p. 211.

(29) D1: MElll: ibid., p. 215.

(30) 1)1: Mtsul, ibial., p. 215-216.

(31) 1)1 mint, ibid., p. 213.

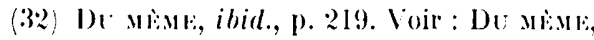
Bull. sore. archeol. Ciers, 1.1, 1954, p. 347-365.

(33) I)); Minl:, ibid., p. 221

(34) I) wi:me, ibia., p. 2.23.

(35) 1)(i Mlisu, ibid., p. 255.

(36) Ihill.
Irouvée a 1.500 mitres de Roquecourbe (Tarn), au sommet d'un éperon dominant, l'itgoût ${ }^{37}$ ? Contemporain du $\mathrm{I}^{\text {er }}$ siècle avant l'ere, cel habital de hauteur, très pauvre, aurait conservé aux temps gallo-romains, un genre de vie archä̈que et des sépultures laillées dans le rocher semblent appartenir à la communauté christianisée $\left(\mathrm{VI}^{\mathrm{e}}-1 \mathrm{X}^{\mathrm{e}} \mathrm{s}\right.$.).

Des restes de briques, préparées pour recevoir un enduit, des chapiteaux corinthiens en marbre blanc de saintBéat, les premiers trouvés à Saint-Loup, au chiteau des $\operatorname{lgres}^{33}$, les seconds a Saint-Nicolas-de-la-Grave au village des Arènes ${ }^{39}$, et la mosaïque géomélrique de Sas-Marly, à Fauroux (Tarn-et(iaronne) ${ }^{10}$, accompagnée de deux colonnettes et de lragments de stucs peints, marquent les emplacements d'édifices. Des lraces d'occupation ont élé relevés dans la grotle de Bourzolles, a Souilhac (Lot. $)^{41}$, et des substructions de villas ¿ Redeuilh"2 et a "La Négade" près de Soulac (Gironde) ${ }^{43}$. La villa de SaintMédard-d'Eyrans (Gironde), occupée du $I^{\text {er }}$ au $I^{\mathrm{e}}$ siècle, étail située au croisement de nombreux chemins paralléles ou perpendiculaires à la (iironde ${ }^{44}$. La découverte d'une grande piscine quadrangulaire, entourée d'une galerie pavée en mosaïque, relevant du frigidarium d'un bain privé, dénonce

(37) I) us:us, ibid., p. 226-227.

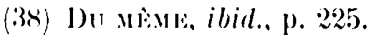

(39) Ibial.

(10) Chanoine Gavk, Bull. archent. hisl. el arlisl. sor. archéul. Tarn-el-Garomme, I.XXX, 1953.3, ?. 1:3-1:31.

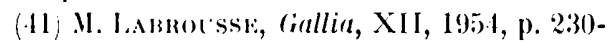
$2: 31$.

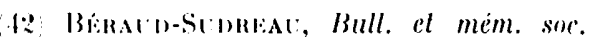
arrheol. Bordeand, I.VII, 19.45-1950, p. 17.

(13) Massit, ibid., p. 24.

(1.) G. Cotrey, Gallia, XII, 195.1, p. 208-209. 
l'imporlance de la ville de saint-Romain. ¿ Loupiar (Gironde) to.

Il ne semble pas que l'avancement. des fouilles du grand edifice des Cars. it saint-Vlerd-les-(Oussines (Correze) ${ }^{16}$ soil encore sultisant pour préciser la destination exacte du monument : thermes monumenlaux, ou bains privés d'une grande villa. De nouvelles salles furent. reconnues, ainsi que des canalisations pour l'écoulement des caux de pluies. en direction du ruisseau voisin. Au cours des travaux, un dépotoir a éte exploré, contenant des poteries communes el sigillées du ${ }_{\mathrm{I}} \mathrm{e}$ siècle. La présence de fragments à décor eslampé ou à la roulette lendrait a prouver la conlinuation de l'occupation aux III ${ }^{\mathrm{e}}$ we siècles. Lors de travaux de voirie a Brive (Corrèze), une cuve de calcaire, une mosäque, des tuiles et des tessons sigillés, ont été mis au jour sur l'emplacement de l'ancienne église Saint-Pierre ${ }^{47}$. Des traces d'occupation gallo-romaine sont signalées à Molèdes (Cantal) ${ }^{48}$ el au domaine de "La Chassagne", a Peyrat-la-Xonière (Creuse) ${ }^{49}$. Aux limites de communes de Giat et Voingt (Puy-de-I)òme), s'élendent les ruines d'une aggloméralion ${ }^{50}$, dont on connaît le cimetiere à incinération et les ustrina en bordure de la voie romaine, ainsi que les ruines d'une construction du $\mathrm{I}^{\mathrm{er}}$ siècle avec escalier inlérieur.

Dans le vallon des Chaudes, en amont des piscines gallo-romaines, jadis

(45) Bíralin-Sunrat; Bull. el mem. sor. archéol. Bordeaur, LVIr, 1945-1\$50, p. 5-6, 18.

(46) M. Vazenters, Gallia, XII, 1954, p. 360367 ; - Bull. soc. lellr., sc. el aris Corrèze, 1954, p. 11-25;--P. F. Folruier, Gallia, XII, 1954, p. 199.

(47) P. F. Fol'rater, ibid., p. 198.

(48) Du MÈme, ibid., p. 197.

(49) DU мÈmr, ibid., p. 199.

(50) Du Minr. p. 200-201. dégagées. de mouveaux vestiges de l'elabliss:ment thermal antique de Néris (.llier) ont élé reconnus, mais n'ont pas blé conservés. In plan en a été dressést.

sur la rive droile de l'Ouche, dans les champs, s'étendent les ruines d'une villa, a Pomarède, a $2 \mathrm{~km} .400$ d'Eyvirat (I)ordogne):2. Révélée par la photographie aérienne, la villa de saintPreuil (Charente) ${ }^{53}$ représente une exploitation agricole importante, limitée sur trois de ses colés par le tracé de la voie romaine de Saintes a limoges, sćtendant sur plus de 400 hectares, a proximité d'un ruisseau, la Samaronne. sur les lerritoires de Jaulnay, de Clan .1 de Chasseneuil (Vienne) ${ }^{5}$, courenl. le's ruines d'une agglomération : autour de l'église de Jaulnay, importantes substructions avec ares de soutènement, mosaïques, enduits peints avec semis de lleurelles; aqueduc amenant les eaux des coleaux voisins; petit temple périptère a Clan.

En Brelagne, un élablisiemenl imporlant de la cilé des Osismes est en cours de dégagement à Trouguer, à Cléden-Cap-

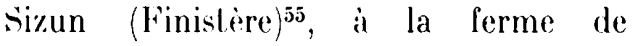
Pratlouchouarn en Plouénan (Finistère). I. Mouron (Morbihan), dans le champ de "La Bande du Pé ", des substructions apparliennent à un établissement galloromain ayant succédé à un établissement armoricain. In site fortifié est en cours de fouilles a Co\%-Yaudet en Ploulec'h (Cotes-du-.Yord)

Less recherches faites à Jublains

(5) De Mล̀me, ibid., p. 193.

(52) 11. Siccondat, Bull. soe. hisl. archéol. l'érigord, LXXXI, 1954, 0. 47-48.

(5)3) F. EYglis, Gallia, XII, 1954, p. 189.

(5) DU MEse, ibid., p. 176-181.

(55) P. Mrentat, ibid., p. 156-160.

(56) De nìme, ibid., p. 162-163.

(57) Du mìme, ibid., p. 168.

(58) I): mise, ibill, p. 15i-156. 
(Mayenne) $)^{59}$ pour retrouver l'entrée du temple n'ont pas donné le résultal espéré, mais ont révélé l'existence de plusieurs lerrasses différentes et du mur oriental, revêtu sur ses deux faces d'enduils peints, de gralfiles sur la face extérieure. Lu Sud-Est du Lemple. vers l'aboulissement du cloaque, un ancien foyer et d'innombrables coquilages appartiennent it la cuisine of au

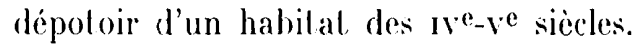
Ce n'est pas un dépotoir qui a été trouvé au fort de Chelles (Seine-et-Marne), derrière l'ancienne usine a plàtre, rue A. Bickert ${ }^{60}$ : lessons el luiles proviennent des niveaux supérieurs et ont été apportés sur cet emplacement lors de l'exploitation a ciel ouvert de la carrière. Une carte archéologique de l'époque gallo-romaine a été publiée par P. Durvin pour les environs de Creil61. In établisement fortifié du début de celte même époque a été découvert dans les bois de la Forîtrie, a Allonnes (Sarthe)62.

Jans l'Yonne, la villa de "La Tóle de Fer", à Cirimault ${ }^{\text {3 }}$, qui s'élend sur une quizaine de pières, reliées par un couloir et dallees de calcaire, se rallache au groupe des etablissements agricoles de la région de Noyers. Ellle possède une très grande cave, desservie par un escalier, dotée d'un soupirail ouvrant sur la cour de la villa el de quatre niches praliquées dans les murs. Less séries monétaires recueillies permetlent de reconstiluer l'histoire du

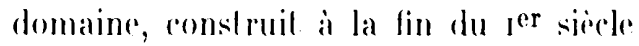

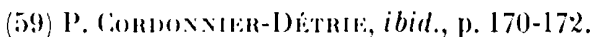

(60) (i. Tisstik, Bull. ster. arrhiol. et hisl. Chelles, 195.1, p. 18-50.

(6) Timare (2) hen industriel au $1 / 20.0000$, ]9. 1 .

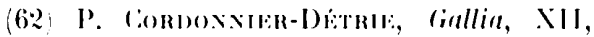
1954, p. 172.

(6.3) R. I.oles, ibid., p. 52:3-5:1. ou au début du $\mathrm{II}^{\mathrm{e}}$. détruit apres 267 , reconstruit a la fin du ${ }_{1 I}{ }^{\mathrm{e}}$ siècle et définilivement ruiné au milieu du $\mathrm{r}^{\mathrm{e}}$. Ces conclusions sont a rapprocher de celles apportées par les fouilles des grandes villas languedociennes, précisant l'existence d'une campagne de reconstruclions des élablissements agricoles apres les désastres apportés par les invasions du troisieme quart du III ${ }^{e}$ siècle. Le plan d'une villa a élé relevé au lieu-dit "Dailly", à Villeperrol ${ }^{64}$. Des sondages, au "Barbeau", en bordure du chemin du Poirier, a disy-sur-Thil (Còle-d'()r), près du "Pré de la Grange", ont fait connaitre la présence de substructions et d'une aire de circulation limilée par une muraille ${ }^{65}$.

In inventaire des vestiges galloromains a élé donné pour le Clunisois ${ }^{66}$. La région de Crissey (Sianne-el-Loire) ${ }^{67}$, déja peuplée au Néolil hique el aux temps rellicques, a été occupée aux $11^{\mathrm{e}}$ et $11^{\mathrm{e}}$ siècles de notre ire. De nouvelles découvertes ont élé lail es sur le site de Carignan (Ardennes) 68 en particulier a Montilleul et a Hannogne-Haint-Hilaire ${ }^{69}$, au "Chemin de La Val-Roy", une fosse remplie de lerre noire a donné de nombreux tessons, dont une moilié de plat avec l'estampille de IOIDIVs.

Dans l'est de la Gaule, une station gallo-romaine importante s'élend sur la rive droite de la Nied, au "Haut des Pierres" de Remilly (Moselle) ${ }^{70}$, el au voisinage de Miltellbronn, une villa a été

(6.1) Do: stims, ibid., p. 521.

(6.) G. (insuall, Rer. arrheol. Esl, V, 1951, p. $19 \%$.

66) L. Marivix, Amn. Bourgogne, XXIV, 1954, p. 131-1:3:.

(67) A. Gros, Mèm. soc. hisl. el d'archéol. Ghalon-sur-sainne, XXXIII, 1954, p. 95-96.

68) (i. Golmy, ciallia, XII, 195.4, p. 147.

(69) J): w⿳亠口冋s, ibid., p. 148.

(70) Cahiers lorrains, V11. 195.1, p. 39. 
releves pres de la lailerie ${ }^{71}$ une autre entre Bourscheid et Mittelbronn a élé bouleversée par les travaux d'un camp d'aviation ${ }^{72}$. Des fonds de cabanes d'une station gallo-romaine sont signalés it Mützenhausen (Bas-Rhin'; près d'une source el en bordure de la Hochfeldergasse ${ }^{73}$. I.e lracé de la double canalisation Hullolsheim-Strasbourg a été suivi sur le lerriloire d'Oberhausbergen (BasRhin $)^{74}$. Parallelement à la tranchée abrilant la conduite, a Irtigheim, coumt un chemin de griss concassé el, a 7 m. 40 ¿ l'Ouest, on dégagea une roule en hérisson de pierres calcaires, comportant deux ornireres espacées d'environ $1 \mathrm{~m} .40$.

Les fouilles du relais routier de l'l'sspann, pres du col de Saverne (Bas-Rhin) ${ }^{75}$ a la frontiere des Médiomalriques et des Triboques, de la Germanie supérieure et de la Belgique, apportent de nouveaux enseignements sur l'occupation du sol el sur l'évolution urbaine de saverne, dont le développement est lié à l'histoire de la slation routiere du col. On peut, en effet, se demander si le développement de l'agglomération de la plaine, Saverne, n'est pas la conséquence de l'abandon au cours du $\mathrm{I}^{\mathrm{e}}$ siecle de la slation d' Lsspann el de l'exode progressif des cultivateurs indigines des plateaux. La toponymie a peut-être conservé le souvenir de celte dualité : Tres Tabernae serait le nom de la slation du col, Tabernis, celui de la ville de la plaine. Les baliments du relais qui s'échelonnaient sur une cinquantaine de milres le long de la voie romaine, remontent au débul de l'Empire et semblent avoir élé incendiés à deux

(71) Ibid., p. 25.

(72) Ibid., p. 19.

(73) A. STuEbre, Cahiers d'archeol. el dhisl. Alsace, 134, 1954, p. 12-13.

(7.) J.-J. H.tTr, Gallia, XII, 1951, p. 196-197\%

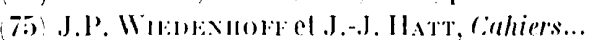
.1sace, 134, 1954, p. 35-51. reprises, en 70 et en 97 de nolre ire. Les fouilles ont lait connaitre quatre états successifs de constructions : bitiments en bois augustéens, fondations de pierres seches et bois de Tibère à Néron, de pierres sous les Flaviens et Trajan. Les céramiques laisient entrevoir un abandon au cours du ${ }_{11} \mathrm{e}$ siecle et une nouvelle occupation sous les séveres. Il semble bien que le vicus roulier de l'Lsspann ail subi, au moins par deux fois, les conséquences des événements ayant amené la destruction du camp romain de Strasbourg.

On resle toujours dans l'imprécision lorsqu'on cherche a localiser la mutation d'Anteae, qui ne serait pas sitnée sur le parcours de la voie romaine de Riez, mais à rechercher dans la zone du quartier des Salles, sur te territoire de Inaguignan (Var) ${ }^{76}$.

sur la voie de Forum loconii à Riez, le passage du Verdon, a la hauteur de son confluent avec le ruisseau de Fonlainel'Évèque, était assuré par un pont, dont une des culées a élé reconnue sur la rive gauche ${ }^{77}$. I l'ent rée du village de Maillot, a une vingtaine de mitres du pont de la Vanne $^{78}$, une rangée de pieux lémoigne de la présence d'un ouvrage, pont ou consolidation de berges.

Des sondages sur un point du lracé de la voie romaine de Iyon a Roanne. a Fourneaux (Loire ${ }^{79}$, il ressorlirail que dans la construction de leurs routes les ingénieurs romains agissaient sans idées préconçues, cherchant par tous moyens a assurer l'assielte et l'asséchement de la surface au micux des conditions locales.

(76) Abbe R. Bovik, I'rovence hisl, IV, 1954, p. 3-10.

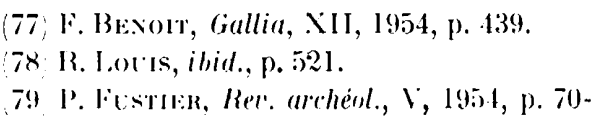


Celle liaison Lyon-Koanne par Tarare n'est pas mentionnée dans les itinéraires romains.

Dans la recherche de l'un de ces itinéraires, il y a lieu de tenir lieu des toponymes qui leur sont particuliers et se rattachent a des faits rouliers, carrefours, auberges, fortins, abreuvoirs, accidents du terrain, ete. ${ }^{80}$.

Les précisions apporlées au tracé de l'aqueduc du Vieil-Évreux (Eure) par l'utilisation archéologique de la couverlure aérienne photographique ${ }^{81}$ invilent à appliquer cette mél hode à l'examen des voies romaines.

On relève un certain nombre de détails apportés au tracé de nos voies romaines: à (asparels (Aude), tronçon en bordure de la rivière $A u s s o n$, reconnu sur $500 \mathrm{~m}$., parallèlement it son cours, vers Ilauterive, au lieu-dit "Les Moulines», vesliges de la ramificalion de la roule NarbonneToulouse ${ }^{82}$; -. a l'Ouest du département du Tarn ${ }^{83}$, une voie Lavour-Toulouse se serait dirigée sivant l'axe de la Xationale 112; au Sud d'Albi, une voie vers Albi passe par Puygouzon, Vigarlet el Bentret; dans la partie occidentale de la Montagne Noire, un vieux chemin suivant l'axe des C. D. 12 el 14 a été reconnu sur le territoire d'Arfons; a la limite des Monts de Lacaune et de l'Espinouse, un vieux chemin représente la prolongation de la voie romaine Béziers, Albi, Cahors sur le territoire du Tarn; .. des vestiges du dallage de la route Chartres-()rléans ont été trouvés au village de La Maladrerie, ¿Orgeres (Eure-el-J_oir) ${ }^{84}$. De lrop nom-

(80) A. Carvos, limmliq. class., XXII, l95.t, 1. 9-28.

(81) J. I.F Ga1.1, Giallia, XII, 1954, p. 3399-357.

(82) Bull. comm. archéol. Narbonne, 1951-195\%, 1. I.VII-J.vill.

(83) .1. LAbnol'sst:, Gallia, XII, 1954, p. 225)226.

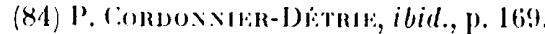

breuses erreurs entachent une élude sur les voies romaines de la région de Bourbonne-les-Bains (Ilaute-Marne) ${ }^{85}$. Une carte est donnée de la région de Verdunsur-le-Doubs (Saòne-et-Loire) ${ }^{86}$.

5. Les sépultures. -... Sur le tracé de la voie romaine d'Apt à Sisteron, "Camin Roumieu " ou "Camin Seinet ", la découverle, a Dauphin (Basses-Alpes), au quartier de la Crau', d'un mascaron, tête humaine encadrée d'une abondante chevelure, dont le sommet est entremèlé dans les entrelacs d'un serpent noué et qui avait appartenu à la décoralion d'un mausolée, laisse entrevoir l'exislence, sur ces emplacements, d'un cimelière païen, comme à Sisteron. Dans le mème département, une sépulture rontenant une urne en verre brisée, un vase it deux anses el une lampe chrélienne a torsade, a élé trouvée à Manosque, devant le garage "Manosque tutomobile $2^{2}$, ainsi qu'un cippe funéraire surmonté de l'ascia à Montsalier ${ }^{3}$.

L'éboulement d'une carrière près du Moulin Pagnol, is La Colle-sur-Loup (Alpes-Maritimes) ${ }^{4}$, a dégagé une grotte sépulcrale, utilisée depuis l'âge du Bronze jusqu'au Bas-Empire, abritant des sépultures sous tuiles avec offrandes de monnaies depuis le milieu du ${ }_{\mathrm{II}^{\mathrm{e}}}$ siècle jusqu'au milieu du $\mathrm{Iv}^{\mathrm{e}}$, des luiles avec dessins incisés avant cuisson figurant des animaux ou des scines de chasses. Sur l'ancienne route de La Napoule à Vence, a "La Faute", prese de Mouans-Sartoux

(45) I.. Cikíconne, Les cahiers Maul-Marnais, 11" 37,1954, p. $51-56$

(a)6 li. Ganss, Mem. som. Whist. el d'archem. chalon-sur-saone, XXXIII, 1954, p. 8II.

1. II. Rollaxn, (iallia, XII, 1954, p. H4.

(2) D) м.ेм1, ibid., p. 445.

(3) De мisme, ibid., p. 146.

(t) R. Bswort, ibid., p. 41: 
(Alpes-Maritimess), au cours de travaux agricoles, on mil au jour des éléments d'architecture, dont deux impostes décorées d'animaux couranls, colombe, chève, lievre, se dirigeant vers un arbre, inspirés des reliefs des missoria, provenant d'un mausolée antérieur au we sièle, et un fragment de couvercle de sarcophage a acrotere. I'ne inscription funcraire du ger siècle a éte recueillie en Camargue (Bou(ches-du-Rhòne), au Yord du Yas de (ioult ${ }^{6}$; autre epilaphe de mome éporque d'un soldat de la XIle légion Rapax el lombe du we siecle au domaine de Gasqui, a Confaron (Var)? du I $^{\text {er }}$ siecle encore appartient la lombe a inhumation trouvece à Trans (Var), au bord de l'ancien chemin de Flayoc, dans le mobilier funéraire de laquelle figure une olpé avec inscription alphabétiforme en cursive ${ }^{8}$. Plusieurs squelettes avaient été inhumés dans une lombe sous luiles plales, sans mobiliers, a Rustrel (Vaurluse)9. I)ans une carricre de sable, a saze (Gard), en bordure de la Valionale 100 de Remoulins a Avignon, s'élend un vaste cimetiere comprenant des inhumalions en pleine lerre ou dans des cercueils de bois; des coffres en lausses calcaires recouverts d'un plarage de mème matiere provenant des collines roisines'o, datés du dernier quarl du ive sićcle. Une sépulture sous luiles des $\mathrm{vi}^{\mathrm{e}}-\mathrm{v}^{\mathrm{e}}$ siecles et une inhumalion des ${ }_{11} \mathrm{e}_{-1 \mathrm{II}} \mathrm{e}^{\mathrm{e}}$ siècles ont été fouillées au chemin des Champs, à Monlélimar (Irò̀mej"11, et à Alba (Ardeche ${ }^{12}$, entre le port de Lescoutay et la Nalionale 102. Ln fragment

\footnotetext{
(5) DU MÈE, ibid., p. 442-443.

(6) Du мìme, ibid., p. 429.

(7) DU мÈME, ibid., p. 438.

(8) Du мĖмr, ibid., p. 438-439.

(9) J. SAtTli, ibid., p. 456.

10) S. (BAgNiBns, ibill, p. 4:25-426.

11) J. SAITLL. ibid., p. 451.

(12) Du Misme, ibid., p. 453.
}

de monument lunéraire a trois personnages a été découvert au domaine de Narennes, à Aumes (Hérault) ${ }^{13}$. En Narbonnaise ${ }^{14}$, a Bize et à Saint-Michel plusieurs tombes onl donné des mobiliers du $111^{\mathrm{e}}$ siècle et un fragment de sarcophage portant l'image du Bon Pasteur, jadis encastré dans un mur du vieux moulin a huile de Bize est, entré au Musée d'Ensérune. Les séries d'auges funéraires pyrénéennes s'enrichissent d'un nouvel exemplaire, avec buste d'homme, ramassé a Esbareich (Itaules-Pyrenées) ${ }^{15}$. In sarcophage aurail élé lrouvé aux Bruches, a Lussan (Gers). dans la vallée de l'Arrat, où l'on signale des monnaies el des luiles at rebord"c. In squelelle accompagné de fragmenls de luiles el de tessons passés au feu, gris, ou sigillés, gisait près du Chemin de Cruves, à Meyssac (Corrize) ${ }^{17}$. In cimetière a été trouvé aux Fougères de Fleural (Creuse) ${ }^{18}$. L'un des coffres lunéraires en pierre de saint-Moreil (Creuse) abrilail un vase ovoüde a reliefs d'applique : Médée, siline. chevaux ${ }^{19}$. De nouvelles incinérations dans des colfres de pierre onl élé lrouvées dans la Haule-Vienne ${ }^{20}$, pres du village des Forges, it Saint-Sauviac-sur-Vige; au lieu-dil "Less suchauds", i Thouron, village des Placieux, el a saint-Pardoux, village des Chàtaignolles, celle-ci de la deuxième moitié du ${ }_{1}$ e siécle. Un autre colfre funéraire est signalé à Monesmes, à 1 kilomètre de Chàtaignolles.

(13) J. JaxNoray, ibid., p. 415-416.

(14) J. Jatros, Bull. archéol. Narbmine, 1951-1952, p. I.IX-LXI ; 101-102.

(15) M. Labrocssie, Gallia, Xil, 1954, p. 2:20.

(16) Dc llsult, ibid., p. 221.

(17) P. F. Fol r.ien, ibid., p. 198.

(18) Du MÈne, ibid., p. 199.

(19) Dt мละ̀ะ, ibid., p. 199.

20) J. Waice, ibid., p. 186-187; J. P1:k-

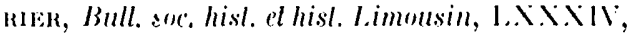
1954, p. 1-1; E. Viscext, ibid., p. 586-587. 
Les cinquante-neul urnes cinéraires en verre recueillies dans la Haute-Vienne ${ }^{21}$ fournissent des repères chronologiques pour la datation des sépultures. Ia plupart appartiennent à la forme 3 de MorinJean (Romain I). Les bouleilles cylindriques sont rares après le ${ }_{11} \mathrm{e}$ siecle, alors que les formes prismatiques à section carrée, abondantes au ${ }^{\mathrm{e}}$ siècle, n'ont été que rarement trouvées au $\mathrm{III}^{\mathrm{e}}$. L'olla a anses, peu fréquente, disparaît avec la première moitié du II $^{\mathrm{e}}$ siècle.

Sur l'emplacement d'une villa et à proximité d'une voie romaine, à Champniers (Charente), un squelette, sans mobiliers funéraires, gisait dans une tombe sous tuiles au "Plantier des Amiraux ${ }^{22}$. A Puyravault (CharenteMaritime), lieu-dit "Palseau " ${ }^{23}$, parmi les débris d'une sépulture en briques, on recueillit un tesson de La Graufesençue et une bague de bronze,dont le chaton porte un monogramme fait de trois lettres jointes. Des cimelieres ont été reconnus it Saint-Piat (Eure-el-Loir) ${ }^{24}$, lieu-dit "La Folie" et pris des dolmens de Changé ; au Pelit-Pieu, a Sougieressur-Sinotle, à śaint-Clément et ì SaintMartin-du-Tert re (Yonne) ${ }^{25}$.

Une fouille de contròle dans le cimetière de l'Ouest, à Dijon ${ }^{26}$, où les découvertes se poursuivent depuis 1938, renseigne sur les conditions de son occupation : rareté des incinérations et fréquence des inhumations ainsi que du dépòt dans des sarcophages aux $11^{\mathrm{e}-\mathrm{VI}^{\mathrm{e}}}$ sjecles; extrème densité des tombes se superposant sur plusieurs élages, les plus 350 .

(21) Ji. Driagie et J. Plinhlik, ibid., p. 3.18-

(22) I. Eyciun, ibid., p. 188.

(23) Du Mînt, ibid., p. 190.

(24) P. Cordonnitr-D'́trik, ibid., p. 169.

(25) Ann. Bourgogne, XXVI, 1954, p. 130.

(26) (i. Grimacd, Rev. archeol., 195., I, p. 51-59. profondes rencontrées à 6 mèlres sous le sol moderne; à la partie supérieure, lombes chrétiennes, dont l'une sera à l'origine de l'abbaye de Saint-Bénigne.

De nouvelles tombes d'enfants ont été dégagées dans le cimetière de "bébés", à La Croix-Saint-Charles du Mont Auxois (Coite-d'Or) ${ }^{27}$. Une seule contenail une incinération. La disposition des sépullures, dépendant de la direction des banes rocheux contre lesquels elles s'appuient, interdit loute orientation fixe.

Les dix tombes fouillées dans le cimetière de Barisis-aux-Bois (Yonne) s'inscrivent entre la fin du ${ }_{11}{ }^{\mathrm{e}}$ et la première moitié du $\mathrm{Iv}^{\mathrm{e}}$ siècle et appartiennent à un petit élablissement agricole, installé au voisinage après l'invasion, entre 280305 après J.-C. ${ }^{28}$.

La main momifiée tenant une pièce de monnaie, conservée au Musée de Roanne (Loiret), a été trouvée dans un cimelière à inhumation du I $^{\text {er }}$ siecle $^{29}$.

Une inscription de Lamarzeille Coled'()r), connue par des copies de la fin du xvinle siècle el du début du $x_{1 x^{e}}$, ne se rapporte pas à un ex-volo, c'est une épitaphe, rédigée en latin "de campagne" du III siècle, par Sanuaca, fille de Calusios, pour elle-mème, pour son mari Saciru et pour son fils Ulattis ${ }^{30}$.

Des renseignements sont donnés sur les découvertes faites au quartier SaintJacques, a Troyes (Aube) ${ }^{31}$, dans un cimetiere gallo-romain, silué sur l'emplacement, de l'École normale d'instituteurs et recouvert par des sépultures des xive

(27) Ahbe .J. Jo1s, Rev. archeol. list, V, 1954 , p. $97-98$.

(28) Abhe 13. Lackons, Ciallia, XII, 1954, p. $367-380$.

(29) J. Raxat), Rev. archéol. Est, V, 195.4, p. $357-359$.

(30) P. J.eßsis, ibid., p. 338-3.14.

(31) J. Bat:BR, .1/manach de IIndependant le l'Aube, 192:5-19:8 (195.1), p. 62-63. 
et xvine sircles; les tombes irrégulierement groupées s'échelonnent du $\mathrm{I}^{\mathrm{er}}$ au $N^{\mathrm{e}}$ siecle de notre ère. Le mobilier funéraire de la tombe de la fillette de La Plan(holle, a Vitry-le-François (Marne) ${ }^{32}$, élait représenté par des bracelets de hois (?) ou de bronze, un fragment de boucle d'oreille, un collier de perles en verre de couleur et une figurine en argile blanche, l)éesse Mire Ienant un enfant. Dans une autre inhumation, près d'un squelette féminin, avaient élé déposés une onochoe en terre rouge, un peigne double en bois; onze épingles mainlenaient la chevelure, l'une en bois à tète anthropomorphe, une autre à tête polyédrique en verre de couleur verle. Dess restes de sépultures ont été reconnus au lieu-dit "La Vigne de Gerson", à Berby ${ }^{33}$, et a Charleville (Ardennes), place de Nevers ${ }^{34}$, on mit au jour, à proximité du tracé de la voie romaine parallèle à la rue de Flandres el dans une fosse creusće dans le schiste, un sarcophage, fail de trois parties soigneusement assemblées à sec el calées par de grosses pierres, abritant le squelelle d'un homme, déposé sans mobilier, dans un rercueil de bois. L'intérêt de la trouvaille est de faire connaître un lieu de sépulture sur la rive gauche de la Moselle, en un point de la ville où les découvertes d'antiquilés sont rares. Dans le département de la Moselle, une tombe de la première moilié du ${ }^{\text {er }}$ siècle a élé mise au jour près de la lerme de Kastelwad, à Hibelsheim³. Dans la vallée de la Blies, une tombe de Bliesbruck ${ }^{36}$ renfermait un riche mobilier funéraire de femme : au bras droit, bracelet d'or ; au gauche, trois autres d'or, de lignite et de

(32) G. Gocry, Gallia, XlI, 1954, p. 155.

(33) Du MÈME, ibid., p. 148.

(34) Comm. sup. fouilles, 1954 .

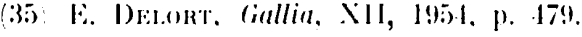

(36) I.e P'ays lorrain, 35, 195.4, p. 71. verre; deux anneaux d'or aux doigts; collier el médaillon d'or au cou ; près du corps avait élé déposée une caissette contenant une figurine humaine en bronze. Dans le Bas-Rhin, sépultures à inhumation et à incinération du début

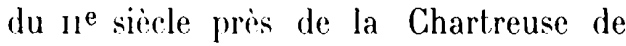
Konnigshoffen, i Eckbolsheim ${ }^{37}$; dans le sarcophage en grès vosgien de Selt $z^{38}$, silué en dehors et en bordure de l'agglomération romaine de salalia, on retrouve aussi, pres d'un squelette de femme, un roffret de bois, recouvert de plaqueltes de bronze, décorées au repoussé, dans lequel avaient été déposés une clé à poignée en forme de main, des monnaies de Maximien I)aza, de Constantin, de Constantin le Jeune, de Constant et de Constance II, un jeton de verre mullicolore, deux annelets debronze et un morceau de verre brunatre ovale, jadis monté en bague; à la hauteur de la tête avaient été placés un barrillet de verre frontinien, une épingle en argent à lête terminée par une boule dorée el, près de l'épaule, une monnaie de bronze de Maximien Daza. L'une des deux pierres tombales, trouvées en 1931 a Saverne, était décorée de deux Amours lesquels flanquent le cartouche contenant l'épitaphe ${ }^{39}$.

L'ascia fournit toujours matiere à discussion. De nouveaux documents sont versés au débal ${ }^{40}$, dont une ascia trouvée a Lyon avec taillant opposé à une hache, considérée comme pouvant être la matérialisation de l'ascia funéraire ou légionnaire. La vogue de la représentation de

(37) J.-J. HATт, Gallia, XII, 1954, p. 496.

(38) Du mène, ibid., p. 498-499 ; - C. SAuer, Cah. d'archéol. et d'hist. Alsace, 134, 1954, p. 71-72.

(39) J. BACHNAYER, ibid., p. 33-34.

(40) A. Ardor et P. I. Cotcrots, Rev. hist. relig., (XII), 1954, p. 8-29) ; P. II. Dival, RE.A, LVI, 1954, p. 441-413. 
cet instrument sur la tombe s'inscrit environ l:) apres J.-C.

La présence, dans certaines sépullures, de talismans, disques perforés of sciés a la base de bois de cerl ou d'élan, tombés a la mue, pourrail sexpliquer par un passage du lestament de Lingont ${ }^{4}$. Cerlains exemplaires ont été recueillis aussi dans des maisons de Verlaull (Cille-d'(or) $)^{42}$.

6. Arts el métiers. Commerce el industrie. J)ans cerlains cas, un examen de la végétation $^{1}$ permellrait de distinguer des autres les ferriers d'origine gallo-romaine. Au voisinage de La Charilé-sur-Loire (Niève), on a pu constater la présence de stations a Atropa belladona $L$. aux ferriers de Murlin, de La Ronce, de La Vache, de Bellary et de Sainte-Colombe. D'aulre part, les scories antigues se presentent. sous la forme de plaques de fonle grossière et fragile gris de rouille. les modernes. vertes noires oflrent des cassures vit reusers el luisantes.

La petite histoire dess fouilles de Mandeure (I)oubs) ${ }^{2}$ fournit une indication sur l'aclivilé économique de la ville galloromaine. L'n peu aranl 1911, un nommé P’équignol, qui réalisa une cerlaine fortune en exploilant les ruines, céda a la Monnaie 200 kilogrammes d'argent en lingots poinçonnés pouvant daler de l'époque sévérienne.

Des vestiges d'élablissements mélallurgiques ont été explorés a l'Impernal de Luzerh (Tot), sur l'emplarement du rempart gaulois ${ }^{3}$, représentes par deux

(41) J.-J. Haxt, Rev. archeol. Lesl, V, 1954, p. $5 \%$.

(12) R. Jorrnor, ibia., p. 59-66.

(1) A. Conombst, Ree. archeol. Est, 1, 19:4. p. 338.

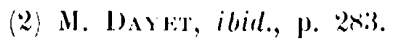

(3) .1. Lannolssi:, Gallia, NII, 1954, p. 2:30. fours sans doule jumelés, l'un pour le grillage du minerai, l'autre pour sa réduclion (1 ${ }^{\mathrm{er}}$ siècle apres. J.-C.) ; - - canalisalions de bois pour le lavage du minerai, ou pour act ionner une soufllerie, à Vénizy (Yonne). près de la source du Sevy deux fonds de basins avec cuvelle d'épuration à Mérignas (Gironde) $)^{5}$.

I'n exemple intéressant d'exploilation de carriere en vue de la fabrication de sarcophages est donné par les recherches failes au lieu-dit "Le Bois des Ciroltes", ¿2 kilomelres au sud d'Arcy-sur-Cure (Yonne) $^{6}$ : au sommet de la falaise corallienne dominant la rivière et à quelques 300 mètres de la voie d'Agrippa, s'étendent de vastes fronts de taille, avec des blocs en voie d'extraction et les empreinles de sareophagess détachés sur 85) mitres de longueur el 25 milres de hauleur. On a pu relever deux modes d'exploilation : extraction en lit et en délit; le développement. en profondeur de ce dernier mode amenant la formation de chambres. L'outillage utilisé comprend des pires simples ou doubles, des coins, des masies et des leviers. La carrière était. desservie par quatre chemins pratiqués à travers le rocher et deux glissières reliant l'exploitation à un chemin longeant la Cure, peut-être utilisée aux haules eaux pour le Iransport des blors. L'exploitalion semble avoir été brusquement abandonnée.

In alelier de fabricant d'objet d'os el de corne était installé, au ne-ve siecles, dans la fosse du théatre de Drevant. (Cher)?

Cn inventaire des céramiques d'Arezzo

(1) R. Lous, ibid., p. 52:3; Almn. Bun'gogne, X.NVI, 1954, p. 130.

(i) (i. Cocprer, ibid., p. :209-210.

(6) P. Povian, Rev. archeol. Lst; V, 1951, p. $: 99-45$.

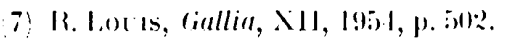

(8) M. L.nsrocsse, ibid., p. 301-321. 
trouvées a saint-Bertrand-de-Comminges (Haute-Garonne), montre que les conclusions de J. Téchelette restent toujours valables quant à la répartition de ces fabrications à travers la Gaule. Bien peu de nouvelles pièces furent découvertes depuis un demi-siecle, abstraction faite des bords du Rhin, la céramique ornée aréline ne se rencontre en Gaule qu'à l'état sporadique principalement dans les villes de la Narbonnaise, a Lyon et dans les grands oppida (Mont-Beuvray, Verlaull, Mlésia). Soil paurrelé, soil dillérence de goùl, soit plut òt incompréhension des scenes mythologiques illuslrant, res productions, la clientèle gauloise marqua une netle prédilection pour la vaisselle unie d'Arezzo.

Cependant celle poterie trop coûteuse allait renaîlre en Gaule sous une forme populaire, mieux adaptée aux goûts et aux ressources de la clientele, avec les fabrications de Montans, de Banassac, de La Graufesenque, de Lezoux el de tant d'autres aleliers, et si ces productions ne répondent pas aux caractères d'une grande industrie, au sens moderne du lerme, elles offrent loutefois certains aspects les diflérenciant de l'artisanal. Il s'agil d'un art industriel, tant par les procédés de fabrication que par l'organisation de la venle sur des marchés loinlains ${ }^{9}$. De cetle dispersion à travers le monde romain, un nouveau témoignage est apporté par la découverte, dans les mobiliers funéraires du cimetière de Chantemelle (Luxembourg) de poteries sorties des ateliers de Crestus, Licinus et Volus, travaillant à La Graulesenque entre les rignes de Claude et de Vespa$\operatorname{sien}^{10}$.

(9) P. .I. Dovar, in Industrie. Ret'. de la fédèr. des industr. belges, VIII, 1954, p. 275283.

(11) H. R., L'anliq. class., 1954, p. 180.
La céramique arétine a joué un ròle important dans la formation du répertoire décoratif des potiers gallo-romains de Montans (Tarn) ${ }^{11}$, dont les modeles avaient été vraisemblement transmis par des migrations de poliers el peut-ètre par les soldats. Iu reste, ces influences arélines reparaissent à $\mathrm{I}$ a Graufesenque et à Lezoux. Mais si ces éléments décoratil's sont communs à Montans et à La Graufesenque, il en est autrement des autres rapporls. Peut-ètre dans ces échanges de potiers ol de modiles entre les deux aleliers la voie fluviale du Tarn a pu jouer un ròle. Leur contemporanéité s'allirme de plus en plus, peut-être Montans pourrait-il se prévaloir d'une certaine antériorité dans le temps.

sur le sile de La Graufesenque (Aveyron $)^{12}$, les fouilles de 1953 ont amené la découverte du prolongement de la colonnade précédemment dégagée, puis au N.-E.. pres de la ferme d'un fonds d'habilalion bélonné riche en céramiques, dont un beau poinçon de Germanus représenlant Hercule, et au S.-E. d'un dépotoir ayant donné des tessons, principalement des officines de Calvus et de Bassus, des fragments de fours, tuyaux el cales. La reprise des recherches aux Martres-deVeyre (Puy-de-Dòme) ${ }^{13}$ a fail connaître les ruines d'un four avec de nombreux tessons et un outillage de polier : 108 marques onl élé identifiées et, de leur dispersion a travers l'Empire romain, il parait ressortir que l'exportation de l'atelier était surtout dirigée vers la Bretagne; certaines de ces productions ont élé aussi trouvées chez les Nerviens, en particulier a Bavai.

(11) M. Deraxd-Lefebrre, Gallia; XII, 1954, p. $73-88$.

(12) P. F. Fockxier, ibid., p. 193-195.

(13) De miske, ibid., p. 200 ; - R. TeYRISSE, Germania, 32, 1954, p. 171-175. 
Une nouvelle ollicine du potier Satlo vient d’ètre découverte a Mitlelbronn (Moselle ${ }^{14}$, abritée dans deux hangars contigus, dont les toitures étaient supportées par des piliers de bois reposant sur des blocs de calcaire. Du four, placé au Sud, il ne reste plus que le conduil de l'alandier, long de $8 \mathrm{~m}$., fail d'énormes dalles. La poterie recueillie comprend des vaisselles ordinaires, ruches, écuelles, coupes à trois pieds, gobelets (nI ${ }^{\mathrm{e}}$ sierle); des poteries rouges unies (1) ag. 40-32), bols assez profonds (fin $\mathrm{II}^{\mathrm{e}}$, $\mathrm{III}^{\mathrm{e}}$ ), des assielles portant la marque de Calullus, Marcianus et Augustinus, potier de Rheinzabern, mais sur la plupart sont appliquées les rosaces de l'alelier de Faulquemont-Chémery; des sigillées ornées reproduisant presque tous les modeles de Sallo. La grande nouveaulé de l'ollicine est dans la découverte de vases entiers el de nombreux lessons du polier Cibisins, dont les principaux poingons représentent un grand llùliste, un qualuor liberlin, des paons el de pelils écussons triangulaires.

On peul, en partie, reconstiluer l'histoire de l'atelier, installé environ 160 par les poliers de Faulquemonl-Chémery que rejoignirent des potiers de Rheinzabern et d'Ittenweiler. Son existence se prolongea probablement jusque vers 260, il disparut au moment de l'efiondrement. du limes.

A Konigsholfen (Bas-Rhin) les poliers et les luiliers de la VIIIe légion, installés au temps des Flaviens dans les quarliers sud-list des canabae, se lransporterent, a parlir du règne de Trajan, près de la Chartreuse, au voisinage desquels une losse à détrilus a élé fouillée ${ }^{15}$. La marque Sexli,

(14) J. Driont, Gallia, XII, 1954, p. 478 479 ; - .1. 1.r\%\% Annuare sor. d'hist. at d'arrhèn. lorraine, 1954, p. 97-100.

(15) J.-J. HATr, Gallia, XII, 195., p. 196. sur une tuile trouvée a Heiligenberg, pres de l'écluse, montre que les poliers de ce centre fabriquaient à la fois poterie sigillée et tuiles ${ }^{16}$. La variété des fabrirations est une des caractérisliques des officines de Vichy (Aolier), et il serait vraimenl nécessaire de leur consacrer une élurle d'ensemble ${ }^{37}$.

Les louilles d'un dépotoir ont fait connailre l'exislence de l'un des aleliers produisant, a Lombez (Gers), au lieu-dil "Galane", des petiles tasses sans anses, décorées de motifs géomélriques, plus rarement végétaux, généralement moulés, quelquefois tracés à la barboline, trouvaille importante puisqu'elle fait connaitre l'une des ollicines spécialisées, au ${ }_{1}^{\text {er }}$ siècle de notre ère, dans l'exécution d'une catégorie de vases qui furent, répandus a travers toute la Gaule, la (iermanie romaine st jusque dans la Péninsule Ibérique, témoignant aussi de la variété et de la décentralisation des industries de la lerre-cuite en Gaule dis celte époque ${ }^{13}$. Les amphores a fond plat (I)ress. 28 et Pellichet 47) des $11^{\mathrm{e}}-111^{\mathrm{e}}$ siècles, trouvées au "Collet Long", à La Crau d'llyères (Var $)^{19}$, se ratlachent aux productions d'un atelier, donl les fours, avec plusieurs chambres juxlaposées el voûtées en briques, ont élé reconnus adossés à une bulte sur les bords du Gapeau. Entre Porta-Binson el Chàtillon (Marne), l'atelier céramique de Bimon élail en activité à la fin du ${ }_{11}{ }^{\mathrm{e}}$ el au début du $1 v^{\mathrm{e}}$ siècle ${ }^{20}$.

Le dépòt de dolia, de jatles, de petils vases, lrouvé au Clos-lileury, à Inne-

(16) C. Horst\%, Cahiers d'archénl. et d'hisl. Alsace, 134, 195.4, p. 52.

(17) I) A. Mortivi, Rer. archeol. list, V, 1954, p. $57-59$.

(18) M. Labrolsss, Ciallia, XII, 1954, p. 2222.

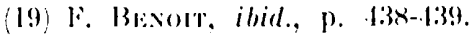

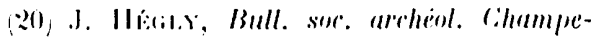
mise, 17, 1954, p. :21-2:2. 
masse (Savoie), représente-t-il le contenu de l'alelier d'un polier ou du magasin d'un commerçant'? C'est, l'entrepòt d'un tuilier gallo-romain qui a été trouvé à Lucy (Loire), silué à $80 \mathrm{~m}$. de l'emplacement des fours reconnus au siecle dernier et dans lequel deux types de tuiles avaient élé déposés sur qualre lits horizonlaux ${ }^{22}$.

La diversilé des lessons de vases planélaires, recueillis en 19.12, 19\%2, 19\%3, a Tournay (Belgique) donne des possibilités nouvelles pour reprendre l'examen des problemes relatils aux centres de fabrication el i la chronologie de ces productions ${ }^{23}$. La matiere première fait connaître cinq variélés de terres : a) lerra nigra, b) lerre rose saumon avec engobe beige; c) terre brun chocolat avec engobe beige luisant; d) lerre ocre ou rose saumon ¿ couverte dorée; celle dernière variété n'est encore connue que par les tessons de Tournai et ceux conservés au Musée d'Art el d'Histoire de Bruxelles; $e$ ) terre fine blanche, dite "lerre a pipes". Deux mélhodes furent ulilisées pour l'application du décor sur le vase. Un premier groupe porle des reliefs d'applique, retouchés ou non a l'éhauchoir. Le sujet ful moulé séparément, puis fixé sur la paroi. Dans le second groupe, le décor est directement estampé, le moule étant placé sur la paroi el le sujel imprimé par une pression s'exerçant de l'intéricur. Ouant aux centres de fabrication, il semble que Bavai n'eut pas le monopole de ces produclions. La matière, lerra nigra, de cerlains tessons de Tournai est tris proche des terres utilisées par les poliers ménapiens au début du $\mathrm{I}^{\mathrm{er}}$ siècle

(21) A. Brthl, Gallia, XII, 1954, p. 461. (22) J. Bromardor, Rev. de la Physiophile, juin 1954, p. 15-18.

(23) M. Anavin, I.tolomus, XIII, 1954, p. $10-50$. de notre ire, el il ne serait mème pas impossible qu'ils soient sortis d'une ollicine tournaisienne. I)ans ce cas, les exemplaires de Tournai seraient plus anciens que ceux de Bavai. L'emploi de la " terre à pipes " ramène vers les ateliers de Cologne, où d'ailleurs deux moules à décors planélaires ont été trouvés. Les plus anciennes fabrications sont à rapporler au regne de Claude et se poursuivent jusqu'au milieu du ne $^{\mathrm{e}}$ siecle. On constate a la fin du ${ }^{\mathrm{er}}$ el au débul du s${ }^{\mathrm{e}}$ l'apparilion des exemplaires a couverte dorée, ou tournés en "lerre de pipes » et, dans le mème temps, se manifeste une simplification des procédés de fabricalion, c'esta-dire le passage a un stade industriel, conséquence de commandes plus nombreuses.

In bon instrument de travail est apporté par le catalogue des lampes antiques du Musée central romano-germanique de Mayence, classés par époques et surtout toules reproduites ${ }^{24}$.

I'une histoire générale de la verrerie en Belgique on reliendra une chronologie : Romain I, du début de notre ère à 192 ; Romain II, 192-406; époque franque, $40(6-408$, et des renseignements sur le commerce du verre et la condition ouvrière des verriers en Gaule Belgique ${ }^{25}$. S'il semble que les origines de la diatrela restent encore incertaines ${ }^{26}$, d'utiles précisions sont apportées sur les lasses en verre moulé avec représentations de

(24) 11. Mexze:, Anlike Lampen in Röm.Germa. Zenlralmuseum zu Mainz. Katalou XV. Mayence. 1954 ; Voir aussi : I. Kıснғхвв:сн, Sacalburg Jahrbuch, XIII, 1954, p. 5-62.

(25) R. Chambox, Histoire de la verrerie en Belgique du $I I^{\mathrm{C}}$ siècle à nos jours. Bruxelles, 195.4 .

(26) K. Wendmaxx, Glaslechnische Berichle, 1954, p. 33-34. 
courses de quadriges dans le cirque ${ }^{27}$, qui seraient sorties d'un même atelier, travaillant en Gaule, dans la vallée du Khòne et exportant ses productions en Suisse, en Belgique, en Allemagne, en Afrique du Nord, aux $\mathrm{II}^{\mathrm{e}}$ et $\mathrm{III}^{\mathrm{e}}$ siecles. Le début de ces fabrications pourrait peut-être se reporter jusque dans le $\mathrm{I}^{\mathrm{er}}$ siècle, un fragment de verre à figures de gladiateurs ayant été recueilli dans un Lombeau onbrien du début de ce siècle.

I)ans l'histoire de la viticulture galloromaine $e^{28}$, un cerlain nombre de points paraissent acquis : origine orientale de la technique de la taille de la vigne; importation des vins de Campanie en Gaule; formalion dès les lemps gallo-romains des vignobles bourguignons, bordelais et mosellans; extension vers le . Vord et multiplication des vignobles secondaires au Moyen àge.

Le chemin maritime suivi par les amphores apportant en Ciaule les vins italiens est jalonné par une suite d'épaves de navires, coules le long des còtes génoises et provençales, el les variations des estampilles apposées sur ces récipients renseignent sur les conditions de ce Irafic:29. S'il est encore dillicile de déterminer quel est, de Tilius el de Seslius, le négociant, l'armateur ou le polier, une chronologie de la marque ayant pu ètre élablie, forme 13, 200-100 avant J.-C., forme $\mathrm{G}, 110-30$, on possede des dates assez précises pour ce commerce. Les amphores portant cetle marque sont dispersées de parl et d'aulre de l'axe rhodanien. Au $1^{\text {er siecle Chalon-sur-saone }}$ est la plaque lournante d'où les produils

(:7) J. 11. (. Kenx, Rev. archeol, 1954, 2, p. 12:1-135.

(28) R. Dıx, Jommage à Incien fiphre, p. $111-120$.

(29) E. Thevexor, Rev. archéol. Esl, V, 1954, p. 234-243; - J. Y. Coustrat, The nal. geogr. Magazine, janvier 1954, p. 1-36. médilerranéens sont dirigés vers le centre et l'Est par le Rhòne et la Saòne, et à parlir de Besançon par le Doubs. Dans la répartition des marchandises la batellerie de la Saòne a joué un ròle très importanl, mais ses témoignages matériels sont encore bien peu connus ${ }^{30}$; on peut toutefois supposer que ce matériel a fort peu évolué pendant longlemps. Pendant cette période qui s'étend de la fin du $\mathrm{II}^{\mathrm{e}}$ siecle jusqu'i la fin du I $^{\text {er }}$ siecle avant l'ère, une bonne partie de ce trafic passait par le port d'Agde (Hérault), avant que celui de Narbonne ne prenne, à l'époque romaine, une place prépondérante. On ne s'expliquerait pas sans cela le grand nombre d'épaves antiques reconnues sur cette parlie de la còte méditerranéenne pourtant restreinte ${ }^{31}$.

C'est aussi par le commerce du vin qu'on peut comprendre la présence, en Bourgogne, de grands monuments funéraires, décorés de reliefs relevant du cycte dionysiaque, tel te fragment incorporé dans une dépendance du Palais des Dur's el déposé au Musée de Beaune ${ }^{32}$. L'extension de ces mausolées, fréquents dans la Gaule orientale et dans les pays rhénans, est la conséquence de la richesse apportée à ces territoires par le vignoble. In renseignement important sur les mordalités de cetle exploilation est apporté par la découverte faile à Roulliac (Aude), sur le plateau de Tartare, en bordure de l': Lude, entre Carcassonne et Limoux, d'un four de potier et de lessons d'amphoes du type de Dressel ${ }^{33}$, représentant.

(30) L. Armand-Cadinat, Rev, archeol. Est, V, 19:54, p. $56-57$.

(31) A. Bouscani:s, Rev. des él. Ligures, XX, 195.1, p. 45-57; --. .J. Javionay, Gallia, XII, 1954. p. 445.

(32) F. Thevevor, Rew. archénl. Esl, V, 1954 , p. $259-263$.

(33) J. Jaxxoray, Gallia, XII, 1954, p. 314414. 
les vestiges de la figlina de l'un de ces domaines, où l'on fabriquait les amphores vinaires. Iorsqu'on pourra donner une leclure exacte des estampilles apposées sur les amphores, il ne serail pas impossible, élant donné les restrictions imposées aux indigines dans la cullure de la vigne, de constaler que le domaine élait la propriété de colons italiens. I'n autre témoin du commerce de l'huile et du vin est représenté par la derouverte d'amphores a saint-Martory (Haute(iaronne), sur la rive droile de la Garomne. l'ancienne Cialagurris serail aussi plus étendue qu'on ne le supposait ${ }^{34}$.

Au dossier de l'oulillage vilicole, on ajoulera les falr: viniloria de Saint-liemyde-Provence ${ }^{35}$ et du Musée de Sens ${ }^{36}$, l'une recueillie dans l'Yonne, l'autre aux environs de sens. I)ans cette mème collection figurent trois coupe-chardons découverts a Fonl aine-Màcon et a Rosouy (Yonne). Le musce de Dijon conserve un émondoir de Béru (Yonne) el des serpes provenant de Roilly et de Flavigny-surOzerain (Còte-d'Or) ${ }^{37}$.

les couches gallo-romaines de Vichy ont donné des oulillages variés, témoins d'une activile artisanale et industrielle développée : compas, regle de fer, truelle hrellelée, cognée; malériel de marinier, ancre a deux branches el, gaffe fourchue; outillage de bourrelier, alenes droiles ou courbes, piquoir, percelle unie; spatule d'oculisle ${ }^{38}$.

I peson recueilli a Bavai dans les

(3.1) M. I.ABrotsse, ibid., p. 216.

(35) H. Rollaxi, Rev. archeol., 1954, I, p. $82-83$.

(36) P. Paknt\%ot, Rer. archeol. Est, V, 1954, p. $147-151$.

(37) P. I.Euke, ibid., p. 151-152.

(38) Dr A. Уontwar, Tourisme 54, $1^{\circ} 50$, janvier $19 \overline{5} \mathrm{t}$ ruines du grand edifice ${ }^{39}$, porte au fléau une graduation complete correspondant au poids d'une livre et d'une demi-livre.

In groupement typologique et chronologique des nombreuses fibules provinciales romaines des musées de Mayence, de Worms et de l)armstadt, est appelé à rendre de bons services pour la datation de ce matériel trouvé dans notre pays ${ }^{40}$.

Un certain nombre de monuments sont a rayer des répertoires de la sculpture gallo-romaine : le pilier de Varhires, au Musée Borély de Marseille ${ }^{41}$, qui apparlient a la fin du xir ${ }^{\mathrm{e}}$ ou au xive siecle et a été ulilisé comme support de bénilier ou de chaire; - le prélendu taureau à trois cornes du musée de semur-enAuxois4, ayant fait partie de la collection Nodot, est d'origine égyplienne el représente la vache Halhor; - le sanglier à trois cornes du Cabinet des Médailles n'a pas été trouvé avec le taureau d'Avrigny ${ }^{43}$.

Parmi les sculptures récemment découverles, on reliendra : a Vallauris (AlpesMarilimes), dans la collection Arnera ${ }^{\mathbf{4 4}}$, buste de Pan, barbu, à oreilles de bouc, cornes naissantes sur le front, couronné de lierre, bronze, trouvé au Trou de la Chevre d'Or; - têle de I)ionysos, marbre, àgé el barbu, moustaches tombantes, couronne de lierre et de grappes de raisins, dans un jardin a Mleria (Corse) ${ }^{45}$; - deux bustes en marbre de bonne facture, Silene au lorse velu rurieusement

(39) H. Hrífelet, el R. Jory, Lalomus, XIII, 1954, p. 417-419.

(40) G. BEhrexs, Jarbuch d. Röm.-germ. Zenlralmuseum Mainz, I, 1954, p. 220-226.

(41) F. Bвxort, Protence hist., IV, 1951, p. $65-66$.

(42) A. Con.numet, Rev. archéol. Est, V, 1954, p. $3335-336$.

(43) I. DAYET, ibid., p. 334-335.

(44) F. Bixolt, Gallia, XII, 1954, p. 441.

(45) Do Mr.me, ibid., p. 443 . 
trailé, et philosophe ayant formé le couronnement d'hermès, à Nîmes, dans la cour de l'Orphelinat Coste, rue Grétry ${ }^{46}$; - Lorse mulilé de Mercure, calcaire du pays, à Saint-Clar (Gers), trouvé à Rochegude, statue funéraire de personnage drapé, au carrefour d'Ayreni, fronton de mausolée. masque tragique accosté de deux dauphins à Empourruche ${ }^{47}$; lorse de stalue funćraire de togalus, sirène el lète de bélier en bas-relief, marbre blane de saint-Béat, à Auch ${ }^{48} ; \ldots$ hermès de Troubat (Hautes-Pyrenées) ${ }^{\mathbf{4 9}}$; antéfixe en lerre-cuile, tête de Gorgone entre deux volutes de la grotle de Ia Marbrière, à Saint-Médard-de-Presque (Lot), rappelant ceux du temple de Luzech ${ }^{50} ;$-- torse d'athlète, trouvé cours Genet, à Saintes ${ }^{51}$; - déesse-mère en calcaire lenant un enfant emmailloté; divinité masculine ayant appartenu à un groupe du dieu et de la déesse assis, tête de cheval harnaché à Cosne-sur-Loire $(\text { Nievre) })^{52}$; - fragment de déesse-mère brisée, lenant une patère et une corne d'abondance, a Nevers (Nièvre $)^{53} ; \ldots$ fragment de géant anguipède, les jambes serpentiformes redressées dans le dos, a Entrains-sur-Nohain (Nièvre $)^{51}$; - tête de Mercure, bronze, forêt de Compierre, a Saint-Révérien (Nièvre) ${ }^{55}$; - stèle, marbre, homme debout, à Baugy (Cher) ${ }^{56}$; -- statue de femme assise, portant une tunique recouverte d'une draperie, dont

(46) J. JахNORAY, ibid., p. 425-426.

(47) M. Lannocsse, ibid., p. 223-22.4.

(48) DU misms, ibid., p. 221.

(49) I) U Mème, ibid., p. 220.

(50) D) mist, ibid., p. 231.

(51) Rev. Sainlonge el Aunis, N. S. 2, 1952, p. 143.

(52) R. I.oris, Gallia, XII, 1954, p. 508-509.

(53) DU MÊMı, ibid., p. 508.

(54) Du mêle, ibid., p. 510.

(55) Du мiмls, ibid., p. 509-510.

(56) Du м.ेмe, ibid., p. 501-502. un pan est ramené sur l'avant-bras gauche, les pieds chaussés, assez mutilée, trouvée dans le lit du ruisseau La Sirène, à proximité de son confluent avec l'Ouche, ${ }_{11}^{\mathrm{e}}$ siecle ${ }^{57} ; \cdots$ slatuette, marbre, petit personnage grolesque accroupi, à Sens, Grande Rue ${ }^{58}$; lète, pierre, les oreilles simplement indiquées, à rapprocher des lêtes de Chorey, provenant de la région de Renaison a Ambierle, près de Roanne ${ }^{59}$;

petit pilier rectangulaire, gres, terme a la partie supérieure, tête colossale avec excavation circulaire au sommet du crâne, stile funéraire à personnage tenant une coupe et une mappa de Montceau-lesMines $^{60}$; - statue mulilée de Mercure, la main droite sur une tête de bélier, le caducée dans l'autre main, calcaire, à Sainl-Marceau (Ardennes) ${ }^{61}$; - quatre tambours de la colonne et groupe du dieu cavalier au géant anguipède, à Dommartin-la-Chaussée (Meurthe-et-Moselle) ${ }^{62}$; nain bossu, portant un coc el une amphore, à Strasbourg, rue du Vieux-Marché6 -.- épilaphe de L. Capitolinus, dans un cartouche soutenu par deux génies ailés, nus, tenant d'une main le bouclier d'Amazone $e^{64}$.

7. Religion. -- I'observations sur les dieux de la Gaule ${ }^{1}$, dont quatre cents noms indigènes sont parvenus jusqu'à nous, une centaine accolés à celui d'une

(57) G. Grínac', Rev. archéol. Esl, XII, 1954, p. $195-197$.

(58) R. Lours, Gallia, XII, 1954, p. 519.

(59) I'. DÉchestetrle, ibid., p. 89-90.

(60) I. Armand-Cindiat, Mém. sor. d'hisl. et d'archeol. Chalon-sur-Saone, XXXIII, 1954, p. 79-79.

(61) G. Gocrs, Gallia, XII, 1954, p. 148.

(62) li. Drlond, ibid., p. 482-483.

(63) J.-J. IIATT, ibid., p. 193.

(64) I. Bacmmarien, Cah. d'archéol. el d'hist. Alsace, 132, 1954, p. 33-34.

(1) P. .I. Deva., Rev. hist. relig., CXLV, 1954, p. 5-17. 
divinité romaine, il semble se dégager un synchronisme à cinq éléments : survivances de culles préhistoriques; cultes celtiques; culles gréco-romains; cultes orientaux monothéistes, peu mélangés aux autres; ct tout a fait a part, culte impérial. Déjà M.-L. sjoested avait bien mis en lumiere le caractere polyvalent des dieux celtiques, ce qui n'a pas été sans aider a la fusion avec le panthoén grécolatin. Le lexte de César précise quelquesunes de ces correspondances, parmi lesquelles on peut reconnaitre : un dieu inventeur des arts, Lug-Mercure; un mailtre des dieux, Taranus-Jupiter; un dieu guérisseur, Mercure, le nom de l'entité cellique étant inconnu; un dieu de la guerre, Teutates-Mars; une déesse présidant aux arts et métiers, Minerve, dont le nom indigène est, inconnu. A celte liste il faut ajouter une divinité infernale, Sucellus, un dieu forgeron, le Gobniu irlandais, assimilé à Mercure ; enfin Esus, avec lequel aucune correspondance romaine ne peul être établie.

Le caraclere de la religion romaine en Provence ${ }^{2}$ laisse apparaître nettement celte dualité. Aux còtés des cultes ofliciels plus politiques que religieux, de Jupiter, des Lares Augusles, de Rome el d'Auguste, la survivance des divinités indigènes est autrement importante, se cachant sous le nom romain. Les conceptions des immigrants latins se sont confondues dans la masse des croyances tradilionnelles. De ces hybrides Sylvanus est un des éléments les plus curieux. Un récent relevé des sanctuaires galloromains découverts dans le département du Loiret $^{3}$ conduil à de semblables conclusions, les caractères celtiques étant encore accentués par les formes

(2) A. GRENIER, CRAI, 1954, p. 328-335. (3) Abbé R. Mocflet, Rev. archéol. Est, V, 1954, p. 204-205. architecturales données à la maison du dieu.

L'un des lémoignages nouveaux de ces survivances celtiques dans la religion gallo-romaine est l'exaltation de la face et de la tête humaine, Lraitée, dès le temps de l'indépendance, dans la sculpture et sur les monnaies. La représentation dans les arts celtique et, gallo-romain de la tête, partie pour le tout, est un trait original qui sépare ces manifestations de celles de l'art gréco-romain et qu'on peut expliquer par la lendance des arts celtiques à la schématisation el à la simplification. Elle releve aussi d'une conception selon laquelle la lète est le siège de l'àme et du principe vital. De là encore, la chasse aux crànes et la traduction plastique de la puissance de la mort concrétisée par l'apposition d'une main sur une tète seule (Entremont), ou par celle équivalente d'un fauve androphage sur le cadavre humain réduit a la figuration de la tête. Pour les dieux comme pour les hommes, l'essentiel est la tète, d'où les dieux sans corps, c'est-à-dire ceux dont la figuration se réduit à une tête reposant sur un socle ou sur un pilier. Des monuments, comme les têtes colossales de Chorey, creusées au sommet pour recevoir une libalion, sont très différentes des hermès médilerranéens. Aussi ne peul-on toujours interpréter comme des têtes coupées ces figurations. Celle exaltation de la tète se Iraduit aussi par le volume exagéré donné a celle partie du corps humain, dont le détail peut ètre à peine esquissé, images de Cernunnos, figures funéraires réduites à la lèle, parfois amovible. Au reste, cette prééminence de la têle survit dans la littérature galloise et irlandaise (légendes de Bran, de Saint Patrick) et dans le cycle arthurien. Ainsi en Gaule et en GrandeBretagne, les têtes isolées, les tricéphales, seraient la représentation pars pro loto s'une divinité déterminée, soit sous, 
une forme simple, soit la forme d'une répélition d'intensilé soulignant la loulepuissance du dieut.

Des monuments du lype de ceux de Beaurepaire, de Roquepertuse, de Solingen, d'Ilolzgerlingen, sur lesquels, au second àge du Fer, la tète seule est sculplée, le corps restant brut, permettent une interprélalion du passage du texle de De passione el virlulibus sancli Ioamnis marlyris, dans lequel Grégoire de Tours signale l'existence, is Brioude, d'un grand sancluaire abrilant une colonne porlant les images de Mars et de Mercure et dans lequel on célébrait. des fềles païennes comportant un combat a mort que se livraient deux jeunes hommes armés d'épéess. Il ne s'agil pas, en effel, d'une colonne au dieu cavalier et au géant anguipède, mais d'un Ianus cellique. a rapprocher du monument de Reims portanl une figure imberbe, Mars, el une aulre barbue, Mer'ure. Celui-ci ayanl élé fréquemment. représenté sous l'aspect d'un vieillard barbu, (irégoire de Tours aurait été amené à identifier ainsi les deux teles.

Le culle du cavalier el la consécralion hippique sont des motil's communs au lond religieux ef culturel préromain de la Méditerranée, comprenant le littoral ligure, provençal et ibérique. Il se présente a Mouriès sous sa lorme la plus primilive, antérieure a toute influence cellique el représente un pur apport méditerranéen ${ }^{6}$. Ce culle laisse pressentir celui d'Épona, qui reste étranger au panthéon nordicue du monde cellique. On peul rechereher dans la

(4) P. IAsmbrants, L'erallation de la lêle dans la pensée el l'arl des Celles. Jiss. archaeologr. Gamdenses, vol. 11. Bruges, 1954.

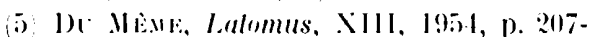
217.

(6) If. Bkxort, Publications Ann. Faculti d. I.ettr. Aix, nouv. sir., no $7,1954$.
Péninsule Ibérique des archélypes de l'Épona gallo-romaine, suite de figure anlerieures aux images gallo-romaines, diviniles dompleuses de chevaux et cavaliers héroîsés? La même méthode de recherches esl appliquée il l'anguipede, dont le rapprochement avec les monstres hippophores de la Méditerranée montre les origines méditerranéennes: Ces influences se manifesteraient dans le thème d'Épona ${ }^{9}$, qui pourrait êlre comparé à certains aspects religieux de la Cirice archaïque, et des parallèles ont été tentés avec Déméter Moelena et Poseidon Hippios. Ces tentalives audacieuses demandent une grande prudence. Apres Rhiannon, la cavalière de l'épopée galloise, voici Macha, l'héroïne irlandaise de la Yeuvaine des Clates, qui prend rang parmi les ancètress cell iques d'Épona. Petile-fille de l'océan, c'est une bonne, ménagere qui court plus vite que les chevaux du roi et meurt en fin de course, en mellant au jour deux jumeaux, non sans avoir ensorcelé fous les hommes de la l ribu. Mais au vrai, que savons-nous de la mythologie d'Épona? que la lète d'Epona, en Cisalpine, lombe d'après te calendrier de cuidizzolo le 18 décembre, suivant de pres les consualia, (1:) décembre) lète des animaux de trail, pendant lesquels on donne des couronnes de fleurs aux chevaux et aux mulets. De lous ces essais d'interprétalion, on pourrait peut-être dégager quelques-uns des trails d'bpona, a la fois divinilé psschopompe et général rice de lécondité, présentant aussi des rapports aver les déesses-mères. Encore un hybride ${ }^{10}$.

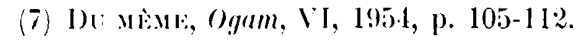

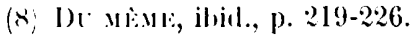

(9) J. (inicolent, ibid., p. 25)-16, 75-81), $137-133, \quad 269-272$.

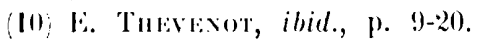


Ces associalions de fonctions ou de personnages divins sont tris apparentes dans ce yu'on peut savoir des sancluaires d'Entrains (Niivre). La bourgade. assise dans une zone limithrophe entre les Éduens et les Senons, était un centre roulier d'où rayonnaient six roies et qui élait enlouré par des cours d'eau sur trois de ces cotés. Cetle position géographique explique la présence, a Entrains, de sancluaires consacrés à Mithra el au rulte des eaux, aux colés des lemples d'Ipollon (Borvo), la divinilé principale, d'Épona, des Déesses-Mires. de Minerve et d'Hercule. Ces deux séries de personnages divins, dieu solaire el divinité des eaux, ne sonl pas entièrement distinctes et des connexions les rappro(hent plus ou moins élroitement. La fusion s'opere aux ${ }_{1 I^{e}}{ }_{-I I}{ }^{e}$ siècles, entre les croyances anciennes et nouvelles, provoquant un vaste syncrétisme, et il n'y eut pas ruplure de la continuilé religieuse. L'éloignement de la bourgade des grands centres administralifs eut pour conséquence le peu d'emprise du panthéon gréco-latin sur l'ensemble des croyances et, sous des noms el des formes rhangeantes, les cultes indigines prolongierent leur existence, enrichis, a partir du $11 \mathrm{I}^{\mathrm{e}}$ siecle, des apports mystiques venus d'Orient, en attendant le christianisme. Ce pouvoir guérisseur qui s'allache à des dieux, souvent considérés sous d'autres aspects, est aussi appliqué à Hercule, vẻnéré à Vichy, comme a Glanum, en lant que dieu bénéfique, auprès des sources salutaires!1. On peut hésiler entre Isis el les IDéessesMeres de l'Mllier, inlerprélation qui repose sur les découvertes faites a Vichy d'une lerre-cuile d'Anubis et d'un manche de patìre en céramique locale,

(11) DL: мis.us, ibid., p. 245-248. orné de la figare d'lsis assise allaitant un enfant, ${ }^{12}$.

Deux essais d'interprétation des noms de Cernunnos'3 el de sequana ${ }^{14}$ sont proposés. Au sujel de la représentation du dieu barbu aux bois de cerf surmonlant la lète, trouvé sous le chour de Volre-I)ame de Paris (E. 3133), de bons arguments sont apportés en faveur du relour à l'ancienne hypothese du dicu aux cornes. On ne pourrait traduire "celui qui a le sommet de la tèle comme un cerf", selon une récenle inlerprélation ${ }^{5}$. Dans le nom de la seine, plus que le caractere sacré de la source, il faudrail rechercher !expression du ròle joué par le lleuve dans la vie économique, le plus court chemin pour joindre les còtes de la Manche au couloir rhodanien.

Le taureau à trois cornes, dont le groupe le plus important est localisé chez les séquanes, ne se prète à aucune assimilation avec des divinilés connues. A l'époque romaine, il aurait eu un caractere talismanique, précisé par la triplicilé, la valeur symbolique du chiflre 3, exprimant la pluralité indéfinie et infinie, la puissance portée à son maximum1 ${ }^{16}$.

lin faisant connaître l'existence ì Vimes d'une station de la vicesima he'erditalium, la dédicace d'un villicus à Silvain ${ }^{17}$ gratifie le dieu de l'épithète sanclissimus, encore inédite en Narbon-

(12) Dr A. Morlet, Tourisme 54, $\mathrm{n}^{\mathrm{o}} 55$, juillet, $19 \div 4$.

(13) P. Lebre, Rev, archéol. Esl, V, 1954, p. $183-185$.

(14) F. TивvкNot, Vie el langage, 1954, p. $215-219$.

(15) LE Roc: Ogam, 1953, nos 25-26, p. 324329.

(16) II. Droxid, I'anliq. class., XXIII, 1954 , p. $403-428$.

(17) J. Armand, Rev. archéol., 1954, I, p. $198-203$. 
naise. Le sarcophage du triomphe de Bacchus au Musée des Beaux-Arts de Lyon met en lumière le caraclìre funéraire du thème dionysiacque ${ }^{18}$.

Aux listes des mains dolichéniennes, on ajoutera : un exemplaire disparu, trouvé a Reims, rue Coquebert, et qui n'est connu que par un dessin, et celui d'Arzilly (Côte-d'Or), dont le pouce supporte, appuyé contre l'index, un petil godet ${ }^{19}$.

La découverte de la dédicace d'un temple a Montjustin (Basses-Alpes) précise l'existence d'un lieu de culte sur ce site, dominant le tracé de la roie romaine d'Apt a Sisteron ${ }^{20}$, el la favissa, trouvée dans un faubourg de Noyers (Yonne) $^{21}$, appartient sans doute à un sancluaire qui se situerail en bordure de la voie romaine Auxerre-Montbard.

Lne dédicace à llercure a élé relevée a Rize (Basses-ilpesez2. Des autels, des socles, sont signalés a dutichandes-Frontignes et au village de Bernet (IIaute-(iaronne) ${ }^{23}$, a Ilheu (HautesPyrénées) ${ }^{24}$. (arbre et swastika). I saramon (Gers) ${ }^{25}$, le bénitier de l'église est emprunte is un monumenl anlique, laraire ou reliquaire.

Pour la premiere fois, sur le lerriloire des Bituriges, a élé découverl, à saintChristophe-le-Chaudrey (Cher), au lieudit "La Longe", sur le domaine de La Charnaye, les fragments d'un groupe du dieu cavalier au géant anguipède ${ }^{26}$.

(18) A. BRсна, Bull. mus. Iyomnais, III, 1954, p. $1-11$.

(19) P. I.:Bв:., Reu. archeol. Est, 1, 195), p. 329-330, 2:43-245.

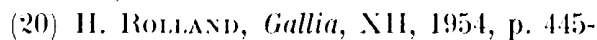
416.

(21) Ann. Bourgogne, XXV1, 195, p. 130.

(22) 11. Rol.LAXD, (iallia, X11, 1954, p. 1.17.

(23) .I. I.abnol'sss, ibid., p. :217.

(21) De Mist:, ibid., p. 220.

(25) Du Mìne, ibid., p. 221.

(26) R. Jocts, ibid., p. 50)4.
8. Numismalique. - I a récente découverte du trésor de Bavai (Nord) conduit à examiner l'ensemble des dépòts enfouis environ 2901. Ceux-ci ne correspondent, pas à des circonstances économiques. Ils couvrent en Gaule septentrionale, un territoire ayant reçu, à partir de 291 , un contingent de colons d'origine harbare, deslinés à relever une paysannerie éprouvée par une invasion non datée. Or, ces événements pourraient être mis en rapport avec la tentalive malheureuse de Maximien contre la Bretagne, qui se solde par autre chose qu'une défaite navale, puisque Carausius put réoccuper sur le conlinent une large tète de pont, comprenant au moins le littoral batave, Boulogne et, peut-être Rouen. Dans la somme, un ratalogue des cachettes montre que la plupart des enfouissements s'arrètent i) Postume'2.

Les antoniniani du trésor de Bischoflsheim (Bas-Rhin) ${ }^{3}$ s'inscrivent entre les rignes de Philippe l'Arabe (244-219) et d'Aurélien (270-27:5). La cachette a été menagée entre 270, date de l'avènement d'Aurélien, el 27.4 , date de la réforme monétaire. L'examen de cerlains revers permeltrail de serrer la chronologie de plus pris et de proposer les années 273 ou 274. Irrégulières et mal irappées, ayant juste assez d'argent pour faciliter la frappe, ces monnaies représentent les lémoins d'un monnayage local ćmanant d'un territoire oit ce numeraire sert d'appoint.

Autres indicalions apportées par les 6.12 monnaies enfermées dans un pol, 376.

(1) J. Gincotit, RAA, JVI, 1954, p. 366-

(2) R. VAssi:tat, Rer. du Nord, XXXVI, 1954, p. 147-169.

(3) D) H. J.oxaUtar, Cah. d'archénl. el d'hisl. Alsace, 13.1, 1954, p. 53-56. 
Lrouvées a Rourroy-les-llerles (Oise) 7) deniers de septime-Sévere a Gordien III émis par les ateliers de Rome. sauf un exemplaire émis à Alexandrie, 568 antoniniani de Gordien III ì Gallien et 184 de Poslume (260-2633). frappées a Cologne, enfouis avant la grande inflation, en un moment où la circulation des deniers élail encore importante. la mauraise monnaie n'ayanl pas chassé la bonne; el par les trésors de Crain (Yonne), achés en 275, at de Checy (Loiret), les pieces d'or d'Honorius et d'Areadius ayant été perdues au passage de la locire, lors de l'invasion de 408-4095. La décourerte de monnaies de Philippe Ier, de Tétricus et de Constantin font connaitre une réoccupation de l'oppidum de Sarbasat (Ariege) au cours de la seconde moilié du $\mathrm{IV}^{\mathrm{e}}$ siècle $^{6}$.

De nouvelles racheltes ont été trouvées : is Soulignac (Gironde) ${ }^{7}$, à NeuvyBouin (Charente-Harilime) ${ }^{8}$, à SaintJean-de-Bray (Loiret) ${ }^{9}$, à Ciuimaëc ${ }^{10}$, a Gouaram-Rozarn ${ }^{11}$ el à Restourel en Plounevez Lochchrist (Finistere) ${ }^{12}$, a Bus-la-Ilésière (Somme) ${ }^{13}$. L'ensemble de ces enfouissements est contemporain des invasions de la seconde moitié du ${ }_{11 I^{\mathrm{e}}}$ siecle.

(4) A. Pigavion, Gallin, XII, 1954, p. 145. (5) G. Fabne, Rev archiol. Est, 1, 19:4, p. 203.

(6) II. I.npotssi:, Gallia, XII, 1954, p. 219.

(7) Bull. et mem. soc. archeol. Bordeaur, 1945-1950, p. 23. 191.

18, F. Licilx, (iallia, XII, 1954, p. 190-

(9) R. locis, ibid., p. 504-505.

(10) P. Merlat, Gallia, XII, 1954, p. 161162 ; - Bull. soc. archém. Finistire, LXXIX, 1953 , p. xx.

(11) Du MÈne, Gallia, XII, 1954, p. 163164.

(12) Bull. sonc. archeol. Finislere, I.X.XIX, 1953, p. xis.

(13; M. Mleich el F. Wassell, Bull. lrim. soc. antiq. Picardie, 1954, p. 209.

\section{VI}

\section{TEMPS CHRÉTHes het MÉROVINGILNS}

Il ne saurail ètre recommandé aux amateurs de re que son auteur appelle les "livres majestueux" de feuilleter rertains tableaux de la Gaule du BasLimpire'. Du róle joué alors par la ville d'Arles, il n'est retenu que le raflinement. de son aristocralie, son bien manger et la richesse des propos de ses habitants.

L'empereur Julien n'aurait pas élé assiégé derrière les murailles de Sens (Yonne), mais au "bourg" de Senon (Meuse), l'un des trés rares burgi du Bas-Empire, découvert en France. On peut Irouver peu convaincants les arguments toponymiques mis en avant par J. Nicolle ${ }^{2}$. Il reste cependant difficile de souscrire à la réalité d'un raid germanique qui, ayant ses bases de départ en Nlisace, aurail amené une bande de barbares à mettre le siege, pendant un mois, devant une ville aussi importante que Sens, qu'il semble osé de qualifier d'oppidum tum opporlunum. Il ne s'agissait pas, en eflet, de tenir contre un retour offensif des Germains les avancées de Sens, mais bien plutot les lerritoires silués a l'Ouest des Vosges. dont le quartier général de Julien ne pouvait ètre très éloigné.

Peut-on expliquer la persistance de la présence de Rome en Alsace par les étapes prudentes d'une évacuation progressive, ébauchée en 393-395 pour des raisons intérieures à l'Empire? s'il

1 G. (inossi, Hes Romains alu.t Barbares. Tableaur hishriques de In Ciaule du Bas-Limpire, laison, 195:3.

(2) Ann. Bourgogne, XXIV, 1954, p. 125-1:6. 
n'est pas impossible que le tractus Argentoralensis ait conservé d'uliles lambeaux du limes plus longlemps que les autres pays rhénans, que la grande invasion de 407 , qui submergea toutes les Gaules, n'ait pas entraîné un abandon de l'Alsace, il faut admellre que l'entrée des Huns d'Attila, en 451, marque la fin de Rome sur le Rhin ${ }^{3}$.

Le probleme de la colonisation Iranque a donné lieu à de nouvelles recherches. C'est d'abord un essai reposant principalement sur l'examen des textes littéraires, tendant à fixer les limites dans l'espace et le temps des territoires occupés par les Francs, antérieurement a la période des grandes invasions4. Il ressort de celte recherche qu'on ignore encore beaucoup des caracteres de leur civilisalion. F. Petri ${ }^{5}$ aurait-il rencontré son chemin de Jamas? S'il s'efforce, dilficilement d'ailleurs, de sauver l'essentiel de thèses fortement entachées de racisme, il est cependant conduit i reconnaître que l'examen des cimetières mérovingiens n'apporte plus la preuve airecte de la colonisation germanique dans l'Lurope de l'Ouest. Il n'en serai qu'un reflet indirect. Eludiant quelques aspects nouveaux de l'hisloire el de l'archéologie de la période des grandes invasions, d'après les fouilles du cimetière mérovingien d'listagel (Pyrénées-Orientales $)^{6}$, j'avais insisté sur la persislance extrêmement imporlante des descendants

(3) Émilienne Draccirot, Rerue ditsace, 92,1954, p. $7-28$.

(4) W. J. de Boox, De Franken e'an hun eersle oplreden lol de dowl ran Childerik, 195.1.

(5) Zn Sland der Jiscussion uber die frankische Landnahme und die Enstehung der yermanisch-romanische Sprechyrenze. Darmstadt, 1954.

(6) R. Laxтnн, Neue Beilräge zur Kunstsgeschichle des I. Jahrlansend, Baden. 195., b. $27-31$. de la population gallo-romaine dans le peuplement de la Gaule à cette époque. Ch. Verlinden ${ }^{7}$ esquisse unt théorie nouvelle de la colonisation franque : les saliens n'auraient quilté la Toxandrie qu'environ 454, el leurs établissements, tres peu nombreux, dispersés jusqu'au cours de la Loire, n'auraient pas été suflisants pour exercer une influence sérieuse sur la formation de la fronlière linguistique. Celle-ci serait la conséquence de la colonisation intensive de la partie flamande de la Belgique, après les invasions, dans le cadre de l'État mérovingien et carolingien, mais la grande rarelé des trouvailles relevant de ces époques sur ces mêmes territoires est tres loin de correspondre a une occupation franque aussi imporlante qu'on le suppose. En fail il semble bien que l'ensemble de la Belgique ne fut guire occupée durant les premiers liers du ve siecle, ce qui permet d'expliquer la carence des découvertes franques de cette époque ${ }^{8}$. I'autre part. ce n'est guere avant la fin du vie siecle qu'on retrouve des sépultures barbares dans la Belgique septenlionale, e'est-à-dire dans la partie du pays d'expression flamande. Quelqu'ail pu être l'import ance de l'action exercée par l'occupant franc sur les populalions depuis longtemps en place, celui-ci ne représente encore qu'une minorité. Ayant adopté l'espace vilal, déja exploilé par les (rallo-Romains en Belgique el dans le Nord de la France, l'occupalion franque s'explique d'apres la dispersion des cimelieres, par des facleurs géographiques el économiques

(7) Transurlions of the roy. hisl. Sociely, 195.1, p. $1-17$.

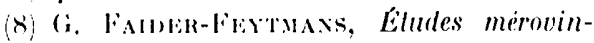
giemnes. Acles des juntrees de Poiliers, ler..3 mai 1652, r. $103-109$. 
el surloul par le raractipe de lérolulion historique dans un pays aux villes rares et aux larges étendues fertiles of cultives. Il en est aulrement de la Touraine9. Les ruines de l'invasion de 27t el un état d'insécurité, qui se prolongera jusqu'au rigne de Const ant in. lémoignent de l'ahandon des trois principaux centres de peuplement gallo-romain : vallées de la loire el du Cher aux environs de Tours, parlie orientale du cours el cours moyen de l'Indre, vallés de la Vienne el de la Carse. Si rertains de ces établissements furenl réoceupés au cours du we sivele des aggloméralions nouvelles sont inslallées loin des centres anciennement habilés al à l'écart des chemins de la circulation, peut-être sur des rantons, précédemment lenus par une paysannerie gauloise, restée à l'écart des centres de romanisalion. Si la conquète wisigothique de la Touraine n'est qu'un épisode polilique, la dominarion franque accentue l'opposition entre. les conditions des peuplements galloromain el barbare. Alors ijue les premiers avaient recherche les sols d'alluvions modernes, faciles a lravailler, el portant bien les réreales, les seconds, sans louldods eviler ces terrains, se sont installés sur des lerres plus paures, limons ef graviers des platraux, au Nord de Tours, el sur le plaleau entre le Cher ef l'Indre, il l'écart des voies terrestres el fluviales. Ces diflerences dans le choix des siles traduisent raisemblablement des modes de vie dilférents, au moins aux origines de ce peuplement barbare, et précisent la part des Francs dans la mise en valeur de nos campagnes. Permanence et changement aussi dans l'ordre politique et social, telle est la conclusion qu'on peul retirer d'un arlicle sur les rassess sociales dans la cilé de Poiliers aux lemps mérovingiens ${ }^{10}$ oì, comme ailleurs, les instilutions municipales n'ont pas survécu aux invasions. Au premier rang de la sociélé on lrouve les grands propriélaires fonciers d'origine gallo-romaine, pépinière d'eveques of de hauts fonctionnaires. Au-dessous de celte aristocratie, les curales representent la rlasse moyenne, plus riche de tilres que de pouvoirs. I Poiliers, comme dans les grands centres urbains du Cenlre el du Midi de la Ciaule. sous le nom de "syriens", sont groupes les marchands orienlaux, irlandais, écossisais, flamands, allemands el scandinaves, venant échanger leurs marchandises contre celles du sud et de l'Ouest de la Gaule dans les ports des îles de lBouin, d'Yeu et de Noirmoulier. Iux còtés de celle société laïque régie par le comle, le clergé forme une classe a parl subordonnée ¿ l'aulorilé de l'évèque donl les condilions varient suivanl les evénements. Ne disposant pas de prérogalives politiques an ve sierle. meme s'il lui arrive de diriger l'opinion publique, l'évèque est amené, au siecle suivant, devant laftaiblissement du pouvoir central, a prendre le pas sur le comte. si l'on sail peu de choses du clergé séculier. on est mieux renseigné sur les réguliers, dont les effectifs ne cessent de s'accroiltre et parmi lesquels on comple déja des missionnaires irlandais. Jans la ville el les faubourgs, des monastìres sont éahlis, el l'apparition de la communauté de femmes de sainteCroix, fondee par sainle Radegonde, n'est aurunement un fait isolé, mais s'insérant dans l'histoire d'un vaste mouvement monaslique. Ie vie siecle 
est une période de transition entre deux àges : le monachisme gallo-romain sous sa double forme, martinienne et provençale, et le monachisme mérovingien du $\mathrm{Vu}^{\mathrm{e}}$ siecle, également sous un double patronnage, colombanien et bénédictin ${ }^{11}$. Il est significatif qu'i la fin du ve siècle et au débul du $v^{\mathrm{e}}$, trois saintes femmes, Genevieve, Glotilde el Radegonde, exercent une action profonde dans le domaine politique et religieux. Ia figure de Radegonde est représentative de ce nouvel idéal de saintelé qui se manileste alors en un moment où le temps des martyrs est clos $^{12}$. Le chrélien hésile enlre deux types de sainteté : la contemplation et l'aclion, et les deux vies que nous possédons de Radegonde refletent, chacune, l'une de ces conceptions opposées. Bien que rloit rée, elle est loin de rester indifférente aux vicissiludes de l'hisloire de son temps : au moindre bruil de guerre, elle s'entremel entre les deux partis, et par son aclion, elle a dans une large mesure aidé a la fusion entre les deux sociélés gallo-romaine et barbare. De telles figures font mieux senlir le ròle capilal du facteur religieux dans la formation de la mentalité européenne. Ch. Dawson ${ }^{13}$ a mis l'accent sur le ròle joué par la conversion des princes mérovingiens, Clovis chez les Franc's, kinut chez les I)anois. Il remarque encore qu'un peuple ne devient vraiment chrétien que lorsqu'il peut se proposer comme idéal populaire l'imilation des héros chréliens. De lii, l'importance de res baptemess spectaculaires, facteurs

(11) Dom (i. Mants, ibid., p. 217-2:2.

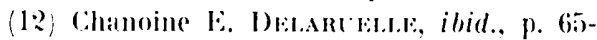
7t; lonise counaxise ibid., p. 15-5).

(13) Ch. Dawsox, lat religion el la formalion de la cirilisalion occidenlale, Paris, 1953.3. essentiels dans la christianisalion de la mentalité harbare.

Aux cótés des textes lilléraires, de nouveaux documents archéologiques viennent i l'appui de ces observations. A Ligugé (Vienne), les fouilles de Dom Jean Coquel ${ }^{14}$ sur l'emplacement, d'une villa gallo-romaine, incendiée a la fin du Ine siècle, ont amené la découverte, le long de l'église abbatiale et d'un oratoire du xive siècle, d'une ronstruction, demi-décagone dont les deux pans intermédiaires sont incurvés, limitée le long du diamitre par un large couloir entre deux murs ol, comportant une colonnade extérieure du còté tournant. Des portes, pratiquées dans la partie droite diamétrale, donnent acciss dans un couloir silué en contre-bas par rapport au sol exterieur et plus encore au niveau de l'aire centrale carrelée. Rasé et comblé, coupé par une Iranchée funéraire que less lessons recurillis datent du ve siecle, l'édifice qui ressemble a un mausolé romain serait le martyrium élevé en souvenir d'un grand personnage, saint Martin, sur l'emplacement de son ermilage, détruil vers 450 par les Wisigoths qui y installerent leurs sépultures. Ce ne peut ètre l'édifice vu par Grégoire de Tours, en 591, qui commémorait la résurrection par Saint Marlin de son disciple mort. On est ainsi conduit a supposer l'existence de deux sancl uaires martiniens à Ligugé.

Des vestiges des anciennes abbayes de saint-Rul el de saint-Paul ont elé releves a Arignon ${ }^{15}$ et a Besanģon ${ }^{16}$. Des sarcophages des $\mathrm{v}^{\mathrm{e}-\mathrm{v} u \mathrm{l}^{\mathrm{e}}}$ sicres ont ele lrouvés sur l'emplacement de

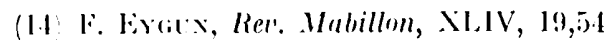
1. 45-94; Gallia, XII, 1954, p. 380-389.

(15) J. Salvin, Ciallia, XII, 1954, p. 123.

(16) I. I.ERA, ibid., p. 469-171. 
l'abbaye de Saint-Rémy, à Sens (Yonne) ${ }^{17}$. La trouvaille en 1610, au cours de Iravaux exéculés dans l'abbatiale, à Saint-I)enis (Seine), d'une horne millaire utilisée dans la construction du grand autel, alors détruit, et portant l'inscription m(illia) p(assuum) VIIII, apporte un témoignage nouveau de l'élablissement du monastere primitif sur un site antique. D'autre parl la Passion de saint Jenis localise le tombeau du martyr in sexto lapide. Ces deux informations ne sont pas contradictoires: ${ }^{18}$. A l'occasion du XIIJe eentenaire de l'abbaye de Jumieges (SeineInférieure, I. Jouan, G. Ianfry et J. Lafond ont publié une histoire du monastere ${ }^{19}$, et dom Patrice Cousin ${ }^{20}$ a relracé la vie monastique du centre de 654 jusqu'a sa dévastation par les Normands en 851 .

A Nice (Alpes-Maritimes), le dégagement de l'ancienne cathédrale de Notre-Dame-du-Chàteau a révélé l'existence d'une basilique à trois absides, plus ancienne ${ }^{21}$. In groupe de monuments chrétiens, débris de sarcophages a personnages, chapileau corinthien dégénéré transformé en bénitier et chapiteau mérovingien, ont été recueillis a l'oratoire de saint-Michel, à Inta (Hautes-Pyrénées) ${ }^{22}$. La stratigraphie du cimetiere de Martres-Tolosanne (Haute(Garonne) permet de reconstituer l'histoire du site paléochrétien ${ }^{23}$ : après la

(17) Ann. Bourgoyne, XXIV, 1924, p. 133.

(18) B. de Montrsoviou-lizex\%ac, Bull. soc. nal. anliq. Fr., 1952-3, p. 175-176; Cahiers archéol., VII, 1954, p. 51-60.

(19) Jumieges à traiers l'hisloire, à travers les ruines, Rouen, 1954.

(20) Congres scienlif. XIIJ cenlenaire de la fondalion de Jumièges, 10-11 juin 1954, Dévillelès-Rouen, 1954.

(21) F. BғхоIт, Gallia, XII, 1954, p. 141-142.

(22) 11. I.ABRotsse, ibid., p. 219.

(23) Dv; Mèst:, ibid., p. 214-215. destruction de la villa romaine, immédiatemenl au sud de l'église, incendiée environ à la fin du $\mathrm{r}^{\mathrm{e}}$ siècle, une communauté chrétienne construit quelques cinquante ans après la primitive église de Sancla Maria de Marlyribus, a l'intérieur de l'édifice; à ses abords immédiats el dans les ruines de la villa s'étendent les tombes d'un très important cimelière a sarcophages. A Montcaret (Dordogne), l'abside découverte au pied de l'abside actuelle pourrait appartenir a l'édifice auquel on peut rapporter les chapiteaux remployés dans l'église actuelle et datés des $\mathrm{VI}^{\mathrm{e}}$-viI ${ }^{\mathrm{e}}$ siècles ${ }^{24}$. De nouvelles recherches à l'angle sudOuest du Chàteau, à Angers (Maine-etLoire ${ }^{25}$, en faisant connaitre les vestiges d'une villa et de l'enceinte de 275 , montrent que, contrairement à ce qu'on pensail, le rempart du Bas-Empire englobait bien le Chiteau. C'est aussi sur ce mème emplacement que le premier évêque d'Angers, Defensor, fixa sa résidence vers le milieu du ve siècle, utilisant les ruines de la villa pour construire la chapelle, à laquelle succéda, en 1104, la chapelle Sainte-Geneviève.

Alors que l'église est, le plus souvent, a l'origine du cimetière, il arrive qu'i d'anciens lieux de culte où les païens se faisaient inhumer, succède un sanctuaire chrétien, tel Saint-Bénigne, à Dijon ${ }^{26}$. L'Église n'aurait-elle pas tenté de substituer à une divinité ou à un héros topique du paganisme mourant un saint local, enterré aux abords de l'antique sancluaire?

Un excellent aperçu sur la lopographie religieuse des premiers temps de la

(24) J. Coupry, ibid., p. 201-202.

(25) Bull. monumen., liXII, 1954, p. 99-100.

(26 P. Leisir, Rev. archéol. Esl, V, 1954, p. $380-382$. 
Provence chrélienne ${ }^{27}$ a elé publié. Sur ces terriloires la fin du ve siecle et le début $\mathrm{du} \mathrm{vi}^{\mathrm{e}}$ correspondenl a une époque d'organisalion de la vie religieuse cl de son cadre matériel. Le groupe d'édifices formé par les églises épiscopales el la demeure de l'évèque se dresse dans un quartier de la ville anticque. I l'extérieur de l'agglomération. les lombes des cimetieres se pressent autour des basiliques, où l'on révère les reliques des marlyrs. Comme i Poiliers, la ville chrétienne a ses monastires : a Arles (Bouches-du-Rhòne)28, la lopographie monastique, qui a pris forme au ive siecle, subit une transformation au $\mathrm{vi}^{\mathrm{e}}$ s. du fait de la concentration de la ville à l'intérieur de l'enceinle du caslrum. lors des invasions. Deux quartiers chrétiens, l'un dans le faubourg de Trinquetaille, l'aulre aux Aliscamps, ont leurs églisess. centres d'une nécropole et point d'all raction de deux monastieres qui seront transferés a l'abri du rempart au v ${ }^{e}$ siecle el, dans le mème lemps, l'abbesse Rusticule bailit une église nouvelle dans son monastire, adossét a la muraille el dont le plan, asse\% incohérent, par suite de remaniements. se lit encore sur le terrain. L'Ililarianum de 'Trinquelaille vint, lui aussi, chercher un abri au centre du bourg forlifié. Autre résultat de ces recherches: restriction du nombre des monuments chréliens de Provence. Les chrélientés du sud-Est ayant élé du ve au xile siecte terriblement éprouvées, querelles sanglantes pour la possession de cess lerriloires, incursions des sarrasins, des

(27) Villes ejpiscopales de Procence, Air, Arles, Fréjus, Marseille el Riez, de l'époque. gallo-romaine au Moyen-Age, par li, Bwort,

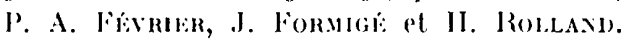
Introluction par Jean llonert, Paris, 1954. (28) 1:. Bravort, El. meroring., p. 10-17.
Normands, des pirales grees, des Hongrois, il n'est pas étonnant que bon nombre des vestiges de ces élablissements aient entierement disparu.

In chapilre, encore très obscur de l'archéologie du Haul Moyen àge reste celui de l'habitation des populations germaniques's du vie au vine siercle. Les découvertes récentes faites en Allemagne'29 apportent toutelois quelques clartés. On tend a distinguer deux types de construclions assez diflérentes : de grandes maisons de bois, groupées souvent en villages, a plan reclangulaire, pourvues d'un foyer central el comporlant des murs doubles constilués par deux rangées de poutres, l'une intérieure, l'autre extérieure disposée en biais, supportant une toilure pouvant descendre jusqu'au sol. Au voisinage de (ess demeures, longues d'une Irentaine de mitres el que les lois germaniques réservaient aux gens libress of aux propriétaires, des greniers avaient élé installés sur des plateformes circulairess reposant sur des poteaux entourant un pilier central (Burgheim, pres de Neuburg-sur-l)anube; Warendorf, près de Munster-sur-Lippe). Le second groupe est représenté par des fosses ou des fonds de cabanes de 3 a $4 \mathrm{~m}$., creusés dans le sol, comme ì Allenstadl, Markolsheim, Qualzenheim, Furdenheim (Bas-Rhin) ${ }^{30}$, dont le remplissage de terre noire et grise a donné les restes de mobiliers domesliques, vaisselles culinaires, pierress de foyers, enclumes, aiguisoirs, peigness d'os, fusaioles, pointes de lloches en fer, melés a des objels du Romain lardif, survivances ou réutilisalions.

(29) G. Brкst, Rel. archiol. Ksl, V, 1954, p. $169-170$.

(30) A. STrmin, cahiers darcheol. et d'hist.

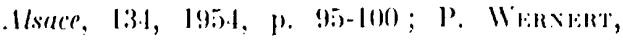
Cinllin, II, 1951, p. 396. 
Dans la construction de ces trés paurres demeures, rencontrées sur la plupart des emplacements de nos villages alsaciens contemporains, les malériaux ulilisés sont te bois et le pisé. L'entrée était pratiquée press de l'angle Nord-Est et la cabane couverte par un loit a pignon. Mais ces pelites constructions ne sont pas loujours a usage de maison, elles furent aussi utilisées romme ateliers domestiques, abrilant des lissages, des brasseries, des fumoirs. Ces fonds de rabane sont encore habiles i la fin de l'époque carolingienne : on les rencontre a L'Isle-Aumont. (Yonne ${ }^{31}$. aver des silos recouverts de roseaux entourant un bàliment à tour carrée en pierre el couverlure de charpente. Lorsqu'il s'agit de maisons importantes, voire royales, on constate la présence d'aménagemenls d'un caractère moins rudimentaire. A Amberloup (Belgique). au lieu-dit "Devant le celli ${ }^{32}$, sur une colline boisee dominant le cours de l'Ourl he, les ruines d'une salle aux murs massifs, en gros blocs de pierre à peine dégrossis. au sol de terre battue, probablement couverte en chaume, avaienl abrite un cellier pour la conservalion des provisions dependant d'un domaine de chasse du monarque. A sens (Yonne), rue Jacques-Taveau, au flane Ford de l'église de Saint-I)idier ${ }^{33}$. une construclion arasée avee piscine, murs de blocage, el tracess des bois carbonisés de la superstruclure, recouverte par les tombes du cimelière de saint-I)idier, appartient aux ruines d'une maison carolingienne. Une villa rarolingienne est signalée à Villiers-sur-Marne (Seine-el

(31) J. Scapleta, Rev. archeol. Esl, V, 1954, p. 170, n. 1.

(32) P. I.HB1:L, ibid., p. 90-91.

(33) J. Nicol.te, ilbid., p. 295-297.
Oise $)^{34} \mathrm{et}$, sur les rives de l'étang de saint-Paul (Aude) s'étendait la villa de Graniacum $^{35}$. Des souterrains-refuges, a Bouex et a Chanlillae (Charente) ont été occupés pendant le Haut Moyen àge $^{36}$.

Ce sont toutefois les cimetières avec leurs mobiliers lunéraires qui restent, toujours la principale source d'informalion. I I)ijon ${ }^{37}$, les trois églises de Saint-Bénigne. de Saint-Philibert et de Saint-Jean marquent encore de nos jours l'emplacement du grand cimetière qui devait s'élendre jusqu'au lorrent du Suzon. Les découvertes récentes ne permettent plus d'opposer le cimetiere chrétien, situé à l'Ouest du castrum, autour de Saint-Bénigne, au cimetière essentiellement païen ouvert le long de la voie romaine de Lyon à Langres, a l'Est du castrum. On sait maintenant que le premier était utilisé depuis le Ilaut-Empire. A Dijon. comme à Narbonne, le cimetière chrélien a succédé a celui des Gallo-Romains, ou plus exactement la nécropole de la banlieue gallo-romaine ne cessa pas d'être ulilisée. Ces constatations obligent a abandonner l'hypothèse de la création d'un groupement funćraire autour du lombeau de Saint-Bénigne.

Parmi les nombreuses recherches nouvelles, les fouilles d'Ed. Salin et de J. Formigé dans la basilique de Saint-Denis ${ }^{38}$ sont particulièrement importantes. La présence de sarcophages dans un caveau du transept Cord, entre le monument de Louis XII et l'autel,

(34) L. SAtxitr, Bull. hisl, Villiers-surMarne, no 12 , déc. 1954.

(35) E. Boxxผr, Bull. comm. anliq. Narbonne, $1951-2$, p. 45.

(36) F. Fycis, (iallia, X11, 1954, p. 187.

(37) P. Gras, Ann. Bourgogne, XXIV, 1954, p. 102-107.

(3x) LE. SAliv, C:RAI, 1954, p. 391-100. 
avait incité le service des Monuments historiques it conduire des recherches méthodiques sur cet emplacement. Cinq étages de sépullures ont été reconnus dans ce caveau, qui, dans l'élat actuel des fouilles, mesure 4 mitres de longueur sur moins de 3 metres de largeur el $2 \mathrm{~m}$. 50 de hauteur, datant du rve au $\mathrm{VII}^{\mathrm{e}}$ siècle el s'élendant sur l'époque carolingienne. les plus anciennes tombes sont gallo-romaines et vraisemblablement païennes. Einfermés dans des cercueils de bois, les squeleltes étaient accompagnés de poteries à engobe rouge el décor de rinceaux et de monnaies de Maxence et de Constantin. Trois autres, presque dépourvues de mobiliers, pourraient ètre chrétiennes et relever de la période des grandes invasions. Au-dessus un sarcophage donna une tête de fibule en argent doré ol de petils lubes d'or deslinés à ilre fixés sur une étofie. A la parlie supérieure du raveau gisaient des restes du viI ${ }^{\mathrm{e}}$ s. et carolingiens. Une tombe féminine a procuré de beaux bijoux. fibule quadrilobée en or cloisonné. garnilure de chaussure en argent niellé ornée de dragons. Cette accumulation de sépultures invile à reconnaître dans ce caveau un des éléments d'un cimetière ad sanclos et l'on est conduit à penser que les corps de Saint Denis, de Rustique et d'Éleuthère reposaient à peu de distance du caveau, à l'encontre des théories actuellement proposées. Il'autre part, la basilique mérovingienne aurail été siluée sur ce mème emplacement. Ces trouvailles confirment re qu'on entrevoyait déji de l'installation du sancluaire sur un site anlique ${ }^{39}$. Autour de la calhédrale de Sisteron (BassesMpes), trois élages de sépultures ont

(39) Voir page 335. été reconnus ${ }^{40}$. Au lieu-dil "La Bastide Blanchen, ¿ Péyrolle (Bouches-duRhòne), sur un site occupé au Néolithique, un cimelière du $\mathrm{v}^{\mathrm{e}}$ siècle fut installé sur le plateaut ${ }^{41}$ - le long du cimetiere de Gasparets (Aude) ${ }^{42}$, des tombes sous dalles du Haut Moyen ige avaient été pratiquées; - sarcophages de l'école d'Aquitaine à Hauterive (Haule-(iaronne) press de la chapelle ruinée de Saint-Martin-de-Lufliac ${ }^{43}$; ..cimelière wisigolhique à la ferme de Galleneuve, à Mouchamp (Gers $)^{44}$; - - dans la (iironde, cimetières ou tombes a Cessac ${ }^{45}$, sur la rive droile de la Garonne à Cadilhac ${ }^{46}$, à Bouliac sur l'emplacement du cimetière moderne et de tombes gallo-romaines du III $^{\mathrm{e}}$ siècle $^{47}$, sarcophages du $\mathrm{vI}^{\mathrm{e}}$ ou du vile siecle près de l'église de Saint-Médard-d'Eyran ${ }^{48} ; \quad-$ curieuses $^{2}$ sépullures à Velle (Charente-Marilime) failes de pierres posées de champ el d'une arrondie formant chevel, avec charbons de bois dans de petits loculi ${ }^{49}$; - squeletles et fosses contenant des cendres à Ligné (Charente) ${ }^{50}$; - - cimelières en Vendée, à sarcophages sans mobiliers te plus souvent, a dizenay, Olonne-sur-Mer. La Boupère ${ }^{51}$; - tombe a Orléans (Loiret), sur le còté Est de

(40) II. Kolacaso, Gallia, XII, 1954, p. 447.

(4I) F. Brwort, ibid., p. 431.

(12) Bull. romm. anliq. Narbonne, 1951-2, p. cins.

(13) II. Inвmotssi:, Ciallia, XII, 195.1, p. $213-214$.

(41) D) MLME, ibid., p. 224-2:5.

(45) J. (o):prr, ibid., p. 207-208.

(16) H. Kanstin, Bull. et mèm. soc. archéol. Bordeaud, 1.V1I, 1945-50, p. 50-53.

(47) Couste, ibid., p. 24 .

(48) Brorad-SLDhlau, ibid., p. 10.

(19) F. Fyalx, Gallia, XII, 1951, p. 191.

(50) D) MÈk, ibid., p. 188-189.

(51) Du Mìms, ibid., p. 191-193. 
la Manufacture des Tabac: ${ }^{52}$ el lessons chréliens près de sainle-Croix ${ }^{53}$; sareophages au vieux cimetiere de Bruire-Dlichamps (Cher) ) $^{54}$ a Donnery (Loirel) $^{55}$, a Brizay ${ }^{56}$ et a Chalonnessous-le-Lude (Maine-et-Loire) ${ }^{57}$; - tombes dans le rocher à saint-Épain (Indre-el-Loire) $)^{58}$; - cimetière avec traces de feux riluels à Langon (Ille-et-Vilaine $)^{59}$; - - sarcophages de pierre ou de platre dans la carriere de sable de Sarcy, is Boutigny (Seine-etMarne ${ }^{60}$ et a Guitrancourt (Seine-etOise), ou l'emplarement des tombes étail indiqué par des stìles à décor géométrique ${ }^{61}$; - fosses quadrangulaires avec mobiliers du Romain tardif et du Ilaut Moyen àge, dans les sablières des (iroseillers et des Mardelles, à Cheny (Yonne) ${ }^{62}$ : dans les gravières de La Placholle, i Vitry-le-lrançois (Marne ${ }^{63}$ et dans le cimetière du Moulin à Vertla-Gravelle (Marne ${ }^{64}$; -- inhumations en position assise dans le cimetière des Rocherets, à Épernay (Marne ${ }^{65}$; dans l'Aube, a Rilly-Sainte-Syre ${ }^{66}$, sur la rive droite de la seine, 28 fosses sans grands mobiliers. tombes mérovingiennes et, carolingiennes it l'Isle-. Jumont,

(52) Bull. liatson proris. soc. archéol. al hisl. Orlemais, jans.-féve. 1954.

53 J. I.otes, Gallia, XII, 195.4, p. 504.

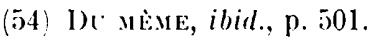

(5)) Bull. Liaison proris... Orléanais, $n^{0} 27$ mars-aviril 1954.

(56) P. Conboxien-Dítrae, Gallia, XII, 1954 , p. 169.

(57) Du Msus, ibid., p. 170.

(58) D) ùंмre, ibid., p. 169-170.

(59) P. MERLAT, ibid., p. 155-166.

(60) A. Pigaviol, ibid., p. 146.

(61) Do мìme, ibid., p. 143-144.

(62) R. Locis, ibid., p. 514-517; Ann.

Bourgogne, XXIV, 1954, p. 130.

(63) G. Gocry, Gallia, XII, 1954, p. 154.

(64) Du mìne, ibid., p. 152.

(65) Du мÈme, ibid., p. 151.

(66) Du mÈne, ibid., p. 150. les premieres an pleine terre et le plus souvent en sarcophages, les secondes dans des cercueils de bois ou des troncs d'arbres évidés ${ }^{67}, 199$ tombes au Cléry, lieu-dit "Les Plantes "68, la plupart en pleine terre, 24 en sarcophages du $\mathrm{VI}^{\mathrm{e}}$ à la fin du vine siècle; - en saòneet-I_oire, nouvelles sépultures dans la partie du cimelière de Curlil-sousBurnand qui semble avoir élé occupée dans le premier quart du $\mathrm{vi}^{\mathrm{e}}$ siecle ${ }^{69}$, sarcophages a saint-Marcel-les-Chalon, a Chagny, pres du Moulin Nicot, et i) Marly-sur-.Iroux, non loin de la ferme du Materal ${ }^{70}$, vase décoré à la roulette dans une lombe à Givry" el. lombes alignées dans les ruines d'un édifice gallo-romain, peul-être un lieu de culle a Cortevaux ${ }^{72} ;-$ dans l'Ain, tombe at Blanat ${ }^{73}$ et au voisinage du cloitre de l'église de $\mathrm{Brou}^{74}$; sarcophages des $\mathrm{VI}^{\mathrm{C}}-\mathrm{IX}^{\mathrm{e}}$ siècles à Palise et tombes nouvelles a Boutelle (Doubs) dans le cimetière de Randebelin ${ }^{75}$; - dans la Gaule orientale, squelette avec clou a la place du cœur dans un sarcophage de la place de Nevers à Charleville $^{76}$ et cimetière carolingien it Altigny (Ardennes) $)^{77}$; tombes sur l'emplacement de l'aérodrome de Cham-

(67) Du mìn, ibid., p. 148-150 ; J. Scapula, Rev. archéol. Est, V, 1954, p. 198-201.

(68) J. Scaptla, ibid., p. 133-1.46.

(69) M. Lafoxn, Bull. soc. d'hisl. et d'archéol. Châlom-sur-Marne, XXXIII, 1954, p. 89-90, $104-106$.

(70) Ibid., p. 83.

(71) Ibid., p. 108 .

(72) M. Boxweroy et R. Perracd, Rev. archéol. Est, v, 1954, p. 395-399.

(73) P. Wildebmen, Gallia, XII, 1954, p. 467 .

(74) Du MÊME, ibid., p. 466

(75) I. I.ERAT, ibid., p. 472-473.

(76) Le pays lorrain, 35, 1954, p. 103.

(77) Gr. Golnr, Gallia, NII, 195.t, p. 146. 
bley $^{78}$ et nouvelles sépultures de la seconde moitié du vile siecle au lieu-dit "Laverneau ", a Cercueil (Meurthe-elMoselle) ${ }^{79}$; lombe à Rupl (Meuse), sur la rive gauche de la saulx appartenant aux $\mathrm{v}^{\mathrm{e}-\mathrm{vI}^{\mathrm{e}}}$ siècles ${ }^{80}$, à Rimling (Moselle), localité importante au $\mathrm{vi}^{\mathrm{e}}$ siècle, à Ifildesheim $^{81}$ et sarcophage devant, la chapelle des Templiers a Metz ${ }^{82}$; -..- dans le Bas-Rhin ${ }^{83}$, sarcophage ì Hohengoefl. lombes à Dangolsheim, Kolbsheim el Westhoflen, sarcophage ou tombes carolingiennes ì Guedertheim. Bietlenheim, Scharrachbergheim, Hilsenheim, cimelière du Zich à Molsheim ${ }^{84}$, installé a flanc de coleau le long de l'ancienne voie romaine de Dachstein avec traces de coulumes funéraires, offrandes alimentaires el traditions romaines fréquentes, lémoignant de l'importance du peuplement gallo-romain dans la région de Dachstein et de Dompeter ; le cimetiere du "Paradis" a Corux-les-Mines (Pas-de-Calais), occupé

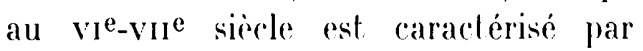
la fréquence des francisques, la pauvreté générale des mobiliers et l'absence d'indices de christianisalion ${ }^{85}$.

La décor de la sépulture a été l'objet de recherches nouvelles. F. Benoit ${ }^{86}$, en publiant 122 sarcophages paléochrétiens d': Irles et de Marseille, apporte un utile complément aux recueils de Le Blant et de Mgr Wilpert. On en retiendra les principales conclusions :

(78) F. I)เ:.oRT, ibid., p. 481-482.

(79) Du Mk̂m, ibid., p. 485.

(80) Le pays lorrain, 35), 1954, p. 103.

( 81$)$ Les cahiers lorrains, VI, 1954, p. 18 .

39 ; I. Iriont, Gallia, XII, 1954, 479-481.

(82) E. Istont, ibid, p. 477.

(8.3) G. SAuEn, Cahiers d'archéol. el d'hisl. Alsace, 134, 1954, p. 112.

(84) J. et E. Grilss, ibid., p. 73-96.

(85) J. IIsuraos, Gallia, XII, 1954, p. 136.

(86) Les sarcophages paléo-chréliens d'Arles el de Marseille. jo suppl. à Gallia, Paris, 1954. présence d'ateliers locaux dès la fin du $\mathrm{r}^{\mathrm{e}}$ siècle, mais absence d'une véritable école arlistique; l'art des sculpteurs arlésiens n'est qu'un reflet de l'art, romain el ilalien du Nord; l'atelier de Marseille représente l'aboutissement de res fabrications, environ le milieu du ve siecle. A Castelnau-d'Estrefonds (IIaule-(Garonne), parmi des décombres on recueillit une plaque funéraire chrétienne en marbre pyrénéen, ornée de la figure d'une colombe picorant ${ }^{87}$; dans le registre inférieur est représenté

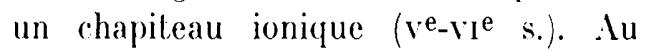
sujet du sarcophage en plomb de Cilleaux (Còle-d'Or). J. Hubert ${ }^{88}$ constate que l'art du Bas-Límpire a légué à celui du Moyen àge la figuration du vase accosté de griffons. M. Durliat ${ }^{39}$ éludie un groupe de sculptures wisigothiques. de Narbonne : fragment de frise en marbre, décorée de cercles partiellement, entrelacés et imposte à cercles contenant. des losanges curvilignes; panneaux avec: ravaliers poursuivant un cerf et croix paltée flanquée de l'alpha et de l'oméga, puis de deux colombes buvant dans un vase; deux panneaux de Narbonne, exéculés postérieurement à la reconquête de la ville sur les Musulmans en 759. Toutes ces pièces relivent d'un art méditerranéen et témoignent de la solidarilé entre la Catalogne et la Seplimanie el aussi de rapports avec l'Italie et l'Árique du Nord. L'un de ces monuments, le support d'autel d'Oupia ${ }^{90}$, appartient a une suite de petils monuments souvent négligés. On a

(87) .I. Labrolssis, Gallia, X11, 1951, p. 213.

(88) Rev. archiol. Est, V, 195.1, p. 81.

(89) El. mérowing., p. 93-101 ; Bull. monum., CXII, 195.4, p. 105-106.

(90) V. P':RRl:, Bull. comm. antiq. Narbonne, $1951-52$, p. $51-57$. 
récemment dégagé d'un mur de soutènement conligu à la soure de siaint-sumian, pris de Brignoles (Vari, un autel-cippe, provenant d'une chapelle anciennement. démolie" ${ }^{91}$. C'est un pilier quadrangulaire, dont la tranche supéricure est creusée d'un loculus pour recevoir des reliques el rantonné de quatre colonneltes. Sur l'une des laces est rudement sculpté un personnage ì lète nimbée, vêtu d'une lunique lombanl au-dessous des genoux, les mains croiscées sur la poilrine, arcosté de deux croix de Saint-André. Ia lace opposée porle une grande croix en lan, surmontée de quatre annelets, les quatre premiers inscrils dans un losange, el deux colombes au registre inférieur. Ln décor géoméIrique de chevrons et de disques et l'image d'une chèvre illustrent les petits collés. L'ensemble de ces figurations éroque l'art wisigolhique des $\mathrm{VI}^{\mathrm{e}}-$ vile siercles. L'intérêt de ce pelit monument est de marquer un jalon dans l'évolulion du lype de l'autel pendant le Ilaut Moyen age. L'aulel de Brignoles dérive diredement de l'autel volif ou funéraire romain. Ce modele sera progressivement, supplanté par l'autel ¿ lable, mieux adapté aux besoins lilurgicues.

Toules ces productions, autels, plaques hisloriées, sarcophages, présentent dans la diversilé de leurs décors une unité réelle quant aux themes décoratifs, expressions de préoccupations relevant du salut éternel, de sentiments de protection à l'abri d'une divinité lutélaire. Cet aspect de la question serait plus particulierement apparent lorseu'on éludie la répartilion en France des sarcophages à décor des $\mathrm{VI}^{\mathrm{e}}-\mathrm{v} I \mathrm{I}^{\mathrm{e}}$ siècleses,

(91) F. Briolt, Provence histor., 1954, extrt. (92) J)enise Fossand, El meroting., p. 117 126. groupes d'Aquitaine, de Bourgogne, du Poitou, des pays de la seine el de Paris, elc. One carle de répartition met en relief la multiplicité et la localisation dess écoles : aquitaine couvrant le Sud-Ouest, poiterine l'Ouest, l'une et l'autre se parlageant les pays entre Loire et Pyrénées. Pour les autres groupes, la distribution géographique est plus complexe et moins tranchée, on constate des chevauchements. I'aulre part, la présence ou l'absence de matériaux ulilisables exerce son action (sarcophages de platre de la région parisienne), d'ou la nécessité de siluer les centres de matieres premieres, carrières, atclicrs de laille, enlrepòts. Il semble que seules les fabrications d'Aquitaine el de Jouarre relevent des traditions antiques, les premieres par hérilage direct, les secondes par un phénomine de renaissance.

Certaines de ces figures sembleraient prèler à une interprélation mi-humaine, mi-animale, des personnages représentés, tels les Fivangélistes du relief de l'hypogée des Dunes de Poitiers, s'il ne s'agissait, au vrai, de l'imitation par les lailleurs d'images do modeles empruntés à l'orfèvrerie ${ }^{93}$. On constate aussi is Poiliers, comme à Saint-Martin-de-Iume (Portugal), l'utilisalion, dans le décor monumental, de bas-reliefs, dont la destination premiere était lunéraire. Ces images de la vision apocalyptique, thème triomphal tries tòt appliqué sur les devants d'autel de Cividale et de Ferrentino (Italie du Xord), sont les lointains modeles des linteaux romans (Saint-Genis-des-Fontaines et SaintIndré-de-sorède).

Un nouvel examen de la mosaïque de l'abside orientale de l'église, à

(93) G. Ganllard, ibid., p. 135-136. 
Germigny-des-Près (Loiret) ${ }^{94}$, avec représentation de l'Arche, dans la chapelle de Théodulphe, a décelé la présence, non d'un modele byzantin, mais d'influences orienlales, principalement musulmanes, oncyades, done contemporaines de l'église carolingienne, parvenue par l'intermédiaire de la syrie ou de l'Espagne. Il faut désormais rayer de la liste des mosaïques du IIaut Moyen àge le pavemenl historié de l'église de Saint-(ienis-de-Thiers (Puy-de-Dome ${ }^{95}$, que L. Bréhier rapportait is la premiere église, contemporaine du $\mathrm{vi}^{\mathrm{e}}$ siecle. Xi par le style, ni par l'iconographie, ni par l'emplacement qu'elle occupait lors de sa découverte, la mosaïque ne peut appartenir aux temps mérovingiens, mais doil ître postérieure de quelques décades à la construction de l'église qui date du $x_{1}{ }^{\mathrm{e}}$ siécle. Des curres des $\mathrm{XI}^{\mathrm{e}}-\mathrm{XIII}^{\mathrm{e}}$ sircles présentent de semblables particularités.

Le coftrel, avec runes of figures de l'église de Mortain (Manche) est le seul exemplaire du chrislmal des saints irlandais, coffret porté en bandouliere aux champs, en voyage, pour l'Eucharist ie ${ }^{96}$.

La présence de boucles ou plaques, de fers de lances, de fermoirs d'aumônières damasquinées, dans la région namuroise ${ }^{97}$, au $\mathrm{v}^{\mathrm{e}}$ et au début du $\mathrm{V}^{\mathrm{e}}$ siècle, laisse entrevoir un territoire jouissant d'une stabilité relative. Si la persistance de traditions techniques a contribué à celte relative prospérité, il faul aussi lenir comple du fait que la production industrielle des grands

(94) A. Grandn, Cahiers archeol. 1953, p. 171-183.

(95) H. STEs, ibid., p. 185-198.

(96) I.. Buotiet, Le christmal de Morlain, Coutances, 1954.

(97) A. Dasror, Annales soc. archéol. Namur, Xl.VII, 1953-54, p. 267-268. centres fut amoindrie au profit de l'art isanat local, moins exposé aux remous des événements. Cetle permanence de l'artisanat gallo-romain, avec ses tendances propres et complexes, les influences de l'Orient méditerranéen ou de la steppe rusise, ont joué un ròle de premier plan et on ne saurait souscrire aux théories venues d'Outre-Rhin sur l'action prépondérante des peuples germaniques en ces matieres ${ }^{98}$. Dans la fabrication de ces damasquinures, un laiton très pur. 20 a $23 \%$ de rinc, oblenu par rémentation, est employé par les barbaricari ${ }^{99}$. Quelques-unes des parures damasquinées, trouvées dans le cimetière siluć sur l'emplacement de l'église des Trois-Xations, à Saint-Denis (Seine), ont été l'objet d'un nouvel examen ${ }^{100}$. Les agrafes à double crochet, à perforation centrale pour le passage d'une chaîne de sûreté, apparaissent au $\mathrm{vII}^{\mathrm{e}}$ siècle et restent en usage jusqu'au $\mathrm{xI}^{\mathrm{e}^{101}}$.

Dans la série des armes, la découverte, dans les dragages de la Saone, de poinles de lances damassées fait connailre une nouvelle classe d'armes offensives exéculcées comme les épées damassées ${ }^{102}$.

I.e mot scramasax pourrait se traduire littéralement par "couleau-hache "103, dénomination convenant parfaitement a celte arme courte, à un seul tranchant, dont on se servail de taille et non d'estoc. Celle-ci est diflérente du mali-sax, le couteau de table.

(98) Li. SAlIs, CRAII, 1954, p. 4.4.

(99) Du mism:, Cuibre, Mélatux, Alliages, 1954 , p. 14-15.

(100) O. Finadssi:, Revue des Arts, 1954, p. $50-51$.

(101) A. Rolsss, Rev. archéol. Esl, V, 1954, p. $3330-334$.

(102) L. Anmaxn-Cindent, ibid., p. 153156 ; A. Colblent, Mem. soc. d'hisl el d'archéol Chalon-sur-Sânene, XXXIII, 1954, p. 101. (103) P. I.(1:11:L), Rev. archéol. Esl, V, 1954, p. 303-304. 
On signale à Orléans (Loirel), dans le quartier de l'église sainte-Croix, la présence d'une céramique noire, ornée d'un chrisme et d'un cerf, inscrits dans un médaillon entouré de palmeltes ${ }^{104}$, semblable aux décors du pays bordelais.

Dans un article traitant des ivoires du llaut Moyen àge et du Moyen àge, II. Stein ${ }^{105}$ lend à réduire le ròle des ateliers Iravaillant en Gaule, ne retenant parmi les documents publiés par F. W. Volbach ${ }^{106}$ que la boucle dite de Saint-Césaire, pouvant ètre al tribuée arec quelque probabilité à ces fabrications de la Ciaule mérovingienne.

Deux plaques de bronze eslampées. Irouveres en 188:1 a Rouen, dans les fouilles d'une sépullure du vir" siecle de l'ahlatliale de saint-(huen. jaddis appliquées

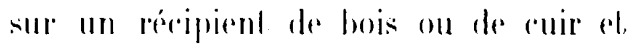
représentant un cavalier, viotu en légionnaire, lranspereanl de sa lanee un animal monsilueux ${ }^{107}$, se rallache is un ensemble dre liguralions d'origine orientale, ansimilées a saint-fieorges, dont le culte est.

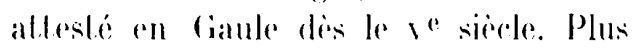
ancienne parail avoir éce la dévolion a d'autres sainls militaires, Maurier et ses compangnons ${ }^{10 x}$, donl on saisil les premieres manifestalions dans Ir dernier quarl du $v^{e}$ siecle (Agaune, Valais) el qui, an ve siecle rayonne dans l'bist el te Midi, principalement dans les pays rhénans of rhodaniens. Entre 118 ol. 418 , Sainl (eermain construil, is Auxerre, un oratoire pour y aluiter les religues recues. dr l'abhaye d'. Igaune, el a l lijon le culle

(10.t) I.Evane, Bull. liatison proris... Orlou nais, no $: \overline{7}$, mars-arril l95.4.

(1105) Cahiers archeol., II, I!5.1, 1.

1106) Voil : Viallia, NII, 1954, p. 57.1.

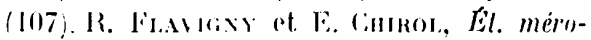
ving., P. 111-116.

(108) R. Louss, Reu. archeol. Est, V, 1954, p. $3 \times 1-3 \times 7$. de Saint Maurice connaît la même fortune diss le début du vi ${ }^{\mathrm{e}}$ siercle.

Plusieurs éludes trailent des relations de commere entre la Gaule mérovingienne et l'élranger : échanges entre les royaumes franes et la Suède, aux vile et $v^{\prime} I^{\mathrm{e}}$ siècles, d'après les découvertes de poteries, verreries et monnaies de la basse vallée du Rhin; siluation sociale des commergants; déclin de ce commerce aux ${ }_{1 \mathrm{X}} \mathrm{e}_{-\mathrm{X}} \mathrm{e}$ siecles ${ }^{109}$. Une mise au point est donnée des rapports de commerce entre les Frisons et notre pays ${ }^{110}$; l'altention est attirée sur l'abandon par les Frisons de leurs bases de Doresslad en $689 \mathrm{et}$ d'Clrecht en 69.1, alors ocrupées par les Franes jusqu'aux invasions normandes. l'importance de scealles el les nombreuses imilalions du monnayage frane par less Frisons, I ris répandues on .lustrasie, lémoignent de l'intensilé du commerese entre les deux régions.

Aver l'Afrique du Nord ${ }^{111}$, les rapports iconomiques. peu importanls is l'époque. romaine - les ports africains avaient. surtoul servi d'escales aux syriens dans leur Irafic avec l'oecident ... se poursuivent cependant aux temps mérovingiens jusqu'ì la lin du vife siecle el ne se résumenl. pas seulement en animaux (chameaux) el produits (datles) exoliques. Jes courants de pensée trahissent des relations d'ordre intellecluel. La querelle du pélagisme alleste des contacts étroits enlre ces dellux pays el l'on connaîl l'exislence de donatistes a Xarbonne environ 1.88-469, à Lyon alu début du va siécle. laes andres, plus encore que les voyages

(1119) II. Janvkiax, lierleljuhrschrifl für

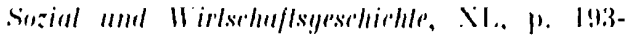
$\because 43$.

(110) P. (.. .J. A. Bons.1:s, Bijdragen lol de Ge'schiedenis der Vederlanden, VIII, 1954, p. $237-250$.

(111) C. Covntors, Rapporls entre l'Afrique el la Cianle au debul du .Mogen àge, Algerer, 1954. 
(royages de Giriffon a Carthage a la fin du $v e^{e}$ siecles, prouvent la prermanener de res sonlacts: salvien de Marseille ulilise des renserignements donnés par des voyagerurs a fricains. (irégoire donne un abregei de l'hisloire des Vandales. Mais la rériprocile n'existe guere, les lfrieains ne porlanl pas grand interel aux choses dre la Caule. La silualion subil une profonde Iranslormalion aver la conquele musulmane, el la dorumentalion s'arrete apres (67). La relative aldivile des porls provençaux s'explique, du vir" an $x^{0}$ sireles. par le commerese avere l'llalie ol non plus avee Carthage. Cependant les relations entre l'Orient el l'oceident ne sont pas

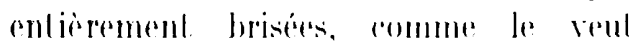
Jenri Pirenne. On peul disculer sure le volume des exhanges. mais non sur leur réalite. des marehands juifs continuenel i apporter en Europe orecidenlate le muse. le bois dalowes. le ramphere la rannelle d'Asie el do Chane. On nous proposese

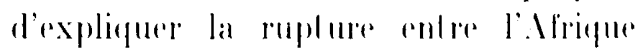
Mineure ef lis Gaulde parr un changement d'itineraires: du val au $1 \mathrm{x}^{\mathrm{e}}$ siinders se préerise le latere de deux roules majeures du commeree entre les deux pays : la chrélienne ella musilmane. la premiere est presque exclusivement lerpestre; la seconde, plus morcelée et plus complexe. a la fois continentale et maritime. enveloppant loules deux la Médilerranée. en un retour à un élal antérient a la conquite romaine.

Le grand désastre qui. all vine sierle. frappa le sud de la Ciaule, l'invasion mulsulmane, eut de graves consépuences pour le commerce maritime de la Ciaule oceddentalent2. Linviron bion, une ere nouvelle s'amorgait dans le domaine allanlique. expliquant la prospérité alors ronsiaté sur ces lerriloires el qu'on doil mellee en rapport avec la renaissance d'un commerce allanlique, ordonné selon l rois roules 192. reliant la Ciaule is la (ialice el a l'kispagne

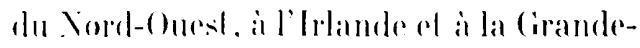
Brelagne orecidenale, aux ports de la

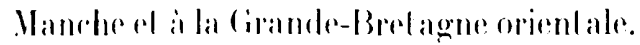

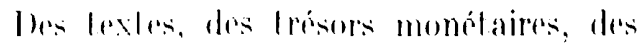
lransports dohjels manufacturés, précisent limporlance de eres relal ions. On prent. antsis se demander si la Ciaule ocerdenlate ne servail pas d"intermédiaire entre la Méditerranere. I'Lipagne. I'Irlande el l'Angleterre, par la voie marilime. Toulefois, il reste dilticile d'élablir la liste des produils irchangés. Le vin paraîl. avoir élé la marchandise la plus recherchée puis le selde saintonge el l'huile de Carbomatise, te fer. L.Irlande envoyait en exhange sers cuirs, sers vilements an grosse laine ol peul-it re son or. l'Anglelerreses draps, la Cornouaille, son etain ; la Ciaule du Kord ef les pays rhénans, leurs verreries ol leurs épées. Autre mar-

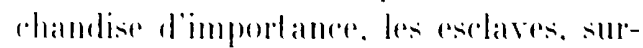

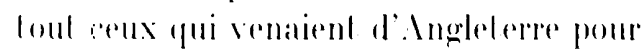

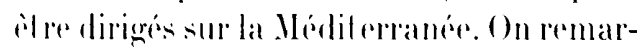

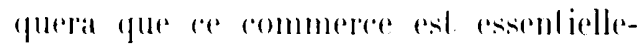
ment represente par des produils de provenance allantique. nalurels ou manufaclurés. of que bien peu d'objets sont originaires des pays médilerranéens. Un probleme reste ouvert, celui des navires ulilises: : il semble que sur les colles allanliques de la ciaule subsistenl les lypes gallo-romains. scapha ol barea. Des le vie $^{e}$ iertere en Irlande. on connail le rorarle. lail de peaux de varhes lixées sur une memblerere dosier. précridant les navires do bris que les Irlandais com-

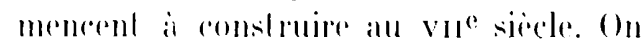
est rencore plus mal renseigne sur lat marine des lnglo-siaxoms, mais il n'est pas jusclu'alux monasteres qui ne possident leurs follilles rirculant, au $\mathrm{x}^{\mathrm{e}}$ sierle. sur les rivieresilla.

Il n'elail pas inulite de se demander a quel usage pouvail bien correspondre

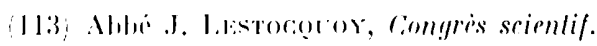

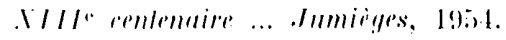




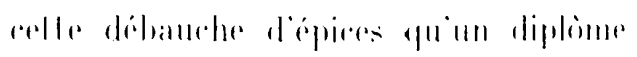

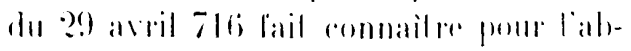

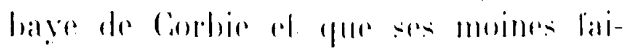

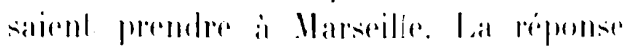

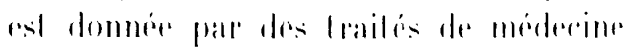
rapolingiens. conlenanl mainles rereolles

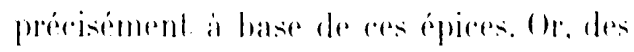
abbayes. comme alle de Saint-Riquier. nourrisialent quolidiennemenl qualere cent pauvers ol solgnaiend assurémenl. bon nombere de malades parmi enx. Ce latie des épiers noms rameme. all $1 \mathrm{~S}^{\circ}$ siecter ans roules eonlinentales. bant vaisemblablemenl allx mains des sian-

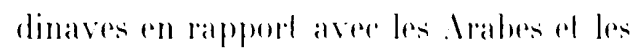
Bryanlins ${ }^{114}$.

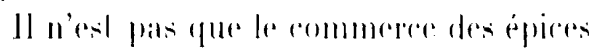
yui ail rommu un imporlant developpere menl, alui des soleries se developlepe plulit quil ne diminue an romes du $x^{0}$ siecle. In témoin de rese exhanges est represente par les fragments du statre de Saint-Calais, reproduisanl un épisode de la chasse de Bahrain, dapres un modiele sassanirle du ve siedeles.

Les lextes hagiographiques dommenl d'uliles indiations sur les voles de communicalion. lel la Passion de saint CereVais"16 : le sainl revienl de Rome au Vans, franchil la same dans la région de Chalon el meurl en forcid de Costiana. Ore le meme rhemin ilail mone suivi an xinde siecle. eonlimuanl une voje préhistorigue.

La mulliplicalion, en Ciature en en Rhemanie, des aleliers monel aires, ayant ru pour conséquenee une lres large dispersion d'une monnaie du plus maurais aloi imposa la mise en usage de la pierre de: touche el de la balance. sur les lerriloires allant de la Lombardie au lienl ol à la

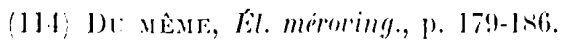

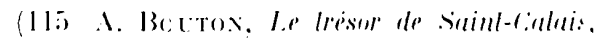
$19 \% 4$.

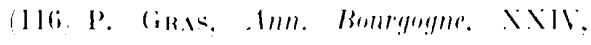
1951, p. $1 \times 5-191$.

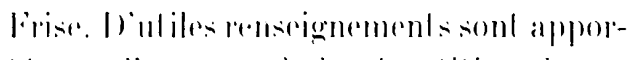

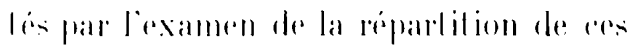

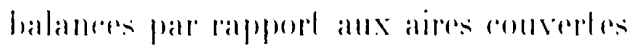

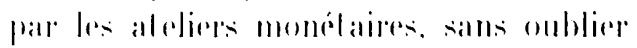
les sepultures dorfieverstiz.

berx groupes de momnaies de la liaule du X.-lE. apparaisisent dans le troisieme, quart du ve siede et au debut du vae, $\therefore$ inserivanl dans le monnayage septenlrional a cole du groupe de Huy el apres cens de Cologne. Treves of Mougin ${ }^{118}$. lin lriens, frappe i Vevers, du monelaire lilherius. a def lroure pres d'.lulun (sacome-el-losire:19.

line grande prudenerest nésessaire dans l'inlerpréalion des deroureptes prétendues musulmanes, failes dans la cour de Ia Madeleine. a Varbonne (Jude) ${ }^{120}$, les substruclions mises au jour élanl au nivean de la basiligue de Ruslique (ves.) el l'are oulrepassí. noyé dans la magonnerie dillicilement rapportable il la construction d'une mosquée, élant tress postérieur à l'époque de l'ocrupation arabe (719-7i)9). Des fouilles sur le site de la balaille de La Berre (Aude) ont amené la découverte de tesions de style omegarle (riale s. t?:2. Les sépullures relevées pres du gue de Ia Pallu, au Moulin de Trans pourraient appartenir aux charniers de la halaille de 730 , au rours de laquelle Charles Marlel défit Mblemaman!22.

\section{Musce des Inliquiles Nalionales. Juin 195)(\%.}

Raymond I.ANTER.

(117) J. WЕвx:Rт, Silzungsberichle der Baygerischen diatemie der Wissenschuflen. 1951, extrt.

(118) (i. low, Rer. numism., be sir., 15, 1953, p. 67-75.

119. R. Loors, ciallia, XII, 1954, p. 50k.

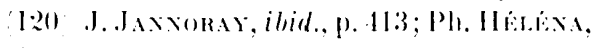

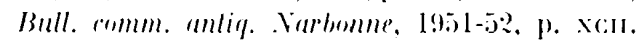
$1: 21$.J. L.ackM, ibitl. p. x6-933.

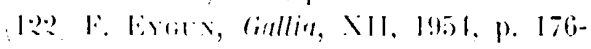
$1 \times 1$. 